\title{
INTERPRETATION OF FUNDAMENTAL RIGHTS IN CENTRAL AND EASTERN EUROPE: METHODOLOGY AND SUMMARY
}

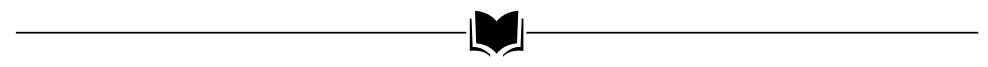

ZOLTÁN J. TóTH

Fundamental rights have become increasingly important since the emergence of modern constitutionalism. The states of Central and Eastern Europe, as third-generation countries of concentrated constitutional adjudication, and in leaving behind the legacy of state socialism, have faced challenges owing to the specificities of their recent history and the problems of transitioning to a democracy governed by the principle of the rule of law. These are substantially different from the problems that countries with first- and second-generation constitutional courts once had to solve, although they have many points in common. One such commonality is that, typically, new constitutions (or constitutions that can be considered new in substance) have been adopted immediately after the end of a dictatorial regime, which, in contrast to the previous situation, already provided for a wide range of human rights. The enforcement of these rights was guaranteed everywhere in these states; however, the different historical situations had given rise to different responses.

The starting point of our research is the hypothesis that the constitutional courts established in the Central and Eastern European legal systems after 1990 started to enforce human rights enshrined in their constitution in a different context, with different historical experiences, and under different social and economic circumstances, legal, and political conditions. Thus, these systems approached fundamental rights differently from their Western and Southern European counterparts. Our hypothesis was that a specific Central and Eastern European system of fundamental rights protection could be detected, with a particular system of interpretation of fundamental rights specific to Central and Eastern European countries but not necessarily to the

Zoltán J. Tóth (2021) Interpretation of Fundamental Rights in Central and Eastern Europe: Methodology and Summary. In: Zoltán J. Tóth (ed.) Constitutional Reasoning and Constitutional Interpretation, pp. 9-98. Budapest-Miskolc, Ferenc Mádl Institute of Comparative Law-Central European Academic Publishing. 
European constitutional tradition as a whole. The latter was explored not through the jurisprudence of the constitutional courts of Western or Southern European countries but through the practice of the European Court of Human Rights (ECtHR). This investigation provided an opportunity to detect general features of European constitutional culture (and to compare these with the features of Central and Eastern European constitutional culture) and to assess the specific legal problems of each Central and Eastern European country in light of the ECtHR's practice.

On the basis of the research design detailed in the first chapter, we expected our research, on the one hand, to shed light on whether our hypothesis is correct and whether there is indeed-at least with regard to the methodology of interpreting fundamental rights (i.e. the procedural-formal issues that constitute the framework for solving substantive legal problems) - a specific Central and Eastern European conception of fundamental rights, and if so, how it differs from the common European constitutional tradition of countries outside this region. On the other hand, we hoped to explore the similarities and differences between the constitutional jurisprudence and interpretation of fundamental rights (and, more generally, the typical modes of constitutional reasoning) of the various Central and Eastern European countries (specifically, the six countries under study).

\section{Research design}

At the end of 2020, a research group was established within the Mádl Ferenc Institute of Comparative Law in Budapest. The group was formed with the purpose of studying the practice of constitutional courts in six Central and Eastern European countries (including the decisions related to international law) and the relevant decisions of the referred international fora. As part of it, the Research Group aimed to present 1) the features of the common interpretation practice of fundamental rights in the V4 and the North Western Balkan (hereinafter, with allowance for a certain geographical imprecision: Central and Eastern European ${ }^{1}$ countries and of the main differences; 2) the similar European legal practice regarding the concerned countries (i.e. the relevant legal practice of the ECtHR) and the European Court of Justice (hereinafter: ECJ); and 3) the similarities and differences between the countries studied in the two previous points and the regional/transnational fora. For this purpose, highly respected experts of the legal system, one from each of the countries (namely, the Czech Republic, Hungary, Poland, Serbia, Slovakia, and Slovenia), were invited for the analysis thereof. Their

1 All examined countries are in the central part of Europe, i.e. Central Europe, and in its eastern half (Eastern-Central Europe). None of them are states of Eastern Europe in a geographical sense. However, as the countries in this region are traditionally referred to as the states of Central and Eastern Europe, we also follow this definition. Nonetheless, we consider it necessary to point out that it is geographically not precise and these are actually not the states of Central and Eastern Europe but of Eastern-Central Europe. 
task was to analyse the relevant national practice of the constitutional court in their own country and to compare it with the practice of the European fora (ECtHR, ECJ) pertinent to the given country. Accordingly, the basic methods of the research are the analytical (in case of the countries) and comparative method (regarding the comparison of the characteristics of the activities carried out by the given fora). ${ }^{2}$

The practice of each concerned country was examined by one researcher, thereby producing 'national reports' to which the chapter titles in the volume also refer. Each national researcher had the following task: to define the most important 30 cases in which, in the last ten years, the constitutional court of the given country made a decision on the merits and which contained a substantive reference to ECJ or ECtHR decisions. In the first main phase of the research, these 30 cases had to be analysed according to a certain methodology for determining which methods of interpretation are preferred by the constitutional court of the country in cases with international relevance, what argument style describes its decisions, and what the most important issues with constitutional relevance are in the given country.

After this, in the second main phase, researchers had to study what methods of interpretation the ECtHR or the ECJ used in their (also 30) cases that were referred to in the decisions of the constitutional court. These decisions of the ECtHR and the ECJ had to be assessed according to the same methodology, as the national constitutional court's decisions were analysed and according to some further aspects. We expected to be able to determine directly how the reasoning style and decisionmaking pattern of a given national constitutional court differ from the ones applied in decisions of referenced 'international' courts.

Criteria for selecting the 30 decisions of the domestic constitutional courts were defined as follows. The selected cases had to be 'important' ones and had to be from the last ten years (2011-2020), i.e. the decision in the given case was made in this period. As the research attempted to focus on the contemporary interpretation of fundamental rights in Central and Eastern European countries, it seemed unreasonable to include former decisions in the sample because the results would not have been timely. However, we could not specify a much narrower examination period owing to the risk that enough 'important' cases worthy of analysis did not exist in the given country. Thus, the ten-year period was the result of a practical compromise. When determining the number of sample items ( 30 domestic cases), we attempted to ensure to have as many cases as enough to draw scientifically useable conclusions and, at the same time, to be processed (together with other 30 ECtHR or ECJ decisions invoked by the constitutional court's decisions) during the period of the research.

As for the 'importance' of the cases, we understood that we could only define rough criteria. We relied heavily on the individual convictions of the researchers involved. A case could be considered 'important' if it established a new dogmatic

2 The comparative method has several scientific forms that, regarding comparative constitutional law, were distinguished and classified into nine different groups by Ran Hirschl. Hirschl, 2019, pp. 18-19. The present research mainly belongs to the categories 8 and 9. 
construction in constitutional law or applied a new legal doctrine; fundamentally changed the system of domestic law (e.g. criminal law, civil law); had outstanding economic relevance; affected a wide range of citizens; or took a position on substantial public or social policy issues. It was neither possible nor necessary to define this criterion more precisely; the authors of each chapter provide the reader with information on the aspects they considered. Nevertheless, since the subject of the research is the interpretation of constitutional rights, any decision that did not directly address an issue of fundamental rights had to be ignored (e.g. a problem regarding the 'political constitution', namely, issues regarding the state structures, the extent of competency of state bodies, the legal status of constitutional bodies). ${ }^{3}$

Consequently, all of the 30 selected decisions of the national constitutional court referred to ECJ or ECtHR decisions. It was essential that the decisions of 'international' courts ${ }^{4}$ were considered on their merits in the selected domestic decisions, notwithstanding the national constitutional court's agreement. The constitutional court could bring up an ECtHR judgment to decide a case on the basis thereof or by using its arguments. Alternatively, the national constitutional court could refer to this decision to declare explicitly deviation or agreement. For our research, both attitudes were deemed equally interesting, as were the most characteristic attitude of the given constitutional court and, of course, the specific arguments used.

Regarding the selection criteria for the 30 ECJ/ECtHR decisions, we ensured conciseness in the research. One ECJ/ECtHR decision (considered the most characteristic in relation with the given legal issue or considered by the national constitutional court to be the most important) had to be selected in case of each constitutional court decision.

3 'Political constitution' and 'political constitutionalism' mean neither, in the narrow sense, the political institutions of a given legal system, the political practice regarding the constitutional rights in the given country, differentiating those from ideal-typical 'legal' constitution or constitutionalism as Bellamy or, taking it further, Gee and Webber did (see Bellamy, 2009, p. x; Gee and Webber, 2010, pp. 273-299); nor, in the broad sense, a cross-border regionalisation or globalisation process in which the political constitutionalism (a critical view of which is given by Hirschl, 2006, pp. 721-754), together with 'economic' (Teubner, 2015, pp. 219-248) and 'societal' constitutionalism (Teubner, 2004, pp. 3-28), unify the different jurisdictions but the organisational provisions and provisions on competency of the national (act of) constitution having necessarily legal nature. Thus, the political constitution, as the modern successor of the former German Staatsrecht, includes the constitutional (already legal) norms determining the organisational structure of the state and the functioning of state organs, principally in Germany and the continental legal systems under German influence. According to Murkens, 'Staatsrecht claims that the existential and homogeneous state is identified and protected by public law, Verfassungsrecht claims that it is illegitimate for public law doctrine and scholarship to base constitutional argument on the extra-legal, pre-constitutional substance of the state' (Murkens, 2013, p. 188.). Pokol described the same process as the duplication of constitutional law (cf.: Pokol, 2019, No. 2.), which, in addition to traditional organisational norms, will also contain the constitutional rights and the even more abstract constitutional values (Pokol, 2019, p. 16).

4 The ECtHR is not a 'truly' international court (Goudie, 2004, pp. 6-7); for reasons of simplification and to follow the common vocabulary (Lemmens, 2018, p. 94), we call it 'international court' in this work. 
For example, the ECtHR, as a quasi-precedent court, ${ }^{5}$ cites its own previous practice at length ${ }^{6}$ (and the same is true of several constitutional courts in Central and Eastern Europe). ${ }^{7}$ Thus, in the same case, the national constitutional court itself may quote several mutually reinforcing ECtHR decisions that are built on each other and, in fact, contain the same arguments. In this case, it would not have made any sense to analyse all of them in the second phase of the research. Especially, these cases typically feature a characteristic decision (a leading case) that contains all the substantive arguments of the ECtHR regarding the particular legal problem. If, however, the national constitutional court referred to several independent decisions that could be considered 'in their own right', then the author of the chapter was free to decide which of them was the most important. The authors took into consideration only the judgment of the Grand Chamber if both chamber and Grand Chamber judgments were rendered by the ECtHR.

As such, there were 30 analysed constitutional court decisions and 30 'international' court decisions (made by the ECtHR or the ECJ), on the basis of which each

5 ' $\mathrm{A}]$ precedent is a judicial decision which serves as a rule for future determination in similar or analogous cases. A decision is to be regarded as a precedent when it furnishes rules which may be applied in settling the rights of parties in other cases' (Jones, 1904, pp. 159-160). Originally, the precedent is the decision of the supreme court formed in the course of English legal development that has to be applied, followed in decisions made in later judicial procedures with the same facts (stare decisis), or, from the late modern period, in case of which the ratio decidendi, the essential elements of the decision, the legal findings extracted from the case are legally binding (cf. Goodhart, 1945, pp. 493-525). Beyond other conditions, a decision qualifies as a precedent if it is made on the basis of facts similar to the ones of the case to be decided. This similarity means the similarity of not only the mere facts but of the legally relevant facts (cf. Schauer, 1987, pp. 577-579) and presumes the identicality of the normative judgment and always contains evaluative elements. The lower courts are always bound by the precedent (e.g. 'vertical precedent') but other courts are bound by earlier decisions only as a general rule (e.g. 'horizontal precedents'; see Barzun, 2013, pp. 1632, 1661, 1663). With the development of comparative law, jurisprudence started to use the concept of 'precedent' also for decisions of supreme courts in such legal systems (continental legal systems) where they do not formally bind the courts deciding later cases (courts of lower instance) but where, owing to the appeal system, they have decisive influence on these later decisions. Similarly to the Bielefelder Kreis, we use the concept of precedent in this 'expanded' sense, which is different from the one developed in Anglo-Saxon system of law. We also observe the consideration of linguistics, which says that the concepts, during their use, go through change in meaning, pick up new meanings, or lose older ones-meaning changes. We always examine the concept of precedent in its legal meaning. For the philosophical meaning of precedent, see Kronman, 1990, pp. 1029-1068.

6 Although neither the ECtHR nor the ECJ recognises formally (and officially) the binding force of its own previous decisions, according to prior experiments, they consider them as guidance, in aiming for the consistency of the judgments and the persuasive power of the propriety of the examined legal issues (and, consequently, 'to help legitimize their decisions to external audiences') and usually make decisions taking them into significant consideration. See Pelc, 2014, p. 549; Lupu and Voeten, 2012, pp. 416-417.

7 The techniques used by the ECtHR to change legal considerations (reasons for differing from previous decisions) are the same as of a classical precedent court: distinguishing and overruling. In the former case, the reason for the deviation is that the legally relevant fact of the new case is not (fully) identical to the one of the previous case. In the latter case, the court (entitled to set precedent) expressly recognises the similarity but does not maintain the binding force of the previous decision (including ratio decidendi, legal argument serving as basis of the decision, reason for decision) because it considers it to be incorrect or (more often) no longer adequate owing to the changed circumstances (Duxbury, 2008, pp. 113-122). 
national researcher had to determine the nature, style, typical or characteristic interpretation pattern, and reasoning of the constitutional court decisions interpreting fundamental rights, and the extent to which the same considerations reveal a different picture in $\mathrm{ECtHR}^{8}$ or ECJ decisions on the legal problems of the given country.

Each chapter consists of the following main parts. A brief introduction delineates the constitutional court of the given country, including information on its position within the system of state institutions (role within the system of the separation of power, constitutional 'mission', and function), its structure, the basic rules of its operation, and its powers. All analyses the researcher considers to be important regarding the given country's constitutional court or essential for understanding the methods of the examination or the conclusions reached can be read here.

In the substantive decision analysis, the authors present the criteria for selecting the 30 constitutional court decisions. This is followed by the analysis thereof, including the fulfilment of an actual research goal, the determination of the characteristics of the constitutional reasoning, and the practice of interpreting fundamental rights of the given national constitutional court. The analysis discusses only the (majority) decision itself and not the separate opinions (dissenting and parallel or concurring opinions)..$^{910}$ The reason for this methodological solution is that a separate

8 The analysis of ECtHR and ECJ and comparison of their practice with that of the certain national constitutional courts may be useful because they have similar functions. Although we do not accept the simplifying statement that the ECtHR or ECJ has the function of a constitutional court (and, thereby, that the Convention or the Charter has a constitutional role in the Council of Europe or the $\mathrm{EU})$, we recognize that this analogy has explanatory power and relevant statements regarding the function of both the domestic law, and the supranational conventions may be made from that. Nevertheless, the view according to which ECtHR or ECJ is 'a kind of constitutional court' is becoming more influential in international law. The ECtHR is a 'transnational constitutional court' (Sweet, 2009, pp. 923-944. For the same regarding ECJ, see Brenninkmeijer, 1994, pp. 103-117).

9 In a dissenting opinion, one member of the given decision-making college disagrees with the majority as regards the operative part because they consider another decision on the merit to be correct. In a concurring opinion, the member of the decision-making college agrees with the operative part, i.e. the merit of the decision, but would have used different reasons to reach such conclusion. Here, 'dissenting opinion' refers to the strict sense of the concept defined by Kelemen. We differentiate it from the 'concurring opinions' in the above sense. As an overall category of the two concepts, we use the expression 'separate opinions' (contrary to Kelemen's 'dissenting opinion in abroad sense' by this comprehensive content). "A "dissenting opinion" means "a separate opinion that diverges from the opinion of the majority of a group. [...] [T] he expression "dissenting opinion" can be used in a broad or a strict sense. In the broad sense a dissenting opinion is any separate opinion of a member of a judicial panel. A dissenter, however, may disagree with the majority only in part. He may "concur" in the outcome of the case but indicate different reasons for reaching such conclusion. In this case her/his separate opinion is called, more technically, "concurring opinion". A dissenting opinion in the strict sense, on the other hand, disagrees with the majority also as regards the ruling. A dissenting judge would have decided the case differently. Conversely, a concurring judge would have simply written the judgment differently, without changing the outcome of the case. Thus, a concurring opinion generally offers an alternative reasoning to the decision, but it may also simply add further arguments (supplementary reasoning) or aim to explain better the opinion of the court (explanatory reasoning)'. Kelemen, 2018, p. 5.

10 The judges of the constitutional courts may present a dissenting or concurring opinion in all examined countries. According to the Polish Act of 30 November 2016 on the Organisation of the 
opinion is not the opinion of the constitutional court as a college, since the opinion of the college is held by the adopted decision. No matter how interesting, exciting, or persuasive the reasoning of the separate opinions, they cannot be considered as the 'officially' accepted arguments or opinions of the given constitutional court since they do not imply the adopted viewpoint of the college. Consideration thereof could jeopardise the goals of research: the separate opinion of a judge of the constitutional court who accepts a strong but 'disruptive' point view far from that of the majority or prefers applying 'exotic' methods used rarely by the college could have distorted the entire sample and given results not reflecting the actual approach of the college.

Within the frames of the substantive decision analysis, the author of each chapter delineates, as the main results of the research, the following: a) the methods of interpretation the national constitutional court used in its decisions; b) the style of reasoning and decision-making of the given constitutional court; c) the characteristics, which can be of interest to the scientific community, of the decision-making of the constitutional court or the relation with the decisions of the international court.

Constitutional Tribunal and the Mode of Proceedings Before the Constitutional Tribunal, 'A judge of the adjudicating bench who disagrees with the majority of the bench voting in favour of a ruling may, before the delivery of the ruling, submit a dissenting opinion, providing a written statement of grounds for his/her dissent; the dissenting opinion shall be mentioned in the ruling. The dissenting opinion may also refer only to the statement of reasons for the ruling'. (Article 106 para. 3). The Czech Constitutional Court Act (182/1993 Sb.) has similar provisions: 'A Justice who disagrees with the decision of the Plenum or with its reasoning, has the right to have their dissenting opinion noted in the record of discussions and appended to the decision with his name stated' (14. §). 'A Panel member who disagrees with the Panel's decision in a matter, or with its reasoning, has the right to have his differing opinion noted in the record of discussions and appended to the decision with his name stated' (22. §). The Slovak Constitutional Court Act (Act No. 38/1993 on the Organizational Structure of the Constitutional Court of the Slovak Republic and on the Proceedings brought to the Court and on the Position of Its Judges) says, 'Any judge, who does not agree with a decision of the General Assembly or the Trial of the Constitutional Court is entitled to require that his distinct standpoint will be briefly mentioned in the records on the vote' (32. § 1). In Hungary, Act CLI of 2011 on the Constitutional Court regulates the rights of the constitutional judges. According to section 66 (2)-(3), 'If a Member of the Constitutional Court who opposed the decision in the course of the voting does not agree with the decision of the Constitutional Court, he or she shall have the right to attach his or her dissenting opinion - along with a written reasoning - to the decision'. Moreover, 'a Member of the Constitutional Court who agrees with the merits of the decision shall have the right to attach his or her reasons in the form of a concurring opinion if they differ from those of the majority'. In Slovenia, the Constitutional Court Act Article 40 para. (3) says that 'A judge who does not agree with a decision or with the reasoning of a decision may declare that he will write a separate opinion'. The Constitutional Act on the Constitutional Court of the Republic of Croatia also provides for the minority opinion: 'The judge of the Constitutional Court who voted against the majority may, within a reasonable time from the day the decision or ruling was written, give reasons for his/her opinion in writing, and publish it' (Article 27 para. 5). 'The judge of the Constitutional Court shall not abstain from voting, except in the case when he/she has participated in passing the law, some other regulation or decision which are the matter of the decision in hand' (Article 27 para. 6). Finally, in Serbia, not the Law on the Constitutional Court but the Rules of procedure regulates this issue: 'A judge shall have the right to a dissenting opinion, based on his or her arguments offered during the deliberations on the proposed decision, if the Court renders a decision or ruling, the ording or reasoning of which, in their entirety or in part, are opposed by the judge' (Article 60). 
In this respect, the subject of interpretation is the constitution (applicable constitutional provisions, fundamental rights) and not statutory law, even if, for example, in a norm control case, the constitutional court also interprets the latter. ${ }^{11}$ Thus, statutory law was irrelevant to the present research; the members of the research group ignored it. The only relevant aspect was how, and using what other sources (beyond the relevant international law), the given national constitutional courts interpreted the applied constitutional norms (constitutional rights) and what arguments they used to justify their decisions.

The (possible) interpretation of the international treaties carried out directly by the constitutional court is important only if such treaties had a constitutional rank in the given legal system (e.g. a norm control procedure exists in the course of which the constitutional court can assess the compliance of domestic legal norms with international legal provisions). Failing that, the referred international treaties could only be considered as sources used for the interpretation of the constitution. In the former case, the international treaty, such as the European Convention on Human Rights (hereinafter: ECHR) is the subject of interpretation that is carried out by the constitutional court applying a teleological method or systemic arguments. In the latter case, international treaties themselves are merely sources for the interpretation of another subject, namely, the constitution (fundamental rights). The latter analysis has been essential for research; the former, only in case the norms of international law have a constitutional rank in the given legal system.

Subsequently, each chapter contains an analysis of the 30 'international' court decisions selected by the author according to the criteria described above and on the basis of the already analysed constitutional court decisions that had references to these 'international' court decisions on the merits. In this context (as another main line of research), the authors present the following (similarly to the evaluation of the case law of the national constitutional court): 1 ) what methods of interpretation the ECtHR or the ECJ used in their decisions; 2) what style of reasoning and decisionmaking characterises these regional decision-making fora; 3) what characteristics, which can be of interest to the scientific community, the decision-making of the ECtHR or the ECJ has.

Both a statistical-quantitative analysis (delineating, in particular, the percentage of occurrences of the methods and arguments used by the constitutional court, ECJ, and ECtHR) and a qualitative-analytical analysis were necessary. In the frames of the

11 'Statutory and constitutional interpretation share commonalities. Both involve the construction of legally authoritative texts. [...] Although statutory and constitutional interpretation resemble each other in many respects, typical instances of the two forms of interpretation differ significantly. The differences concern the authority of constitutional and statutory provisions, the political legitimacy of the bodies enacting them, the generality of the textual language, the age of the provisions, and the ease with which political bodies can override what the courts decide. Any analysis of the two forms of interpretation must attend to these differences' (Greenawalt, 2012, pp. 194-195). 
former, we obtained answers on the frequency of the used arguments, whereas in the frames of the latter, on the role perception of the given decision-making forum and basic features of constitutional reasoning.

Finally, the authors close their chapters with a brief summary, including the most important conclusions, the comparison of the judicial practice, reasoning style, and applied key terms of the national constitutional court and the ECJ/ECtHR, as well as the explanations for the possible or probable reasons for the similarities and differences.

\section{Legal and constitutional reasoning}

\subsection{Theoretical principles}

\subsubsection{Introduction}

There is a difference between the concepts of legal interpretation and legal argumentation (legal reasoning). Legal interpretation is the exploration of the meaning and/or the reason of a legal norm in a specific case. Legal argumentation is a subsequent attempt to justify the application of the norm (in a given way and with a given meaning); essentially, it is a probabilistic reasoning to prove that the premises sought for the conclusion are correct, and also the correctness of the conclusion can be rationally deduced therefrom. ${ }^{12}$ Interpretation 'is a particular form of practical argumentation in law, in which one argues for a particular understanding of authoritative texts or materials as a special kind of (justifying) reason for legal decisions. ${ }^{13}$ Interpretation is a "rational" activity ${ }^{14}$ whereas argumentation is a "rationalising"15

12 In this sense, argumentation has a practical purpose: to persuade the readers of the reasoning of the sentence that it is proper. 'Legal interpretation should be understood within the framework of an account of argumentation, in particular, of practical argumentation. In this framework, it turns out that interpretation can only be a part of legal argumentation, and can only be finally elucidated within a wider view of normative constitutional and political theory, which themselves belong within a broader view of practical argumentation' (MacCormick, 1993, p. 16).

13 MacCormick, 1995, pp. 467-480. For the issue of interpretation as a part of argumentation, see, additionally, Gebauer, 2000, p. 683; Scallen, 1995, p. 1731 and footnote 119 in p. 1734; Jakab, 2013, pp. 1215-1278.

14 'The interpretation of statute law is based on the assumption that the legislator is rational. Statute law is deemed to be a reflection of coherent and logical thought. [...] A rational approach to the interpretation of statutes involves constructing and weighing arguments against one another' (Devenish, 1991, p. 225).

15 'Legal reasoning does not only involve purely rational arguments, but also the evaluation of conflicting interests and the making of value judgments which depend on prevailing legal and moral values and very often on common sense' (Devenish, ibid.). 
one. In case of the latter, the focus is on the power of persuasion rather than on logic, and all arguments suitable for this persuasion are acceptable. ${ }^{16}$

According to Wróblewski, legal interpretation can be considered at three levels. In the broadest sense (largissimo sensu), it covers the understanding of all 'cultural objects' (i.e. things or phenomena created by humans). In the broad sense (sensu largo), this concept includes only the interpretation of expressions of the written or spoken language or any manifestation thereof. Finally, in the strict sense (sensu stricto), we use this concept for exploring the meaning of a text only if we have doubts about the 'correct' meaning thereof and we wish to explore this 'correct' but not immediately obvious meaning. ${ }^{17}$ Below, we use the latter the strict sense of the concept of 'interpretation', ${ }^{18}$ which can be divided into subcategories on the basis of the relation to the text and literal meaning thereof ${ }^{19}$ (but

16 'While argumentation theory partly encompasses the interpretation theory, it is broader, because it covers all acceptable argumentation strategies outside statutory interpretation, such as references to the authority of court decisions, of doctrinal writers, of sources from foreign legal systems, or of non-legal persons or sources (e.g., religious or political ones). It also covers the argumentation as regards personal evaluations and normative standpoints [...]. In all these cases, the underlying paradigmatic theory determines which kind of arguments and which argumentational strategies are considered to be acceptable within legal reasoning' (Hoecke and Ost, 1998, p. 198).

17 Cf. Wróblewski, 1969, p. 45.

18 Based on Wróblewski's theory, MacCormick understands this concept similarly. According to his illustrative example, a problem of interpretation (and an interpretation situation) regarding the "No smoking' sign occurs when doubts arise regarding the meaning of the sign. 'If I see a $>>$ No Smoking $<<$ sign and put out my cigarette in response, I evince simple understanding of the sign, and compliance with it, without any element of doubt or resolution of doubt; I immediately apprehend what is required, and thus interpret the sign in this broad sense of $>>$ interpretation $<<$. There might be a particular occasion when I see a $>>$ No Smoking $<<$ sign while wearing a formal dinner jacket (a $>>$ smoking $<<$ as they call it in French), and pause for a moment to ask myself whether the notice requires me to change into less formal attire, rather than to abstain from tobacco. To think over this doubtful point, and to resolve one's doubt by opting in a reasoned way for one rather than another view of what the text requires is to $>>$ interpret $<<$ it in this stricter sense of the term. By $>>$ interpretation in the stricter sense $<<$, I thus mean entertaining some doubt about the meaning of proper application of some information, and forming a judgment to resolve the doubt by deciding upon some meaning which seems most reasonable in the context' (MacCormick, 1993, pp. 19-20).

19 Goldsworthy, in his reflection to the methodological concept of Jakab, differentiates 'clarifying interpretation' ('revealing or clarifying a law's pre-existing meaning') and 'creative interpretation' ('supplementing that meaning in order to resolve indeterminacies' or 'changing that meaning in order to correct or improve the law') (Goldsworthy, 2013, pp. 1279-1295). This classification is nothing but the well-known differentiation between the secundum legem, praeter legem, and contra legem interpretations, the differentiation among which is based on the realization or non-realization of law application's boundness to the text of the legal norm. On the basis of the German terminology, we can call the two latter interpretations (differentiating them from the simple interpretation /Auslegung/, i.e. from secundum legem interpretation) (judicial) law development (/ richterliche/ Rechtsfortbildung). While praeter legem law development means the filling of a legal gap (gesetzesergänzende Lückenfüllung), contra legem law development is the 'correction' of the act (Gesetzeskorrektur). See Krey, 1978, p. 364). In a further approach, the differentiation between formal and substantive reasons by Robert Summers leads to the same result. The 'interpretive formality' in Summers's approach ultimately means the adherence to the literal interpretation (cf. Summers, 
we see it as an issue of result of the interpretation ${ }^{20}$ and not consider as a purely methodological question; in the present study and the underlying research, we do not add or did not add any consequences to the fact that such subcategories can be distinguished).

Judges basically carry out legal argumentation instead of pure legal interpretation in practice. They do not try, 'with [a] fresh start', to provide the norm proposition with some correct meaning; they want to make a correct and justifiable decision (appropriate to their sense of justice and worldview) in light of a specific case with specific circumstances. They seek arguments of this already made (intuitive) decision that can also be accepted as appropriate by outsiders and, therefore, 'can be defended'.

Demonstration means a special reasoning that leads from certainly true premises to definitely correct conclusions,${ }^{21}$ which is atypical, and even impossible,

1992, p. 147), which has priority over the substantive reasons as long as its application would not lead to absurd results. Then, substantive reasons, that is, essentially, all reasons other than formal ones (literal language) (e.g. 'moral, economic, political, institutional or other social consideration[s]', cf. op. cit., p. 138) may supersede the literal meaning and then (but only then) the legal solutions provided by formal reasons may be overstepped. Therefore, in a different way, Summers reaches the same conclusion as the jurisprudence as a whole: in certain cases, the use of extensive or restrictive interpretation (and, thereby, the praeter legem or contra legem interpretation, even if he uses other terms) - the alteration to the text of the existing norm-is possible. According to the example of Summers, if a statute prescribes that 'No vehicles may be taken into the park', it does not prohibit to bring a World War II jeep into the park and place it on a pedestal as a war memorial (op. cit., p. 147).

20 Traditionally, we can classify and determine the types of interpretation according to three aspects: 1) Classification according to the subjects differentiate the interpretations based on the entity that performs it. 2) By classification according to the methods, we differentiate the interpretations on the basis of the techniques or the sources used. Most of the present chapter discusses this issue. 3) Finally, classification according to the result is based on what meaning compared with the grammatical one (i.e. to the literal meaning of the text of the norm) we will have when we use other methods. This means the quasi checking of the literal meaning, which can result either that the grammatical meaning can be used on its own or that it has to be corrected. There can be three results (cf. Walton, Macagno, Sartor, 2021, p. 35). 3/A) It is possible that the literal meaning is correct, that is, it can be used on its own since the use of other methods or sources would lead to the same result as the grammatical interpretation (this is the so-called declarative interpretation or interpretatio declarativa). 3/B) It is also possible that, by using other methods, we conclude that the grammatical meaning is too strict: the legal regulation does not apply to all cases it should have. In that case, the literal meaning has to be expanded, i.e. the subject matter of the norm has to be extended to the cases not covered by the grammatical meaning. This is called extensive interpretation (interpretatio extensiva). 3/C) Finally, using methods other than grammatical interpretation, we can conclude that the grammatical meaning is too broad: the literal meaning also applies to cases to which it should not (because it would be contrary to the intention of the legislator, the purpose of the statute, etc.). The grammatical meaning has to be restricted, i.e. certain exceptions have to be defined under the subject matter of the norm to which the given norm cannot apply, despite the clarity of the literal meaning. This is the so-called restrictive interpretation (interpretatio restrictiva).

21 Demonstration is 'developed from statements or propositions of which we can ask whether they are true or false' (Perelman, 1965, p. 4). 
according to some, in the field of law. ${ }^{22}$ Demonstration is, therefore, a logical operation by which one can come to a true conclusion from true premises. Meanwhile, argumentation is a rhetorical practice during which one, on the basis of plausible but not assuredly true premises, can come to a probable conclusion, aimed at compelling the audience to accept the speaker's statement. ${ }^{23}$ Thus, 'in argumentation, contrary to what happens in demonstration, we do not justify anything'; the theory of argumentation does no more than to study 'the discursive techniques which make it possible to evoke or further people's assent to the theses presented for their acceptance'. ${ }^{24}$ Similarly, ' $[t]$ he aim of argumentation is not to deduce consequences from given premises; it is rather to elicit or increase the adherence of the members of an audience to theses that are presented for their consent'. ${ }^{25}$

The concept of legal reasoning ${ }^{26}$ is identical to that of legal argumentation. Others say that it includes argumentation, interpretation, and demonstration. The present research cannot decide this legal theoretical debate; however, we use the concepts of legal reasoning and legal argumentation alternatively for similar relations and accept that the par excellence interpretation is also a part of it. Hence, when legal consequences are mentioned, the use of all concepts (i.e. argumentation, reasoning, interpretation) may be considered correct in the sense that all of them try to say something about the actual meaning of fundamental rights. As the subject of the present research is specifically the constitution and not simply the law, we often use the concept of constitutional interpretation instead of legal interpretation and constitutional reasoning (or argumentation) instead of legal reasoning (or argumentation).

22 Demonstration belongs to mathematics and the natural sciences where, within a given set of axioms, conclusions can be reached by the rules of deductive reasoning, which means that the truth of premises cannot be questioned. Therefore, if the logical deduction is formally correct, then the correctness of the conclusion's content will also be doubtless. However, there are no such axioms in law (or in any other dialectical situation). Thus, sooner or later, we will, in the regression chain, get to a point from which the correctness of the conclusion cannot rationally be deduced (Rescher, 1998, p. 317).

23 As premises in law are principles suitable to justify the decisions, and there are always several of them, it is unavoidable to choose from these principles, 'because a plurality of such [acceptable general] principles is always possible, it cannot be demonstrated that a decision is uniquely correct: but it may be made acceptable as the reasoned product of informed impartial choice' (Hart, 1997, p. 205).

24 Perelman, 1963, p. 155, 157.

25 Perelman, 1982, p. 9.

26 Reasoning is an activity when a person acts on the basis of reasons. Reasons have two types: one means the 'inner', mental-spiritual motives of the activity; the other refers to reasons that serve as the justification of a decision, i.e. as an attempt to persuade other persons that the decision made is correct. The first type is irrelevant to argumentation theory. Thus, by the concept of reasons, we understand only the so-called justificatory reasons. For differences between motivating reasons and justificatory reasons, see Dyevre and Jakab, 2013, p. 983). 


\subsubsection{Legal interpretation as the element of process of application of law}

Application of law is decision-making by the institutions of the state (e.g. courts, public administration bodies) enforcing the positive, written legal norms ${ }^{27}$ stated in legal regulations. The application of law has four main parts (phases, elements): 1) determination of the facts of the case [including the selection of the relevant (i.e. to be proved) facts and the defining and proving thereof]; 2) defining the legal norms (including the finding of applicable legal norms and the interpretation thereof); 3) decision-making [first, deciding, on the basis of the found and interpreted legal norms, whether the determined and proved facts fit into the hypothesis of the legal norm, i.e. whether the norm is applicable in the certain case; second, making the specific decision on the basis thereof (e.g. conviction or acquittal of the accused, dismissal of the claimant's claims, or ordering the defendant to fulfil)]; 4) justification of the decision, i.e. the legal reasoning itself: proving subsequently that the rendered decision is correct, or at least defensible (it covers, in particular, the wording of the judgment's reasoning, including either interpretation conducted with a 'fresh start' or presentation of the legal arguments making the decision defensible).

27 Throughout most of history, such norms have not been made. Henry Sumner Maine, one of the pioneers of comparative law science, pointed out in Ancient Law (1861), which is also known and accepted as a foundation of legal anthropology, that most legal systems developed in history are of a 'stationary society'; and even 'progressive societies' established 'legislation' only in the last part of their development. The development of 'progressive societies' has two phases following each other in time and being built on each other: spontaneous evolution and conscious developing. Spontaneous evolution is the formation of the judicial judgement of which religion was the basis. In the second stage, customary law was formed from the increasing volumes of judicial decisions in the course of the aristocracy's monopoly of the knowledge of law (Maine, 1861, p. 15). However, the law often allowed arbitrariness; hence, the citizens enforced, by strengthening popular movements, the disclosure of legal regulations. This is how, in the third stage, the first 'ancient codes', collections of customary law that included the more important legal provisions in writing (e.g. the 'Twelve Tables of Rome'), came into existence. In the second major phase, in the period of progressive societies, law does not develop on its own, requiring creative human activity. Conscious developing has three instruments (created in this chronological order): legal fictions, equity, and legislation. Contrary to spontaneous evolution, these tools can be found only in progressive societies. These societies have the feature of their relations being always more developed than the law of the given era. Therefore, social development always comes before the development of law. To keep up with the social changes and to meet the constantly changing demands and social needs, law has to be renewed regularly. The adjustment of legal relations to social needs was achieved by means of legal fictions. 'Now employ the expression "Legal Fiction" to signify any assumption which conceals, or affects to conceal, the fact that a rule of law has undergone alteration, its letter remaining unchanged, its operation being modified' (op. cit., p. 26). By means of legal fiction, the desired alteration may be reached without formal change of law-the text is not modified (thereby, it meets the needs of ones adhering to traditions) but the unchanged text is interpreted in light of the changed social circumstances. It is renewed regarding its content. In contrast, equity modifies openly the former law, although by means of judicial decisions ('I call Equity, meaning by that word anybody of rules existing by the side of the original civil law, founded on distinct principles and claiming incidentally to supersede the civil law in virtue of a superior sanctity inherent in those principles', op. cit., p. 28.). Legal codes not only openly undertake the altering of the law but also leave it, in a general and abstract manner, to an entity separated from the law appliers (op. cit., pp. 28-30). 
The above parts or elements of the application of law are not (or not necessarily) processes or phases following each other in time but logical steps forming an integral part thereof. These elements can coincide or be carried out in parallel, or can also be carried out several times in real-world procedures. ${ }^{28}$ Depending on our approach to these actions of application of law, different models can be elaborated regarding the actual practice thereof.

The classical model of application of law is (1) the so-called subsumption syllogism: subsuming the fact of life under the hypothesis of a legal norm. According to this model, we find out what happened (we take evidence), search for the legal provision applying to the given fact, and, finally, determine whether the particular fact of life is identical to the abstract fact in the hypothesis of the legal norm. If it is, we apply the norm; if it is not, we do not apply it. Overall, according to this model, we compare the fact of life with the statutory fact and, in case they are identical, we impose the sanction provided for the violation of the statutory fact against person realising the fact of life (violating the legal norm) ${ }^{29}$ It is a syllogistic conclusion, a formal action, where we have two premises: the major one is a norm proposition (text of a norm) and the minor one is a fact of life (events that occurred). The conclusion of these premises is the sentence of the judge. ${ }^{30}$ According to the classical model of application of law, the major and minor premises are not only the starting points of the narrower process of application of law (decision-making process) but also the result of the legal interpretation and the process for establishing facts obtained through the chain of other syllogistic conclusions.

This model of application of law does not work in real-world procedures ${ }^{31}$ since it would be necessary to establish (prove) all facts of the case and to seek the applicable

28 See Szilágyi, 2003, p. 307.

29 A decision includes only solutions for disputed issues of proof, namely, for matters of fact. When a given legal case is decided by determining whether a fact of life, which unequivocally falls within the scope of an unambiguous legal norm, happened or not, that is clear norm logic syllogism or subsumption syllogism (cf. Wróblewski, 1974, pp. 43-44). In these cases, there is no legal interpretation sensu stricto. The norm logic syllogism does not belong to the classical logic since it is not the use of formal rules but the assessment of premises (cf. Szabó, 2001, p. 216). Because the constitutional courts mostly do not decide individual cases but, even upon the request of the concrete parties, carry out the abstract interpretation of constitutional norms, such subsumption syllogism cannot take place in the course of constitutional reasoning.

30 This procedure can lead to actual conclusions if the underlying premises are true. The most famous example is if it is true that 'all men are mortal' and it is also true that 'Socrates is a man', then it is necessarily true that 'Socrates is mortal'. It requires phenomena to be assigned to the proper class of things. The syllogistical conclusion will make sense as logical operation only in that case. However, it is not a requirement to assign these categories to anything occurring in reality. The purely formal conclusion can be illustrated with this example: 'Suppose we say: All gostaks are doshes, all doshes are galloons: [...] we do not know what we are talking about, but [...] we can by the strictes of logic draw the inference that all gostaks are galloons' (Cook, 1993, p. 244).

31 This can also be seen. It may be one reason for a certain degree of distrust that legal entities, in general, feel against judicial decisions. However, other reasons may apply. The causes of dissatisfaction with the administration of justice, as for the causes of dissatisfaction with any system of law, are the following: '(1) The necessarily mechanical operation of rules, and hence of laws; (2) the inevitable 
legal norm only afterwards. However, to make the judicial decision-making operational in practice, only facts relevant to the application of the norm need to be established and proven, i.e. a norm is needed in advance to select from the infinity of facts. ${ }^{32}$ Establishing facts cannot be otherwise than that the judge is a priori aware of what norm (or at least what range of norms) to apply and endeavours to determine and prove the relevant facts in the light of this. For that, however, the judge needs to know which norm's application is relevant-which is not possible without knowing at least the most elementary facts. ${ }^{33}$

Furthermore, it could be another mistake to assume that not the facts but the norms are given (we have norms for all facts and if we find the relevant facts, the norm 'itself will also come', and we only have to use it depending on the concrete facts). Principles behind the norms lead to objective results; hence, a single right answer could exist in conflicts between human rights or in other value-based conflicts, as a moral category. ${ }^{34}$ Given that human rights are also morally based, moral answers regarding human rights become legal answers; it is not clear, as in any other case, which to apply. The person (personality) of the one who evaluates these answers basically defines which they will choose and, on the basis thereof, what scope of facts they will take into account (consequently, what the outcome of the case will be). ${ }^{35}$ Introducing the dichotomy of easy and hard cases will not take us much further. Since not only the law must be interpreted but also the facts (they are not 'ready for use' for the judge), then all cases are actually 'hard cases' or may become that, any time, through raising new questions or introducing new aspects. ${ }^{36}$ Escaping this circulus vitiosus is possible by applying two models. The common feature of these models is that they consider the classical subsumption syllogism to be naïve and mechanical and to disregard the actual nature of the judicial application of law.

According to one of these models, (2) establishing facts and searching for legal provision take place as the elements of a process that are interlocking, as cogwheels, and inspiring each other, i.e. neither establishing facts nor seeking the meaning of the legal norm; the exploration of its applicability in the particular case is separated

difference in rate of progress between law and public opinion; (3) the general popular assumption that the administration of justice is an easy task, to which anyone is competent, and (4) popular impatience of restraint' (Pound, 1906, p. 3).

32 'In their interpretive activities, judges participate - to a greater or lesser extent - in the process of creating the law. [F]irst, however, there must be a law to interpret' (Marmor, 1990, p. 62).

33 'The judge is interested in establishing facts only in so far as they may have legal consequences in the case before him; to do so they must be qualified [...]' (Perelman, 1966, p. 376).

34 Dworkin, 1996, pp. 87-139.

35 The approach of Alexy seems to be more persuasive; the judge does not subsume but balances between the values behind legal norms and they do not make a decision on the basis of either but define the scope so that the principles could prevail with the least restriction (cf. Schlink, 2001, p. $\mathrm{x}]$. There is an assumption of a necessarily individual evaluation and, therefore, subjectivism in legal practice (cf. Alexy, 2003, pp. 433-449).

36 Bengoetxea, 1993, p. 194. 
mechanically (or in time) but the processes co-occur and building on one another. ${ }^{37}$ Pursuant to the other recent model, (3) application of law is not (only) logical but (also) evaluating and intuitive activity, the process is reversed: the conclusion (the sentence considered to be correct) comes first and, for this, the judge seeks the premises from which they can get to the sentence found intuitively to be correct basing on their life experience, legal and other (sociological, psychological) knowledge, and morality or general habit. Thus, in this model, the judge sets up a hypothesis and from that moment, they insist on it relying, basically, on their sense of law and intuition. ${ }^{38}$

Although the first model is simpler than the second and third ones, by accepting it, we would sacrifice the reality on the altar of the easy (but false) modelability. Judges are also humans who are influenced by their own prior experience, values, preferences, education, bias, ${ }^{39}$ and certain professional and other customs that help make decisions and justify the rendered judgement. Thus, the judges' behaviour in practice can be described by models (2) and (3) (or a combination thereof). As a result, the legal (constitutional) reasoning will contain not only impartial, objective legal conclusions but also efforts for subsequent justifications that underpin the judge's conviction adopted intuitively or determination that is previously based on their incomplete factual knowledge (supporting either of the views of the necessarily biased and concerned parties).$^{40}$ These are, accordingly, probabilistic arguments that justify that the decision is not arbitrary but do not support the fact that it is the only possible right decision. Such reasoning will contain unbiased, impartial interpretations blended, in a tangled manner, with the subsequent efforts for justification. Since it is not possible

37 The adjudicator concludes to the applicable norms from the facts, and then back from those to the facts to be proved and again to the applicable norms from the facts proved in that way until they achieve their persuasion formed in the final judgement. Hence, the blink of the judge wanders continuously back and forth between the facts and norms (Engisch, 1943, p. 15).

38 'Judicial reasoning [...] constitutes a model of practical reasoning, aimed at justifying a decision, a choice or a claim, and establishing that they are neither arbitrary nor unjust: the judicial ruling is justified if the conclusion following its reasons conforms to the law' (Perelman, 1966, p. 373). The authors of the movement (and not school) of Legal Realism also emphasize the judges' possibilities to choose, which cannot be eliminated, where the decision is only apparently based on legal arguments. The judge chooses from many legal arguments (and achieves a version of judgement) considering which conclusion is compatible with their values, i.e. they get back from the desirable result to the selection of categories, which can serve as base for their legal conclusion (Radin, 1993, pp. 195-198). The fabled bon mot of Oliver Wendell Holmes may be its summary: 'The prophecies of what the courts will do in fact, and nothing more pretentious, are what I mean by the law' (Holmes, 1897, pp. 461).

39 Judges (and jury members) are characterized by unconscious biases, hidden traits, and predispositions that influence even establishing facts, e.g. on that whether they believe a witness or not (Frank, 1973, p. 152). This is affected by several stimuli, including the personality of the given person, which 'is a product of numerous factors, including his parents, his schooling, his teachers and companions, the persons he has met, the woman he married (or did not marry), his children, the books and articles he has read' (ibid.). Thus, 'the decision will depend on the peculiar personality of the particular trial judge who happens to be sitting' (Frank, op. cit., p. 154). In sum, '[w]e must eliminate the myth or legend that judges are more - or less - than human' (Frank, op. cit., p. 147).

40 MacCormick, 1993, p. 20. 
to untangle these interpretations (this would require getting into the judge's mind), the present research studies not only the methods of pure legal interpretation but also all instruments of legal (constitutional) reasoning. We determine which, in the practice of the concerned constitutional courts and regional decision-making fora, is more characteristic and which is less from the methods or sources mentioned by the court in the reasoning of its decision to make and/or justify it.

\subsection{Development of jurisprudential thinking on methods of interpretation}

\subsubsection{Formation and impact of Savigny's interpretation canon}

The theory of interpretation as scientific discipline is, basically, the product of German pandectism. In the Middle Ages and in Modern Times, several handbooks and maxim collections of topics were published..$^{41}$ These works did not have a system (unless we consider the generally accepted opinion according to which we, during application of legal norms, have to insist on literal meaning [ius strictum] or, for practical reasons [e.g. its use would be unfair or maybe expressly absurd], we deviate from it, a 'system'). This method was called duplex interpretatio and, in the strict sense, it did not mean a methodological categorisation but a classification according to the results of interpretation. ${ }^{42}$ The impact of the Roman-law tradition re-discovered from the eleventh century and the respect for the legal categories of the Middle and Early Modern Ages were so strong that prestigious legal academics used the duplex interpretatio as a starting point even long after Savigny's well-known classification. For example, Bernhard Windscheid differentiated two interpretation methods: the grammatical (grammatische Auslegung) and the logical (logische Auslegung). ${ }^{43}$

Another pandectist, Ferdinand Regelsberger, expressed a similar opinion. ${ }^{44} \mathrm{He}$ also thought that, basically, two types of interpretation existed: the grammatical and

41 See more important ones in England: Holdsworth, 1938, pp. 188-191.

42 All these may be traced back to the axiological and ontological questioning whether only righteous law can be law. It is rooted in Roman law where this problem manifested in the opposition of ius strictum and ius aequum (for the relations between the two conceptions and their consequences regarding the applicability of the positive law, see Tóth, 2016, pp. 119-120). Its general legal theoretical consequences materialized in the contradiction between natural law and positive law and later in the appearance of human rights and constitutional rights above statutory law.

43 The interpretation called 'logical' helps apply a given norm even if it has no reasonable meaning or, on the contrary, has more reasonable meanings and one must be chosen from them (Windscheid, 1873, p. 51) or if the grammatically correct (understandable) expression is substantively incorrect (Windscheid, op. cit., p. 53). 'Logical interpretation' (which does not have too much to do with formal logic) has two princpal means: the examination of historical circumstances of creating the given statute and the determination and application of the purpose the legislator wished to achieve with the given statute (Windscheid, op. cit., p. 52). 'Logical' interpretation is a synonym of 'non-grammatical' interpretation, which has the techniques of 'historical' and 'teleological' as its main methods.

44 Regarding the true nature of analogy, there was a substantial conceptual difference between them. Windscheid considered it as an independent operation of interpretation (and not as a method) but Regelsberger did not (cf. Windscheid, op. cit., pp. 54-58; Regelsberger, 1893, pp. 155-161). 
the logical. While the former one (which has to be the starting point of all interpretation) explores the meaning of the words used by law on the basis of ordinary or special legal language (if any), ${ }^{45}$ the latter one controls this meaning and extends or tightens it if necessary. ${ }^{46}$ In the course of that are the following considerations: 1 ) the comparison between the meaning and the law as a whole, the law on similar subject ('related' law), all legal norms regarding a legal institute, or the moral and social tasks of the law (die sittliche und soziale Aufgabe des Rechts); 2) the purpose of law (der Zweck des Gesetzes, ratio legis); 3) the 'higher principles' (höhere Prinzips, ratio juris); 4) the historical basis or geschichtliche Grundlage (i.e. the contemporary social reason for the legislation) of the given legal regulation; and 5) the (subjective) will of the legislator (der Willen des Gesetzgebers). ${ }^{47}$

Duplex interpretatio, the method of Donellus, prevailed not only in the Germanbut also in the English-speaking world ${ }^{48}$ This is proved by the fact that even the summarising work (not affected by the theories of Savigny, Jhering, Heck, or their followers) of the Englishman Thomas Erskine Holland ${ }^{49}$ published long after the turn of the century knew only two types of methods in the course of doctrinal interpretation regarding both private and public law: grammatical and logical interpretation; ${ }^{50}$ and, similarly to the German pandectists and legal philosophers of the Modern Ages, he defined the latter as the reference of literal meaning. ${ }^{51}$

The common feature of all these theories was that they had no coherent hermeneutical methodology but, in fact, enumerated, similarly to the classical period of the Roman law, the possible methods of interpretation of legal texts in an incidental and arbitrary manner. They also reduced the interpretation to the analysis of whether the literal meaning of the written norm is identical to any meaning that moved away from the text (to a meaning extractable from the text or even independent from that,

45 Regelsberger, op. cit., pp. 145-146.

46 Ausdehnende Auslegung (interpretatio extensiva) and einschränkende Auslegung (interpretatio restrictiva) (cf. Regelsberger, op. cit., pp. 152-154).

47 Regelsberger, op. cit., pp. 147-151. We can see from the enumeration that Regelsberger also considered 'logical' interpretation (logische Auslegung) covers all procedures that did not expressly aim to explore the grammatical meaning-systematic-contextual, teleological, historical, and substantive interpretation according to our conception today.

48 From the early Modern Age, to counteract the growing legislative work of the parliament, the English courts, which applied the norms of common law existing as case law, attempted to interpret the statutes literally. This was also aimed to push the statute law back-this was the so-called literal rule. Adherence to the literal meaning of the text of statutes was broken only by the Golden Rule (according to which, this meaning may not be used if the application of the statute produces an inconsistency or absurdity) crystallized at the end of the nineteenth century. The mischief rule formulated in Heydon's case (1584) meant the effectiveness of reasonableness (which corresponds with the 'logical' side of duplex interpretatio). For narratives of judicial application of law in English legal history, see Goodrich, 1986, pp. 54-55.

49 Holland, 1916.

50 Cf. Holland, op. cit., pp. 425 and 432.

51 He also differentiated, depending on the possible result of this comparison, between extensive and restrictive interpretation (ibid.). 
or 'external' meaning). Until the middle of the nineteenth century, and for a while after Savigny, there was no outstanding theory that would endeavour to explore regularly and delineate the different methods of legal interpretation used in legal practice. Friedrich Carl von Savigny was the first who attempted to define, distinguish, and systematise the four main methods of interpretation: grammatical, logical, systematic, and historical. ${ }^{52}$ Grammatical interpretation (interpretatio grammatica, ${ }^{53}$ das grammatische Element der Auslegung) explores the general meaning of the words, expressions, sentences, texts, and conjunctions attributed to the given word, expression, etc. by an ordinary person who knows the given language well. Logical interpretation (interpretatio logica, das logische Element [der Auslegung]) uses the formal rules and logical principles of thinking to determine what the text of a legal norm means (or does not mean). By systematic interpretation ${ }^{54}$ (interpretatio systematica, das systematische Element [der Auslegung]), conclusion regarding the meaning of a legal provision can be drawn from its position in the system of legal norms, and the type and function of the surrounding legal norms. In the course of historical interpretation (interpretatio historica, das historische Element [der Auslegung]), we determine the actual meaning of the legal norm with the help of the (probable) intention of the contemporary legislator creating the legal norm. ${ }^{55}$

Later, a fifth method, the so-called teleological interpretation, joined the canons of Savigny. The basis of its use in law was the idea of Jhering: law is not a self-contained system to be examined for its own sake ${ }^{56}$ but contains norms that have tasks to be carried out and functions, i.e. (social) purposes, which have to be enforced also by judges. ${ }^{57}$ This 'goal idea' was further developed by Philipp Heck, who assigned the judges to apply the results of the (also social) balance of interest of the legislator. ${ }^{58}$

52 Savigny, 1840, pp. 213-214.

53 Savigny did not use the Latin names in the course of delineation of the methods (elements) of interpretation.

54 Savigny did not discuss the interpretation methods in the order considered today as 'conventional' (and also followed in this research). He studied the historical 'element' of interpretation as the third method and defined systematic interpretation only after that as the fourth one.

55 These methods do not compete with but complement each other, i.e. in a certain case, we do not apply either the one or the other (choosing the best method to apply) but all of them have to be applied because they can authentically determine the meaning of the text only together (op. cit., p. 125). Furthermore, the meaning of the text cannot always be determined exactly; we only have to try to get the closest as possible to the true meaning of the text in the rich range of its meanings (op. cit., p. 216).

56 In his early works, Jhering says exactly the opposite thereof. This statement does not characterise the entire work of Jhering but only his works following his dogmatic-centric, concept analyser period.

57 '... das Recht kennt nur eine Quelle: den Zweck' (Jhering, 1877, p. XIII). The content of the statute can be determined only through its purpose, i.e. the 'teleological further development' (teleologische Entwicklung) of the (merely written) law (cf. Jhering, op. cit., p. 426).

58 The judge has the task to seek for the will of the legislator ('Forschung nach dem Willen des Gesetzgebers')-exploring what social needs the legislator took into consideration when creating the legal norm. However, this is not the search for the psychological will (subjective intention) of the 'real' legislator but for the causal factors creating the law, namely, determining what was (could be) the original (objective) purpose of the statute in light of the historical circumstances of the creation thereof (cf. Heck, 1914, p. 64). 
The gradual disintegration and slow expansion of the traditional canon began in the second part of the twentieth century, primarily in the German-speaking world. Former methods were renamed; new interpretation techniques and sources of reasoning of application of law were discovered. In his five-volume, large methodological summarising work, ${ }^{59}$ Fikentscher took the four plus one division as a basis and added one method, the so-called evaluative interpretation, using the prior results of jurisprudence. ${ }^{60}$ Bydlinski recognised reasoning funds that he did not call as 'methods of interpretation' but by the thematising thereof, he anticipated the ideas of the Bielefelder Kreis. ${ }^{61}$

59 Fikentscher, 1975.

60 Fikentscher deviated from the traditional canon regarding two aspects: he did not consider the logical and systematic interpretation to be two independent methods but a uniform, coherent interpretation technique; he recognised evaluative interpretation but only as a tool used to control the practical accuracy of the meaning determined on the basis of other methods. Hence, in his view, the following were the methods of 'the Canon': interpretation on the basis of the text, i.e. literal interpretation (Auslegung nach dem Wortlaut) as the necessary starting point of all interpretation of legal norms; logical and systematic interpretation (Auslegung nach Logik und System), in which logic, according to him, did not principally mean the application of the rules of formal logic but, similarly to the perception of the 'system', the consideration of the legal context of the text of the norm; historical interpretation (historische Auslegung) as the use of legislative history related to the concrete norm to explore the intended meaning of the text of the norm; 'interpretation' based on the 'value of the result' (der Wert des Ergebnisses), which, contrary to others, is not a method 'in its own right' but merely a technique to control the meaning determined by other methods; and teleological interpretation or 'interpretation according to the purpose' (teleologische Auslegung, Auslegung nach dem Zweck) (cf. Fikentscher, 1975, pp. 668-681).

61 Among interpretation techniques expressly called 'interpretation methods', Bydlinski differentiated the literal (grammatical), systematic-logical, historical (based on the legislator's intention), and objective-teleological. Bydlinski used wörtliche Auslegung (grammatische Auslegung), systematische-logische Auslegung, historische Auslegung (Auslegung nach der Absicht des Gesetzgebers), objektiv-teleologische Auslegung (Bydlinski, 1982, pp. 437-453) and divided the last type into five further subtypes. Hence, according to him, the following belong here: teleological-systematic interpretation as the method for determining the objective meaning (independent from the legislator) of the statute (ratio legis); interpretation of the text of legal rules consistent with the constitution; argumentum ad absurdum; interpretation according to the 'nature of the thing' (Natur der Sache), which may provide assistance on how to interpret certain obvious, self-evident life relations, even with content that opposes the meaning determined by some other methods, or may serve as a regarding reference; finally, comparative law arguments in the course of which concrete foreign legal rules or legal solutions generally applied in other (mainly similar or the most advanced) legal systems can be used for interpretation of domestic law (cf. op. cit., pp. 453-463). Bydlinski also analysed techniques that he did not call 'legal interpretation methods' but which, regarding their functions, are close to them. Hence, he recognised also the principle lex specialis derogat legi generali being intended to resolve the (apparent) contradictions of positive law. Regarding 'supplementary legal development' among the procedures being able to fill 'statutory gaps', he specified both types of analogical conclusion (statutory and legal analogy) and the inverse thereof, the technique of 'teleological reduction' or 'restriction', the principles a contrario and a fortiori (Umkehrschluß and Größenschluss) together with the involvement of universal ('natural') legal principles into interpretation. He also mentioned law application based on the case law or judicial practice and 'legal thinking'. 


\subsubsection{Methodology of the Bielefelder Kreis}

By the 1980s, it became apparent that the canon of Savigny was outdated. The variable interpretation techniques and reasoning tools of the modern application of law cannot be inserted therein. A group of distinguished law scholars, the socalled Bielefelder Kreis, ${ }^{62}$ was formed to examine the actual practice of modern courts. It decided to conduct, under the guidance and direction of Robert Summers, a remarkably detailed international research covering all substantial segments of administration of justice that enables practitioners to determine, inter alia, what interpretation methods and reasoning techniques are applied by the courts in those countries belonging to the European legal culture. ${ }^{63} \mathrm{~A}$ total of eleven arguments were differentiated and classified in four main categories: ${ }^{64}$ linguistic arguments, systemic arguments, teleological/evaluative arguments, and the method called argument from intention that belongs to none of the previous three groups, i.e. this is a transcategorial argument over the three other categories.

Two specific methods belong to linguistic arguments forming the first category: the argument from ordinary meaning and that argument from technical meaning. When applying the first one, we try to explore the 'obvious meaning' that would be attributed, on the basis of the everyday meaning of ordinary words, to the norm in question by a person speaking the given language at an ordinary level. If the everyday meaning would allow interpretations leading to several results, then the most generally accepted - the most obvious-must be applied. If it is not possible to decide it, the given provision must be understood with the meaning that, as a result of the use of other methods, is probably considered to be the most appropriate to the wider

62 The prelude to the group's formation was the IVR World Congress in Philosophy of Law and Social Philosophy in Helsinki in 1983 where some participants proposed to map the condition of the contemporary judicial law application. In 1986, following three years of ad hoc research, these legal scholars decided to carry out a systematic research regarding certain aspects of adjudicating by examining the operating features of the justice systems in their own country (cf. MacCormick, 1991, pp. XI-XIII). Finally, the legal scholars of nine countries (Argentina, the US, the UK, Germany, France, Italy, Sweden, Finland, and Poland) performed the empirical study of their countries in this respect (until 1990), including the study of the arguments applied during interpretation of legal norms (op. cit., pp. 1-2). Although, in the course of the latter, they researched the methods of 'statutory interpretation' but by 'statutes' they also meant all normative actions that were created by any public body entitled to make abstract norms mandatory for citizens and applicable during judicial law application (op. cit., pp. 10-11, 25). Constitutional interpretation (where a constitutional court was at all) was not included since it was not considered to be an adjudicating activity in terms of the subject of the research. The elaborated methodological classification could serve as guidance for researchers of constitutional interpretation methods. The concept 'interpretation', as the subject of the result, was understood in sensu stricto, and meant the determination of the actual meaning of ambiguous legal norms (op. cit., pp. 12-13).

63 'European legal culture' refers to jurisdictions with European origin, based on European grounds, i.e. with the terminology of Zweigert and Kötz, the members of the 'Romanistic', 'Germanic', 'Anglo-American', and 'Nordic' legal families (cf. Zweigert, 1998, pp. 74-285) and, in the classification of David, of the 'Romano-Germanic' and 'common law' legal families (cf. David, 1985, pp. 22-25).

64 Cf. op. cit., pp. 21 and 512-515. 
context. ${ }^{65}$ On the contrary, the latter argument uses a special technical meaning instead of the ordinary one; in this case, we attribute a meaning to a given word, to which meaning would be attributed by a person of a particular (legal or other) profession, as terminus technicus, a special professional meaning. ${ }^{66}$

Six methods of interpretation (3-8) were determined in the range of the 'systemic arguments' ${ }^{\prime 67}$ belonging to the second category: the argument from contextual harmonisation, the argument 'from precedent', the argument from analogy, the logical-conceptual argument, the argument from general principles of law, and the argument 'from history'. In arguments from contextual harmonisation, the meaning of a given legal provision is explored on the basis of its position in the legal ${ }^{68}$ system. ${ }^{69}$ The argument 'from precedent' does not mean merely the consideration of precedents in the course of interpretation, which is typical for the common law system, but, in general, the statutory interpretation achieved by the reasonings of previous court decisions. ${ }^{70}$ In arguments from analogy (also called 'arguments based on statutory analogies ${ }^{71}$ but, actually, meant to be a systematic-contextual based extensive argumentation as the result of interpretation) ${ }^{72}$ we interpret a(n existing) legal norm in the light of a relevant legal norm regulating an other but similar subject matter so that the meaning of the latter would also cover the case regulated by the former norm. ${ }^{73}$ In logical-conceptual argumentation, we apply the meaning of a given legal concept generally accepted and elaborated by the jurisprudence in the given system in all cases when that legal concept appears in a legal regulation. ${ }^{74}$ In arguments from general principles of law (according to the Bielefelder Kreis), to explore the

65 Cf. op. cit., pp. 464 and 512-513.

66 Cf. op. cit., pp. 464 and 513.

67 Arguments other than linguistic (also the systematic ones) have three functions: they can confirm the everyday or technical (i.e. literal) meaning of the words used by the legal rule; underpin the accuracy of the application of another meaning against this grammatical meaning (i.e. can 'deteriorate' literal meaning); clarify the actual meaning of the words, expressions, sentences with obscure linguistic-grammatical meaning (cf. op. cit., p. 465).

68 As we can see, it is identical to the systematic interpretation in Savigny's classification.

69 Cf. op. cit., pp. 464-465, 466-467, 513.

70 Often, these do not use a concrete previous relevant judicial decision to explore the meaning of the legal norm with obscure text but a set of such decisions; i.e. they refer not (only) to 'precedents' in the strictest sense but to the entire case law regarding the legal provision in question. The essence of the argument in both is the same: the courts interpret the given norm as other courts did when they decided previous cases with similar facts, i.e. the adjudicating bodies making decisions in latter similar cases use, as a sample, previous judicial decisions to decide the given legal interpretation problem (cf. op. cit., pp. 467, 487-490, 513).

71 Cf. op. cit., pp. 465.

72 Accordingly, this argument covers all others because any other argument can be used to determine the 'significant' similarity of the meaning of two statutory provisions.

73 Cf. op. cit., pp. 467, 513-514.

74 Cf. op. cit., pp. 465, 467, 514. Through the operation of interpretation, we strive towards conceptual coherence in the legal system. We do not use formal logical (or quasi-logical) arguments to explore the implied but not explicit meaning of the text (as we would do using interpretatio logica defined by Savigny). 
'correct' meaning of a certain provision, we use either substantive moral principles that serve as (partial) basis for previous court decisions and enable 'correct', interpretative decisions or general principles determining the entire legal system (and usually recognised also at the constitutional level); or widely used rules of a branch of law characterised as having general clauses. ${ }^{75}$ Finally, in 'historical' (in fact, customary law) interpretation, the meaning of the legal norm in question can be determined on the following grounds: regarding the circumstances of the process of legislation, what purpose and function the created legal regulation has ${ }^{76}$ and what meaning or what understanding (solidified and accepted by lawyers) has been subsequently attached to this legal provision during the long years of its use (including the meaning attributed by courts, the conventional doctrinal understanding, and the fact that the meaning created in such a manner is appropriate for the legislator, who would have otherwise changed the text of the norm in question). ${ }^{77}$

The third category contains the teleological and evaluative arguments: the argument from (statutory) purpose and the argument from substantive reasons. The former orders to apply the one from the potential meanings (determinable by other methods) of the legal norm to be interpreted, which is oriented mostly to the goal, social purpose, and function of the given norm, and (regarding also the expectable factual consequences) serves them the most. ${ }^{78}$ The latter requires, in the course of legal interpretation, the direct use of values that have or had influence on the legal provision in question and, generally, on the formation and structure of the legal system. ${ }^{79}$

Finally, the fourth large category is the argument from intention that itself is, as a transcategorial technique over the arguments of the other categories, the eleventh interpretation method. It seeks the will of the legislator: what it wanted to achieve when creating the norm with such text. It is considered to be 'above' the arguments of other categories because it covers all of them. When applying this method, the judge has to ask what meaning the legislator wanted to attribute to the words and expressions included in the statute, into what legal context it wanted to place the provision in question, whether it wanted to rely on the prior results of court interpretation, whether it wished if the law created by it was interpreted and applied analogously, and so on. ${ }^{80}$

75 Cf. op. cit., pp. 465, 467-469, 514.

76 The placement of this argument is confusing because it also belongs to interpretation number 10, argument from (statutory) purpose.

77 Cf. op. cit., pp. 465, 469, 514. It is a considerably diffuse, diverse argument that combines the elements of teleological, historical (based on the determination of the legislator's intention), substantive, legal conceptional, and other arguments.

78 Cf. op. cit., pp. 469, 514. This method is the teleological interpretation formed during doctrinal development after Savigny's classification of four categories.

79 They may include certain direct moral, political, economic, or social considerations: aspects that serve as the theoretical basis of a given legal norm or the entire legal system (cf. op. cit., pp. 469470, 514-515).

80 Cf. op. cit., pp. $21,470-471,515,522-525$. 


\subsubsection{Recent attempts in classification of methodology of argumentation theory}

The methodological classification of the Bielefelder Kreis provided the development of argumentation theory with a significant impetus. It had such a huge impact that, from the 1990s, this classification has been the standard of methods of interpretation and argumentation, which the legal academics wanted to either use without changing (mainly during legal sociological research) or exceed methodologically or, maybe, complete or specify (its use in favour of legal sociological examination and the purpose for development of argumentation theory are occasionally present at the same time in the same research). Eventually, all research (even if their methodologies are not exact matches to the one used by Bielefelder Kreis) started from this classification. ${ }^{81}$ However, some new methodological classifications must be highlighted from the further development of history of argumentation theory, whose classifications proved to be determinative, either on their own (doctrinal importance) or as a result of their use during the empirical legal sociological research, and also inspired the methodology of the present research.

In his legal sociological research analysing 600 decisions of the Hungarian Supreme Court, Pokol applied a methodological classification differentiating ten specific arguments ${ }^{82}$ : ' 1 . Interpreting the legal text in view of the meaning of the words in everyday language; 2 . Interpreting the legal text in view of the special/technical meaning of the words, provided that a given word or phrase has such a meaning either in addition to its everyday meaning or has no other than such a meaning; 3. Contextual interpretation means the type of interpretation of the legal text where the words of each provision are construed in compliance with the meaning attributed to them when fitted in the entirety of the law or a complete body of related laws; 4. Interpreting the legal text on the basis of law logistics maxims; 5 . Interpreting the legal text through analogy; 6 . Interpreting the legal text on the grounds of precedents set at the time of previously enforcing the given law; 7. Interpretation on the grounds of legal dogmas and doctrines; 8. Interpreting the legal text in the light of implied ethical values of law or certain branches of law; 9. Interpreting the legal text in the light of the aims of the given statute; 10. Interpreting the legal text on the grounds of the will of the legislator. ${ }^{83}$

Pokol (mostly) followed the division of Bielefelder Kreis when studying statutory interpretation. Later, Jakab laid down his own methodology in the course of researching on constitutional reasoning. Jakab presumed, as we have also done above, that argumentation and interpretation are different (he also used the concepts of

81 We do the same in the course of the present comparative law examination.

82 In his later work in French language, he identified eleven arguments, adding interpretation in light of fundamental constitutional rights and principles (cf. Pokol, 2007, p. 397). In his work in Hungarian, he broadened it to twelve arguments (cf.: Pokol, 2005, pp. 227-228), also recognising 'interpretation referring to legal principles' (an individual, specific type of interpretation on the grounds of legal dogmas and doctrines) as a new independent method (op. cit., p. 227).

83 Pokol, 2001, p. 465. 
'argumentation' and 'reasoning' as synonyms) and considered 'interpretation' as a specific kind of argumentation. ${ }^{84} \mathrm{He}$ noted that 'most arguments in constitutional reasoning aim to interpret the constitution' ${ }^{85}$ However, there are types of argumentation that do not aim at interpretation. These include analogies (including, in the broader sense, teleological reduction ${ }^{86}$ ); establishing the (valid) text of the constitution; and arguments on application of the text of the constitution (briefly: arguments on the applicability of the constitution). ${ }^{87}$ In addition to these 'rare exceptions', there are interpretation methods ${ }^{88}$ themselves (the majority of arguments) that can be divided into three argument types (and two more methods outside these). The first argument type is the 'ordinary or technical meaning of the words', which is identical to the classification of Summers since it covers the plain meaning of the words and the legal and non-legal professional meaning. ${ }^{89}$ The second argument type is called 'systematic arguments' within which the 'harmonizing arguments' ${ }^{90}$ the 'referring to precedents which interpret the constitution', ${ }^{91}$ the interpretation 'in the light of doctrinal concepts or principles', ${ }^{92}$ and the 'linguistic-logical formulae based on silence ${ }^{93}$ can be distinguished. The third argument type is the 'evaluating arguments', ${ }^{94}$ to which the 'relying on the objective purpose of the norm', ${ }^{55}$ 'relying on the intention of the constitution-maker' ${ }^{96}$ (also including 'argumentum ad absurdum'), ${ }^{97}$ and 'sub-

84 '[A]rgumentation [...] is used as synonymous [...] with reasoning. Interpretation [...] means determining the content of a normative text. [...] Consequently, what is traditionally called "a method of interpretation" is in fact a type of argument used to interpret a text' (Jakab, 2013, pp. 1219-1220).

85 Jakab, op. cit., p. 1220.

86 Cf. Jakab, op. cit., p. 1221.

87 Jakab, op. cit., p. 1220.

88 '[T] $]$ he vast majority of arguments are interpretive in their nature' (op. cit., p. 1223).

89 Jakab, op. cit., pp. 1231-1233.

90 It practically corresponds to 'argument from contextual-harmonization', the method of classification by Summers (Jakab, op. cit., pp. 1233-1235).

91 Jakab, op. cit., pp. 1235-1239.

92 Jakab, op. cit., pp. 1239-1240.

93 Jakab classified here not only argumentum a contrario but also argumentum a maiori ad minus, argumentum a minori ad maius, and other maxims (which can be classified to a contrario) (cf. Jakab, op. cit., p. 1240).

94 These are arguments that help 'beyond the legal context' to interpret the (constitutional) norm (Jakab, op. cit., p. 1241).

95 Jakab, op. cit., pp. 1241-1243.

96 Jakab, op. cit., p. 1246. He distinguished it from objective teleological arguments by calling it 'subjective teleological arguments', which focuses on the 'intention' of the entity creating the norm (also including the use of legislative history or travaux préparatoires as source). It tries to explore its will definitely. It is somewhat surprising that during writing, together with Fröhlich, the Hungarian chapter in the legal sociological research based on this methodology, the CONREASON Project, he already dissolved the difference between objective and subjective types of teleological interpretation and, regarding both, he used the word 'purpose'. The two authors expressed the latter with terminus 'purpose of the constitution-maker (including travaux préparatoires)' (Jakab, 2017, p. 415), blurring the analysed clear distinction between the two methods, while the original classification even included this clear line.

97 Jakab, op. cit., p. 1249. 
stantive arguments' (interpreting norms in the light of non-legal [e.g. moral] aspects) belong. ${ }^{98}$ Further interpretation methods, which cannot be classified to any of the three groups above, are the 'referring to scholarly works' ${ }^{99}$ and 'arguments from comparative law'. ${ }^{100}$ The above classification served as basis of the Project CONREASON launched in 2015, which had the ambitious aim 'to develop the most comprehensive and most systematic analysis of constitutional reasoning that has ever been produced'. ${ }^{101}$ For this purpose, in the course of the actual research, the research participants analysed, on the basis of the methodology described, a total of $760^{102}$ leading cases of the constitutional or supreme courts of sixteen countries, ${ }^{103}$ of the ECtHR, and the ECJ, and sought to define the contemporary characteristics of 'constitutional reasoning' and the similarities and differences between countries or legal systems. ${ }^{104}$

98 These can be only exceptionally applied, e.g. 'where no other arguments can help, or other arguments lead to interpretations contradicting one another and one has to choose' (Jakab, op. cit., p. 1250).

99 Jakab, op. cit., pp. 1251-1252.

100 Jakab, op. cit., pp. 1252-1254.

101 Jakab, Dyevre, Itzcovich, 2015, p. 3.

102 Cf. Jakab, Dyevre, Itzcovich, 2017, p. 30. The number 760 is obtained from the substantial changes regarding the Hungarian constitutional system between 2010 and 2011. The analysis of the cases before 2010 was completed subsequently by the authors analysing the Hungarian practice with constitutional decisions between 2012 and 2013, which already (partly) reflected the results of such changes. Jakab and Fröhlich compared the results coming from 40 decisions between 1990 and 2010 with the results coming from 40 other decisions made on the basis of the new rules of competency and with the interpretation of the new constitutional norms, after the entry into force of the new constitution (the Fundamental Law), in 2012 and 2013. For the latter, see Jakab and Fröhlich, op. cit., pp. 430-434). The constitution, named after the German Grundgesetz Alaptörvény, i.e. (correctly) Basic Law or (incorrectly but more often used in English translations) Fundamental Law, also changed the text of the constitutional norms (including fundamental rights), the relevant codified interpretation principles, and the contextual frame of the constitution. Regarding the latter, the appearance of the new interpretation frames serving as preamble, the National Avowal, must be emphasized (see Horkay-Hörcher, 2012, pp. 39-42; Trócsányi, op. cit., p. 10). Furthermore, the new Fundamental Law substantially amended the competencies of the Constitutional Court, as a consequence of which, instead of the previously typical norm control procedures, constitutional complaints became the main procedure thereof (taken also from the German legal system, cf. Hartmann, 2008, pp. 59-166): between 1990 and 2011, posterior abstract norm control represented $50 \%$ of the procedures of the Constitutional Court; between 2012 and 2017, more than $90 \%$ of the submitted motions were related to constitutional complaints (and the rate of the cases regarding abstract norm control fell below 1\%) (cf. Tóth, 2018, pp. 100-101). For all these reasons, the situations before and after 2011 are, in fact, essentially different. Hence, it was a right and justified decision of the authors 'to take a second sample'.

103 These were the following: the High Court of Australia, the Austrian Constitutional Court, the Supreme Federal Tribunal of Brazil, the Supreme Court of Canada, the Czech Constitutional Court, the French Constitutional Council, the German Federal Constitutional Court, the Hungarian Constitutional Court, the Irish Supreme Court, the Supreme Court of Israel, the Italian Constitutional Court, the Spanish Constitutional Tribunal, the Constitutional Court of South Africa, the Constitutional Court of Taiwan, the Supreme Court of the United Kingdom, the Supreme Court of the United States. Cf. Jakab, Dyevre, Itzcovich, 2017, p. 26.

104 We cannot undertake to delineate the results of this comparative legal research. For that, see Jakab, Dyevre, Itzcovich, 2017, pp. 761-797. 


\subsection{On constitutional reasoning in general}

\subsubsection{Characteristics of constitutional reasoning}

The subject of the present research is the examination of the practice of the constitutional courts in six Central and Eastern European countries and of the ECtHR and the ECJ regarding the application of fundamental rights, particularly the analysis of the application frequency and reasoning weight of the methods used by these fora. The research, therefore, enumerates the arguments applied by these fora and compares the practice thereof. Since this type of reasoning is not related to the application of inner positive law by ordinary courts but to the practice of constitutional courts and regional fora regarding the interpretation and application of constitutional fundamental rights, the techniques of the methodology serving as basis for the present research (i.e. constitutional interpretation) also differ from the ones of statutory interpretation. Consequently, the methodology of the constitutional reasoning will also be somewhat different from the general methodology of legal reasoning, owing to the nature of the text of the norm to be interpreted.

The constitution is a special normative text ${ }^{105}$ different from the 'ordinary' statutes owing to its political significance, typical content, function, position in the hierarchy of norms, language, context, mode of creation, enforcement, and many further features. ${ }^{106}$ Thus, constitutional interpretation (interpretation of constitutional fundamental rights by the constitutional courts or the ECtHR/ECJ) also differs from traditional statutory interpretation. Constitutional reasoning will also be different

105 This is not quite accurate. Schmitt recognised a difference between constitution and constitutional law (Schmitt, 2008, p. 75). Although the latter contains the rules on making plain legal regulations, state structure, and the rights and obligations of political unity, it is does not 'establish itself' but depends on the previous choice and political decision of the given political unity as facts (Schmitt, op. cit., p. 77). 'The constitution in the positive sense originates from an act of constitution-making power. The act of establishing a constitution as such involves not separate sets of norms. Instead, it determines the entirety of the political unity in regard to its peculiar form of existence through a single instance of decision. This act constitutes the form and type of the political unity, the existence of which is presupposed. [...] The constitution in the positive sense entails only the conscious determination of the particular complete form, for which the political unity decides. This external form can alter itself. Fundamentally new forms can be introduced without the state ceasing to exist, more specifically, without the political unity of the people ending. [...] On the contrary, constitutional laws are valid first on the basis of the constitution and presuppose a constitution. For its validity as a normative regulation, every statute, even constitutional law, ultimately needs a political decision that is prior to it, a decision that is reached by a power or authority that exists politically' (Schmitt: op. cit., pp. 75-76). In this legal theoretical sense, the text of the constitution, which (and the interpretation of which) we are talking about in this chapter, is not the decision of the political unity itself, nor the constitution with the meaning defined by Schmitt, but only constitutional law. Since this content is traditionally meant as 'constitution' and we, in a work of comparative law, must follow the constitutional wording of national legal systems, then the present work understands the main rules of the political unity (written and historical constitution) when we talk about constitution.

106 Cf. Goldsworthy, 2006, pp. 1-4. 
from legal reasoning in general. Despite the overlaps between the two, constitutional reasoning (carried out by constitutional courts in the course of interpretation and application of the constitution) is, on the one hand, conducted based on the sources and methods other than statutory interpretation (carried out by ordinary courts in deciding legal disputes), and, on the other hand, the use of traditional expressions would be misleading owing to the subject of the interpretation. For this reason, it is appropriate to use a separate methodological classification. ${ }^{107}$ An obvious example is as follows: while the interpretation of statutes, in the course of ordinary legal argumentation and in light of the provisions of the constitution, justifies to be differentiated from the further types of contextual interpretations (e.g. interpretation of statutes on the basis of other statutes), interpretation of constitutional rights based on the constitution requires the consideration of further provisions of norms on their own level, which, thereby, becomes 'simple' contextual interpretation. ${ }^{108}$ The situation is more specific in case of international fora because, for example, the inner law of contracting states is 'foreign' law for the bodies applying international conventions, while their prior case law acts as precedent in their subsequent decisions. For this reason, independent separate classifications may be set based on the special features of constitutional reasoning that can cover a wide range of arguments (methods and sources) specifically used (or useable) by constitutional courts, on the one hand, and by supranational judicial for a, on the other. In the frame of the present research, the starting point was the classification described in point 2.3. The application frequency of these arguments in the practice of constitutional and regional courts has been examined.

\subsubsection{On the concept of constitution ${ }^{109}$}

Formal constitution means the legal regulation(s) and the specific legal norms regulated thereby that were given the name constitution or constitutional norm (e.g. act) by the constitutional power. These norms are at the top of the system of legal norms; hence, any other (logically lower-level) legislation or legal norm included thereby cannot be against them. Material constitution is a much broader category

107 Jakab, for example, takes the opposite view; he thinks that despite the fact that the constitution is 'substantially different from other norms of non-constitutional rank' and that 'the norms of the constitution are much more abstract and/or value-laden than the rather concrete statutory norms', ' $[t]$ here is no need to draw a sharp distinction between these two types of interpretation' (Jakab, 2013, p. 1224).

108 It means that the method of 'constitutional interpretation' (verfassungskonforme Auslegung) developed in German jurisprudence is not only inapplicable but also incomprehensible in the interpretation of constitutional provisions. For more details on the German practice and principles of verfassungskonforme Auslegung, see Denninger, 1984-1985, pp. 1013-1031; Bydlinski, 1982, pp. 455-457.

109 We repeat and emphasise that, by the concept of 'constitution', we understand its constitutional and not legal theoretical meaning. For the legal theoretical concept of constitution, see the previously cited work of Schmitt. 
that covers both the constitution (act(s) of constitution) and all legal regulations, and the legal norms included thereby, which contain more detailed rules of the most important aspects of the legal institutions found in the formal constitution.

All centrally organised human co-existence with sovereignty (society)—that is, all states-have a constitution. It is a feature of modern age that the constitution means one (or a few) highlighted norms (so-called basic norms) adopted under particular rules in a special procedure defined previously for this purpose and which can be amended or repealed in the same way (codified constitution). Some states have not formulated such expressly specified (one or a few) act(s) of constitution; instead, the constitutional norms are contained by several (many) acts (occasionally even lower-level rules) highlighted for their subject matter (not their adopting procedure) and by non-written constitutional customs and conventions. This type of constitution (historical constitution) exists in the UK.

These two types are often differentiated by the terms 'written and unwritten constitution'. ${ }^{110}$ The codified constitution is (necessarily) written but so is the historical constitution. Historical constitution differs from codified constitution, firstly, in that the former has unwritten elements (based on constitutional customs, conventions, and traditions formed during hundreds of years and respected unanimously but not involved in written legal source, i.e. the constitutional culture); and, secondly (and principally), in that neither the constitutional customs nor the pool of written legal norms under the concept of constitution can be determined exactly. Therefore, historical constitutions have parts on which there is broad agreement in that they belong to the constitution of the given state, whereas the classification of other norms is controversial. Consequently, a historical constitution is never closed (unless a codified constitution is adopted subsequently) but is developing in an organic way. Occasionally, there are consensuses regarding more new norms on the fact that these are also the parts of traditional constitution that may modify the meaning or the application of old-time constitutional norms and may expressly derogate their application and lay down new requirements.

In the present research, all examined countries have a codified constitution (even the Czech Republic where the constitutional norms are included in two specifically defined written formal legal sources with the rank of constitution). ${ }^{111}$ Thus, it was not necessary to consider the legal theoretical consequences of how to find out in a borderline case whether a norm to be interpreted qualifies as a constitutional norm. The present research considered all legal norms in the act of constitution (in case of the Czech Republic, in one of the acts of constitution but, owing to the fundamental

110 Cf. Wade, 1993, pp. 4-8. For the use of the concept consider to be correct (regarding not only the English legal system), see Allison, 2007.

111 Apart from the Constitution (which contains provisions on state structure), the Charter of Fundamental Rights and Freedoms is also a constitutional source that includes human and civil rights and is appended to the Constitution.(For the content of these two legal sources, see Glos, 1994, pp. 1058-1069. 
rights being the subject matter of the research, in practice mainly in The Charter of Fundamental Rights and Freedoms) as constitutional provisions.

\subsubsection{On the concept of constitutional rights}

Rights laid down in the constitution and applied factually were originally formulated as human rights during the Enlightenment, to a lesser extent in the seventeenth and mostly in the eighteenth century. Human rights refer to the rights arising from the human nature of people and granted to every person at birth as they belong to the philosophical essence of the human. All in all, human rights are natural or moral rights related to the biological and moral status of humans and provide the conditions and guarantees of recognition, respect, and protection of their personality and of their position (equal to others by birth) in society. Without human rights, people could merely be described by their biological existence and physiological features. As humans are moral beings who are able to place themselves in the world and in society and to differentiate between good and bad, proper and improper, fair and unfair (and to evaluate their own situations and the actions of others in light of all of these), who have desires, expectations, and self-image, the modern constitution must provide protection for this moral status.

Human rights become constitutional rights through their recognition by the constitution of a given state. At the end of the eighteenth century, the first French constitution, in September $1791,{ }^{112}$ and later, based on the French example, ${ }^{113}$ the constitution of the US (with the first ten amendments to the Constitution, the Bill of Rights), in December 1791, defined constitutional rights. The actual realisation of these rights took place only later (in the US from $1803^{114}$ and in Europe only from the twentieth century, in most countries only immediately after World War II or even later) and the sphere of operation of constitutional rights, principles, and values was established, via constitutional review, only from this time.

Human rights serving as a basis for constitutional rights, according to the classification by Karel Vašák, ${ }^{115}$ traditionally have three generations. First-generation human rights mean the political ${ }^{116}$ and civil ${ }^{117}$ rights recognised and determined in the course of the Enlightenment, mainly from the end of the eighteenth century (but, regarding their foundations, required from the beginning of the seventeenth

112 Mitchell, , 1988, p. 2.

113 Lebovitz, 2017, pp. 1-50.

114 Marbury v. Madison, 5 U.S. (1 Cranch) 137 (1803). For the concrete background and circumstances of decision-making of this case, see Nelson, 2018, pp. 90-106.

115 For the first time, this classification was published in the journal of UNESCO in 1977. Vašák, 1977, p. 29.

116 For example, right to vote, access to public office.

117 These are the so-called classic freedoms: freedom of speech, freedom of the press, freedom of assembly, freedom of association, freedom of movement, personal security, right to property, right to life, right to bodily integrity. 
century). These rights are 'negative' in the sense that they oblige the state to refrain from violating them and not to intervene in the sphere of freedom protected by them. Second-generation human rights are the so-called social, economic, and cultural rights, which, from the end of the nineteenth and the beginning of the twentieth century, guarantee the freedom of individuals yet not in a negative way, namely, immunity from the state's interference; these rights also require the state to take actions to establish the possibility of living, employment, and active participation in social life. ${ }^{118}$ Finally, third-generation human 'rights' are the so-called rights of solidarity, which, from the end of the twentieth century, define requirements not recognised as subjective rights. The individual protection and application of these rights are impossible owing to the nature of the interests to be protected. The cooperation of the states is required to protect the interests of humankind as a whole. ${ }^{119}$

Most constitutional rights have two sides: a subjective and an objective side. The subjective side means that the given constitutional right may be invoked as individual right, i.e. on the basis of the given constitutional right, personal legal protection may be granted to any person whose fundamental right is violated. This individual nature of constitutional rights generates two types of duties of the state: a negative (obligation to refrain) and a positive (active) obligation. Negative obligation means that the state is obliged to refrain from the violation of individual fundamental rights: the state may not interfere in the personal sphere guaranteed by a subjective right (unless the interference is based on constitutional reasons; various tests and measures are elaborated by constitutions or constitutional courts for this purpose). ${ }^{120}$ In contrast, positive obligation means that the state is not only obliged to refrain from violating these individual constitutional rights but also to guarantee actively that such freedoms of individuals could not be violated even by other(s). It means that the state is obliged to prohibit such intervention by others in the sphere of freedom and to operate a procedural system that can sanction and thereby prevent others from restricting individual freedom. ${ }^{121}$ Finally, the $o b$ jective side of fundamental rights means that the obligations of the state do not end

118 These are right to work, right to safe and healthy working conditions, right to rest and leisure, right to social security, access to culture, freedom of scientific research, right to education, etc.

119 In Vašák's words, these rights 'can only be implemented by the combined efforts of everyone: individuals, states and other bodies, as well as public and private institutions' (Vašák, op. cit., p. 29). 'Such rights include the right to development, the right to a healthy and ecologically balanced environment, the right to peace, and the right to ownership of the common heritage of mankind' (Vašák, ibid.). The collective rights of nationalities, consumer rights, and, most recently, the right to healthy food and water are also recognised as rights of solidarity.

120 Arising from this obligation to refrain, the state may not violate the people's freedom of movement, freedom of assembly, freedom of religion, private sphere, etc. because fundamental rights protect these individual needs arising from the moral being of a human even against the state. Moreover, such constitutional rights, historically, were established precisely to restrict the state.

121 The sanctions can be civil (compensation, restitution), administrative, misdemeanour penalty, and, in the most serious case, criminal penalty. 
with safeguarding individual legal protection (the subjective side); the state is also obliged to maintain an institutional system that protects the value itself, which serves as basis for the given fundamental right, i.e. independently from the impairments of individual rights. ${ }^{122}$

Based on whether a constitutional right 1) ensures the subjective (individual) legal protection or 2) imposes only an institutional protection obligation on the state or, maybe, 3) expresses, only symbolically, its commitment to achieving certain goals without defining any specific accountable obligations, we can differentiate three types of constitutional norms ${ }^{123}$ individual rights, constitutional provisions on objective (institutional) obligations of the state to ensure basic values, and state objectives. Subjective rights are constitutional entitlements that protect individuals in their person. The constitutional provisions on objective (institutional) obligation of the state are constitutional norms, the violation of which cannot be individually referred to but to which the state cannot be indifferent; therefore, for their protection, the state has to establish regulations that can guarantee the values intended to be protected by such provision. ${ }^{124}$ Finally, state objectives are declarations that record the social policy concerns that the state considers to be important but does not have any specific obligation to realise.

The present research was not limited to the first- or second-generation rights. All rights approved as constitutional rights by the legal system (constitution) of the certain state have been taken into consideration if they generated the obligation of the state to restrain (obligation of non-interference), to enforce the violated rights, or to guarantee the criteria necessary for exercising the rights individually or for making it easier (e.g. legal and institutional system recognising the values that serve as basis for the given right). Hence, the subjective rights and constitutional norms determining the objective (institutional) obligations of the state fell under the scope of our research. Meanwhile, we did not examine the interpretation aspects of constitutional provisions (aims of the state) that did not define either direct obligation of the state to safeguarding the rights of individuals or task of the state regarding the building of the law system for guaranteeing indirectly the rights of individuals.

122 The state is obliged to set the conditions among which this value, already completely independently from the state, can be guaranteed or supported. This is the obligation of objective institutional protection of the state. Such obligation, e.g. can be concerning freedom of religion, according to which the state has to allow churches to operate ideologically committed social institutes (e.g. retirement homes) that carry out religious activity in addition to their social tasks.

123 Using the expression "aw' would not be precise since this implies that these constitutional provisions have the nature of individual rights; owing to terminological rudimentarity, the use of this word can be justifiable.

124 The 'right' to a healthy environment, for example, implies such an obligation of the state to protect institutions without a substantive legal side: nobody has the individual right to request, by direct reference to the violation of their right to a healthy environment, the action of the state in order to prohibit, e.g. the operation of a polluting plant or to reduce car traffic in downtown. The state may not be indifferent to the conditions of the healthy environment; hence, it is obliged to establish the system of conditions that takes it into account. 
Decisions of constitutional courts interpreting constitutional principles and values were considered only if any constitutional entitlement could be derived from them or if, in the course of defining the restriction aspects of constitutional rights by the constitutional court, they had influence on the interpretation of constitutional rights or on their extent and scope as determined by the constitutional court. We also excluded the examination of the provisions on the structure of the state and of other constitutional norms. ${ }^{125}$

\subsection{Particular methods of constitutional reasoning}

The methods of constitutional reasoning, including the ones of constitutional interpretation, have several similarities with methods of ordinary legal reasoning but, compared with them, the former are special in certain aspects. ${ }^{126}$ Therefore, it is reasonable to talk about independent constitutional interpretation separate from ordinary statutory interpretation and about constitutional reasoning (including methods and other sources). ${ }^{127}$

125 A constitution may contain the following. It may regulate the form of the state; the formation, structure, operation, relations, tasks, and competencies of the bodies with a public function in the given state (part of the structure of the state, political constitution); the constitutional rights conferred on citizens or on people residing in the given country, the way of granting and enforcing these rights, the possibilities and conditions of limiting and the guarantees of them and (possibly) the obligations of these persons (part of fundamental rights); the transparent principles determining the structure and operation of the state (rule of law, popular sovereignty, separation of powers, and the unitarian or federal nature of the state); the symbols of the state (e.g. flag, coat of arms, anthem); the types, order, and termination conditions of the special legal order together with the rules and decision-making process prevailing during that; and all issues considered to have great significance by the constitution-maker (e.g. rules of public finance, name of the capital, eternity clauses, denomination of state church, conditions of starting a war or making peace). In the course of the present research, we examined only the constitutional court decisions interpreting the provisions regarding fundamental rights.

126 The research of Bielefelder Kreis delimited statutory interpretation from constitutional interpretation, which (mostly in the US) 'has long been deemed a topic quite distinct from general statutory interpretation' (MacCormick and Summers, op. cit., p. 11).

127 In a previous research regarding the interpretation practice of the Hungarian supreme courts, the author of the present chapter used a partly different methodological classification regarding statutory interpretation, precisely owing to the differences between statutory and constitutional interpretation (cf. Toth, 2016, pp. 173-201). The source of inspiration in case of that division regarding the methods of statutory interpretation was also the classification of the Bielefelder Kreis (case of methodological division serving as basis for the present research). The aforementioned research was only completed with some recent, subsequently spread or appreciated methods (e.g. comparative and some other methods) and clarified, chiselled borders between these techniques (with the employed division not the only one and not necessarily the best way to separate the methods of argumentation and sources of interpretation). The same is true also for methodological classification serving as basis of the present research. A unified methodology was necessary to compare the results of the countries concerned and to perform this task efficiently. This division seemed to be, methodologically, the best and the most appropriate. 


\subsubsection{Grammatical (textual) interpretation}

Legal texts are (supposed to be) written for ordinary people. As such, it is important that ordinary people understand them as easily and smoothly as possible. Law can fulfil its function to influence behaviours only to the extent that people understand the legal requirements. Hence, it is absolutely necessary to start from the linguistic-grammatical meaning in the course of interpretation of legal texts. Accordingly, this is the elementary method of legal interpretation that can be modified or further developed ${ }^{128}$ but cannot be eliminated. ${ }^{129}$

The (codified) constitution (which is the common type in all the countries studied here) is also a written legal normative text. Grammatical interpretation as an elementary way of interpreting law comes into play when exploring the meaning of constitutional rights. The most trivial method of interpretation is grammatical interpretation. ${ }^{130}$ It can be semantic (lexical), on the one hand, when we explore the meaning of the words and expressions of the norm in question within the given language. On the other hand, it can be syntactic (related to syntax), when we determine the relations between certain parts of the text by interpreting, for example, the conjunctions. Interpretation based on syntax is always the part of ordinary grammatical interpretation, whereas semantic interpretation can either belong to the

128 We cannot avoid at least to correct the scrivener's errors and to overstep the literal meaning even if we respect the text of the act (Grey, 1999, p. 18; Scalia and Garner, 2012, p. 234).

129 The contemporary theoretical ground thereof has been developed and led to the final conclusion by the textualist approach. When exploring the meaning of written legal norms, textualism starts primarily from the text. For textualists, law is what appears in the text of the statute. It is not possible to explore the meaning of a legal text on the basis of other than what is explicitly written in the statute. They believe that the text is objective and is also served by the adherence to the 'ordinary meaning' of the words and expressions used by the statute. This term, in this sense, was first used by Antonin Scalia, the most famous textualist and founder and the 'face' of the school. For the functioning of the interpretation principle, see Scalia and Garner, op. cit., pp. 69-77. Since the ordinary meaning of a word is the same for everyone, textualists say, if we also order the judges to perceive the expressions used by statutes in this sense, then we can eliminate judicial subjectivism. In this way, no judge may interpret the given legal text differently than an average person would. Thereby, the predictable jurisdiction would become possible and the law could get closer to the people and to society. The main problem with textualism, or the unconditional adherence to the text, is that ordinary meaning does not actually exist, since even dictionaries do not necessarily define the same expressions in the same way (Colinvaux, 1997, p. 1146). Against textualism, it is also often mentioned that it cannot take into consideration the changes of the relations in society: if we unreasonably insist on the original text even when the social relations change and we do not modify the statute, then we will be controlled by the 'dead hand of the past' (Redish, 1996, p. 530).

130 This method is generally the starting point. '[W]e can hardly doubt, that there must be principles of statute law enabling us to supplement the literal words in various ways and for various purposes; but, subject to this, the English theory requires the court to try to interpret statutory provisions in accordance with the literal or plain meaning, and without regard to policies or rationales, unless the statute itself is first determined to be unclear' (Atiyah and Summers, 1987, p. 102). This statement is true not only for the English but for continental legal theory and judiciary practice, and not only for statutory interpretation and statutory texts but for constitutional interpretation and constitutional texts as well. 
method exploring the ordinary meaning of the words or an interpretation based on the meaning of a terminus technicus used in a profession.

Syntactic interpretation draws conclusions from the elements of the structure of the sentence and their relations (i.e. subject-predicate agreement, singular and plural terms, use of suffixes, modality of the sentence, conjunctions) regarding the meaning of the text in light of the relation between these elements. ${ }^{131}$ The most important of these is to define the meaning of conjunctions and, thereby, the relation between the elements of the norm hypothesis, which can be of three types. In case of logical conjunction, all elements, without exception, in the enumeration of the hypothesis, disposition, or sanction must be fulfilled for the applicability of the legal provision. In case of alternation (alternative options), the norm is applicable if at least one of its application conditions is fulfilled, in which case only one element of the hypothesis is enough to invoke the applicability of the legal provision. Finally, disjunction (excluding options) means that exactly one from the elements contained in the hypothesis can come true, which excludes the materialisation or the verifiability of the other elements.

As far as semantic (lexical) interpretation is concerned, ordinary grammatical semantic interpretation (or simply, 'ordinary interpretation') is the method of interpretation by which the meaning of a given word or phrase is determined on the basis of the meaning that an ordinary person who speaks the language well at an average level would attribute to it. The grammatical semantic interpretation based on professional terminology (or simply, professional interpretation) indicates the method by which we determine the meaning of words and expressions with consideration to the meaning that would be attributed to them by a person experienced in a given profession and 'speaking the special language thereof'.

The words of the text of a legal norm may also have a meaning within the terminology of considerably different professions. The terminology of the legal profession as the linguistic base mostly used during legislation is, necessarily, paramount. In the course of legal professional grammatical semantic interpretation, the judge makes their decision, in order to solve an interpretation dilemma, only on the basis of the legal technical words, technical expressions with legal meaning, or the meaning (different from ordinary and expressly used in legal profession) of legal termini technici having particular legal meaning. It is, in fact, legal dogmatic interpretation: the special legal meaning, unanimously accepted and recognised by lawyers, of the words is used to solve the interpretation problem raised in certain cases.

Interpretation based on legal principles of statutes or branches of law also belongs to the legal professional grammatical interpretation (i.e. legal dogmatic interpretation). Since the legal principles expressly specified by legal norms are, in effect, dogmatic categories (with especially broad sense), i.e. linguistic elements (used by

131 'Syntax aids construction by looking beyond the lexical meaning of a word to its meaning within a sentence and specifically within the correct construction of a sentence according to the basic rules of syntax and grammar' (Goodrich, 1986, p. 111). 
legal profession), they must also be included by the legal professional/dogmatic grammatical interpretation.

Finally, the further (non-legal) professional interpretation is also the part of grammatical interpretation. In this case, the meaning of a word or an expression is determined not on the basis of ordinary or legal meaning but of the terminology of a profession other than the legal one.

\subsubsection{Logical interpretation}

Logical interpretation is a particular argumentation that is, most often, applied tendentiously when wishing to reach an interpretation result (which, regarding its genesis, is merely felt to be proper in an intuitive manner) opposing the unambiguous literal meaning of the text. Therefore, the use of (quasi) formal logic ${ }^{132}$ typically provides a rational solution that can be 'figured out' by common sense (in this sense, the maxims of quasi-formal logic as universal laws of human rationality and the aspects of common sense are the same). A further feature of logical interpretation is that its application is often not explained; thus, logical arguments are mostly used in practice so that the formula invoked to interpret the text is not expressly referred. Whether, however, the logical arguments are referred to or not, they have outstanding importance in the administration of law, not even primarily in terms of their application frequency but rather of the weight of their arguments. Thus, regarding formal logic, the rules cannot be questioned or refuted, which, therefore, are objective (if their application conditions can be clearly defined) ${ }^{133}$ generally applicable, and valid

132 Logical interpretation is not formal logic since it always refers to concrete cases, the classification of which (for example, determining what is 'bigger' and what is 'smaller') is necessarily subjective. However, the applied thinking schema has logical origin, which explains the label 'logical interpretation', in accordance with the main part of the scholarly literature. The view according to which 'legal logic' is not formal logic is not definitely endorsed; hence, for example, Kalinowski explicitly accepted legal logic as formal logic. Cf. Kalinowski, 1959, p. 53). Perelman, partly arguing also with Kalinowski, enlightened the lack of the logical nature of maxims, as follows: '[Legal logic] is not a logic of formal demonstration but a logic of argumentation which uses, instead of analytical proofs which are compelling, dialectical proofs (in the Aristotelian sense of this distinction) which aim at convincing or at least persuading the audience (in this case: the judge) to arrive at a solution of and determine a legal controversy. Judicial decisions, with their findings and grounds, constitute ideal texts the analysis of which will provide the arguments proper to legal logic. A moment's thought is enough to establish that here is not a case of theoretical reasoning, where starting from true premises one reaches, by means of the laws of logic a conclusion equally true, but a decision which the judge justifies on stated grounds, including the reasons which have enabled him to set aside the parties' objections to his findings' (Perelman, 1968, p. 3)

133 If the fulfilment of these application conditions is not clear because, for example, the previous assessment of the nature of the given situation is needed, then, of course, even logical formulae cannot help determine in an objective manner what the text in question could mean (or often instead: does not [surely] mean). 
anywhere and anytime (in all legal systems). ${ }^{134}$ Accordingly, in cases when reference to them is well-founded, they typically count as the strong arguments of solving an interpretation dilemma.

The most often used logical formulae are the argumentum a minore ad maius, argumentum a maiore ad minus (these two are collectively called a fortiori), argumentum a contrario, argumentum a simili, and argumentum ad absurdum. The argumentum a minore ad maius is an inference from the smaller entity to the bigger one. On the one hand, it applies to prohibitive legal norms: if the smaller, i.e. less serious conduct (conduct with a lower impact) is prohibited, or if the smaller value is legally protected, then the bigger, i.e. more serious conduct (conduct with higher impact) is even more prohibited, and the bigger value is even more protected, even if the latter is not literally included in the text of the legal regulation. For example, if a person with limited legal capacity is not allowed to do certain things, then an incapacitated person is, obviously, even less entitled to do the same. On the other hand, the same maxim applies to the expressed exemption from the fulfilment of obligation granted by law: if an act states that the smaller is not the obligation of someone, it obviously also means that the bigger (including the smaller) is not their obligation as well.

Argumentum a maiore ad minus is an inference from the bigger to the smaller entity. This principle states that if the bigger is allowed, permitted, or legally not prohibited, then the smaller is even more allowed, permitted, and even less prohibited

134 It does not (cannot) mean that logic is able to provide solution to all 'hard cases'. It is possible that, on the contrary, it provides several, mostly equally plausible solutions from which we cannot choose objectively. These solution directions, principles, and guidances are called 'meta-norms' (Wright, 1991, p. 277). The function of these 'meta-norms' is to help in law application and to allow a decision to be made on the questions being regulated by ambiguous or contradictory norms or not being regulated at all. They serve the legal certainty and foreseeability of administration of law. However, there are cases in which more of these 'meta-norms' are usable. For example, the arguments a contrario and a simili may lead, in the course of deciding the same legal interpretation dilemma, to contradicting conclusions. To reduce (or, in a case which is ideal but in its purity is quite rare in practice, to eliminate) the uncertainties arising from legal gaps and the contradictions of positive law, we also need a rule for choosing from the several potentially applicable 'meta-norms' - we need a 'meta-meta-norm' that says when and which one from the several 'meta-norms' the court has to call for help. However, this guidance goes to infinity, since even 'meta-meta-norms' cannot avoid conflict that would need a 'meta-meta-meta-norm' to be resolved, and so on. We can break free from this regressus ad infinitum if we admit that law cannot be perfectly objective and absolutely predictable. It means that there necessarily have to be cases when it is unknown which (positive) norm to apply. According to von Wright, we have to accept that a decision can be arbitrary (cf. von Wright, op. cit., p. 278). Agreeing with Wright's 'acquiescent' position, we have to admit that there is an element of uncertainty in the law that no interpretation of the law can completely eliminate. The correctness of the judgement of law enforcers can only be based on probability. At least in 'difficult cases' (which may occur, inevitably, even in legal systems having the most detailed provisions), legal interpretation (the precondition of law application) is, to some extent, based on value judgement, which unavoidably brings subjectivity to judicial activity and, for this reason, the decision will also be, to a certain extent, subjective. In law, this subjectivity can be limited (excluding arbitrary, indefensible decisions from the possible result of law application) but not entirely eliminated. 
legally. For example, if an assaulted person, under certain conditions, is allowed to take, lawfully, the assailant's life in case of justifiable defence, then, in the same circumstances, they may also cause battery. If certain things can be done even by an incapacitated person (e.g. even an eight-year-old child can conclude contracts of minor importance aimed at satisfying their everyday needs), then the same is also allowed for a person with limited legal capacity (e.g. a fifteen-year-old child). Furthermore, if a legal norm specifies the bigger as an obligation for someone, then the smaller included by the bigger obligation also occurs as the obligation of the certain person. This might be absolute formal logic: if statement $n$ is true for a set, then this statement $n$ must also be true for any subset of that set.

According to the maxim of argumentum ad absurdum, if conclusions resulting from the application of the meaning establishable on the basis of a certain interpretation method would lead to absurd, impossible, contradictory, or obviously undesirable legal practice or case judgments, ${ }^{135}$ then this meaning must be rejected as obviously groundless. For example, if a provision on child protection does not protect but, on the contrary, makes children more vulnerable, then this meaning cannot be applied. Through other methods, a meaning, different from the grammatical one, has to be sought. This is a purely negative method: it does not say what a given provision means but can say what it definitely does not mean.

Argumentum a contrario is inference from the opposite. It considers complementary life situations, where two life situations are possible but one excludes the other. In this case, if a rule exists for one of the complementary life situations but does not for the other one, then the rule being contrary to the regulated life situation would apply to the other (literally not regulated) one, even if it is not included in the text of the legal norm. For example, if two categories (adults/minors, legal capacity/incapacity, capacity to bring legal proceedings/lack of capacity to bring legal proceedings) exist in a legal system, and legislators define only one of them, then with that, a contrario, the other one will also be subject of regulation, since the second category covers the situations not belonging to the first. If only the concept of minors is defined, then those not meeting set conditions would be adults. If only the cases of incapacity are defined by the regulation, then it follows, a contrario, that in all other cases, people have legal capacity. ${ }^{136}$ This maxim also covers argument from silence. In practice, this primarily concerns the interpretation of taxative enumerations, i.e. the conclusion that, in relation to the life circumstances not included in the exhaustive list (or understood as such by the judge), the legal practitioner concludes that the provision applicable to the life circumstances included in the taxative list is not applicable to the life circumstances not included in the list. For instance, when a law defines and prohibits a specific conduct, it also provides, without stating this in the text, that conduct not covered by this prohibition is permitted, i.e. recognised as lawful. 
Argumentum a simili (or argumentum a pari ratione) ${ }^{137}$ is inference from similarity. This means that if there is a legal rule for a given life situation, then this legal rule will also govern (be extendable) to a life situation that is similar in its relevant factual elements to this life situation but which is not literally regulated. The key question regarding the applicability of this formula is the assessment of relevance: in what case can we consider, in some respect, the similarity of two facts to be relevant in the course of interpretation. There is no guidance; it depends on the perception of the judge and inevitably brings a subjective element to the process of adjudication (the same principle applies to the previous maxims).

Analogy (argumentum per analogiam) is a theoretically important case of the argumentum a simili (but rarely used in continental law systems). We do not consider interpretation by analogy (which is legislation in fact) as a separate method of interpretation but as part of a simili argument. ${ }^{138}$ We apply analogy if we have to make a decision but there is no specific rule matching the given fact (i.e. a legal gap), so the rule has to be created by the court on the basis of a similar existing fact. ${ }^{139}$ Legal gap is seen when legislators regulate a life situation as a whole (presence of legal norm regarding the relation and its substantial parts) but, accidentally, forget to regulate a segment thereof. It causes literally 'gap' in the system of legal norms: no rules exist regarding the considered one, but the other segments of the life situation are regulated.

It is an important criterion that a legal gap can occur accidentally; if the legislator intentionally leaves a sub-area unregulated, this cannot be considered a legal gap but rather deliberate permission, where the entities are free to act (that which is not unlawful is allowed). The legislator, as can be determined from the regulatory environment, may want to regulate the whole of the life situation in question but regarding a segment does not even draw up a rule. This gap may occur at the adoption of regulations (i.e. original legal gap) or later because of the impact of social-economic-technical changes (i.e. derivative legal gap).

Analogy is the method of filling legal gaps. In case of analogy, therefore, there is no regulation of a life situation, unintended by the legislator. Therefore, the judge must establish it in the course of applying the law to decide the case in question. Analogy is thus nothing more than filling the legal gap, a quasi-judicial legislation

137 Also known as argumentum a simili ad simile and argumentum a similibus ad similia.

138 We understand $a$ simili as the 'base case' of argumentum per analogiam (cf. Szabó, 1999, p. 171).

139 The opposite of the analogy is teleological reduction, where there is a rule which should not be. There can be 'legal lacuna' (rechtliche Lücke) not only if no regulation exists but also if legal expectations would result from a general principle contrary to the existing rule. In this case, the meaning and purpose (Sinn und Zweck, together 'Telos') of the legal regulation (Regelung) have to be taken into consideration and, on the basis thereof, the existing rule cannot be applied. At this time, the legal lacuna is hidden (Verdeckte Lücke) and the technique of teleological reduction (teleologische Reduktion) has to be applied to eliminate it, i.e. on the basis of the general principle (the purpose of the regulation) the concrete legal norm opposing which has to be ignored (Cf. Larenz and Canaris, 1995, p. 210-211). 
remedying the legislator's omission. ${ }^{140}$ Notably, there is no legal gap or legal lacuna if the legal regulation exists but is not unambiguous; in this case, the ambiguous norm has to be interpreted. Depending on the basis of which the judge creates the missing norm, we can distinguish statutory and legal analogy.

In case of statutory analogy (analogia legis), there is no regulation on a given life situation but a rule exists regarding a similar one. In such case, the judge fills the gap of regulation using the other existing legal norm as an aspect, and decides the case before the court on the basis of the norm found (made) this way. It is the task of the judge to step into the legislator's shoes and to make a decision that the legislator, according to the judge, would also have made (which norm the legislator would have incorporated into the statute) if it had not forgotten to regulate the given life situation. That is, the judge does not fill the legal gap on the basis of their own values or legal concept but in the way, according to them, the legislator would also have filled it if the latter had recognised the gap. For this purpose, the judge does not apply the norm of other but similar life situation, i.e. the decision is not made on the basis thereof (that would be a simple extensive interpretation of that other norm, which would be conducted by any of interpretation methods except grammatical) but considers the justificatory principles of the other norm and the legal policy reasons of the creation thereof and, considering all of these, makes a hypothetical regulation that would have been made also by the legislator.

Meanwhile, legal analogy (analogia iuris), which is no longer imaginable, would be applicable if the given legal system does not contain any regulation on relation(s) of life similar to one accidentally not regulated. The judge should then deduce from the general principles of the legal system and characteristics of the legal culture

140 It is interesting that there are, as exceptions, regulations in (continental) Europe where the legislator, in a given legal norm, provides explicit authorisation to judges to fill the possible legal gaps during law application if otherwise the decision-making is not possible. The best known example is the Swiss Civil Code of 1907 that is still in force (Schweizerisches Zivilgesetzbuch, ZGB). Article 1 of ZGB declares, as principle of interpretation, that the court is entitled and obliged to decide, in the absence of legal provision or customary law applicable in the case, in accordance with the rule that it would make as a legislator. This authorisation is, as the possibility to apply analogy in general, not limitless since the court is bound by the prevailing doctrine and case law determining Swiss law regarding the given issue. 'The law applies according to its wording or interpretation to all legal questions for which it contains a provision. In the absence of a provision, the court shall decide in accordance with customary law and, in the absence of customary law, in accordance with the rule that it would make as legislator. In doing so, the court shall follow established doctrine and case law'. Swiss Civil Code of 10 December 1907, Art. 1. In original language: Das Gesetz findet auf alle Rechtsfragen Anwendung, für die es nach Wortlaut oder Auslegung eine Bestimmung enthält. Kann dem Gesetz keine Vorschrift entnommen werden, so soll das Gericht nach Gewohnheitsrecht und, wo auch ein solches fehlt, nach der Regel entscheiden, die es als Gesetzgeber aufstellen würde. Es folgt dabei bewährter Lehre und Überlieferung. Schweizerisches Zivilgesetzbuch vom 10. Dezember 1907 (Stand am 1. Januar 2021). 
that reflect, supposedly, how the legislator would have regulated the life situation of concern. ${ }^{141}$

Finally, there are also other formulae. An example is the principle of implied powers, according to which, if a given legal regulation prescribes a task for an organ, then this organ has to be considered as authorised with the necessary power even if neither the norm regulating such task nor other norms in the legal system specifies it expressly. ${ }^{142}$ Another example is the principle of eiusdem generis, by which the range of cases of an exemplary enumeration covered by the legal norm can be broadened beyond the factual elements specified exhaustively in the list, by a factual element, but only with ones that are, regarding their relevant characteristics, similar to the specified elements. ${ }^{143}$ (The principle of implied powers seems intended to serve the avoidance of the absurd application of law; hence, it can be considered as a part of argumentum ad absurdum. Meanwhile, the principle of eiusdem generis is, essentially, a special type of argumentum a simili).

These formulae are not purely logical ones, since preliminary (subjective) assessment of the interpretation situation is required for their application, including

141 In modern legal systems, it is hard to imagine that no legal regulation exists not only regarding a given life situation but even regarding another one being similar in any way. Thus, it is not possible to apply analogia iuris. However, analogia legis exists, and judges practically carry out law-making activity when they apply it (with the filling of the legal vacuum, replacement of the missing norm). Since judges have decision-making obligation (they cannot say that they do not decide the case before them), analogia legis may be applied even in legal systems having the most accurate legal regulation. If it is applied, the judge carries out quasi-legislation activity, namely, further developing the existing legal system. At the legislative level, the denial of justice was first explicitly prohibited by section 4 of the French Code Civil in 1804: 'Le juge qui refusera de juger, sous prétexte du silence, de l'obscurité ou de l'insuffisance de la loi, pourra être poursuivi comme coupable de déni de justice'. Translated as 'a Judge who refuses to decide a case on the pretext that the law is silent, obscure or insufficient, may be prosecuted as being guilty of a denial of justice' (Elliott, 1956, p. 83). The classical translation by Wright includes 'does not cover the case' instead of 'insufficient', and on the basis of its commentary, according to the reference of Pound, '[t]his Article abolishes the old practice of the judges of refusing to decide a case on the ground that the law was obscure, and referring the case to the legislature so that it might elucidate the particular law by laying down a general rule for its interpretation' (Pound, 1914, p. 17).

142 According to the principle developed in constitutional law, primarily that of the US (cf. Skubiszewski, 1989, p. 855), and introduced into international law, into the practice of international and supranational law enforcement bodies and is now also upheld in the practice of the ECJ (cf. Eeckhout, 2012, pp. 70-119), 'in international organizations the doctrine of implied powers means that the organization is deemed to have certain powers which are additional to those expressly stipulated in the constituent document. These additional powers are necessary or essential for the fulfilment of the tasks or purposes of the organization, or for the performance of its functions, or for the exercise of the powers explicitly granted' (Skubiszewski, op. cit., p. 856). 'Implied powers are, by definition, supplementary to those expressly granted' (Skubiszewski, op. cit., p. 857; see also op. cit., p. 858). Implied powers is a principle of interpretation developed by legal doctrine for practical purposes. 'The theory of implied powers serves as a rule of interpretation of the constituent instruments of international organizations' (Gadkowski, 2016, p. 46).

143 'The eiusdem generis rule applies when there is a clearly ascertainable class or category or genus, at least two particular words, having a common characteristic or quality, or common and dominant feature, followed by general words which on their own are not clear and unambiguous words' (Samuels, 1984, p. 180). 
the judging of the characteristics of the situation to be regulated, the attempt to determine ratio legis, and the moral and other non-legal aspects leading to the 'proper' decision. The interpreting person's legal concept, values, attitudes, and preferences unavoidably affect all of these elements. It is also necessary to choose from the (quasi) logical formulae, and this choice is not a logical but an evaluating operation that, depending on the chosen interpretation technique, can result in legal solutions being different from one another (and equally defensible). ${ }^{144}$

\subsubsection{Domestic systemic arguments}

Legal norms (principles and rules) constitute a system in which all legal norms have a regulatory environment in relation to which the given principle or rule takes place. Not a single norm is isolated; all of them form an integrate part of the norm system (the entirety of the positive legal regulations), and their meanings can be determined in accordance with the other norms. This is why the need for considering the context may arise in any case of determining the meaning of a norm. It is particularly true in the case of constitutional norms and fundamental rights, as their highly abstract nature often requires contrasting them with other (constitutional or other) norms to find their specific content.

The first group of domestic systemic arguments contains the methods of contextual interpretation. Contextual interpretation has a narrow and a broad sense: we either refer to the place occupied in the constitution by the constitutional provision, norm, or fundamental right to be interpreted or we contrast them with other constitutional provisions ${ }^{145}$ or fundamental rights. In a broad sense, this includes when the Constitutional Court determines the meaning of a given constitutional provision on

144 Citing the example of Pierre-André Côté, Devenish asked how we can interpret, in case of a cheetah, the by-law according to which 'dogs [must] be held on a leash in public places'. The reasoning set out is as follows: 'Firstly [...] it can be argued that the cheetah must be leashed because the reason justifying the rule for dogs (protection of person and property) applies equally to cheetahs. This is reasoning by analogy or a pari argument. Secondly it could be argued that the cheetah must be leashed because it is more threatening than a dog to persons and property and thus the justification is even greater for the application of the by-law. This a fortiori reasoning (with stronger reason or more conclusively). Thirdly it could be argued that the cheetah need not be leashed, because the bylaw applies only to dogs. This is a contrario argument (by way of contrast or in the opposite sense)' (Devenish, op. cit., p. 227).

145 This includes not only the normative text of the constitution but also its (possible but, in new ones, already typical) preamble. The constitution of each examined country contains a preamble that may fulfil several tasks (specifying the source of sovereignty; establishing historical narratives; outlining a society's supreme or fundamental goals; statements on national identity; references to God or religion. Cf. Orgad, 2010, pp. 716-718). Preambles may have three functions: ceremonial-symbolic, interpretive, and substantive (cf. Orgad, op. cit., p. 715). Since the preamble is an 'accessory' of the normative text of the constitution, it always 'says something' about the intention of the constitution-maker or the political or social circumstances serving as basis for the making of the constitution the interpretive function as necessary. If the positive norms of the constitution may (or, sometimes, must) be interpreted in the light of the preamble, that will necessarily be contextual interpretation (because the preamble is also a written text included in the constitution). 
the basis of, in conjunction with, with respect to, and in conformity with other specific constitutional provisions. In a narrow sense, however, we talk about contextual interpretation only in cases where we explore the meaning of the constitutional norm on the basis of its purpose, which is merely the result of its place in the system of the legal norms. (Par excellence contextual interpretation in the narrow sense covers the case where we attempt to determine the meaning of the fundamental right to be interpreted on the basis of the constitutional charter, part, chapter, or title of the constitution that contains it, without its comparison to other specific provisions.)

The often-used maxims of contextual interpretation in the broad sense comprise the derogatory formulae, which provide guidance for resolving contradictory provisions of the constitution (the constitutional norm collision). In practice, courts use three of such important formulae. According to lex superior derogat legi inferiori, a rule higher in the hierarchy derogates a lower one. ${ }^{146}$ The maxim lex specialis derogat legi generali states that a special rule derogates a general one. The formula lex posterior derogat legi priori means that a later rule derogates an earlier one.

Constitutional norms may also be interpreted on the basis of domestic statutory law being lower than the constitution (acts, decrees): it is not typical and, normally, goes against the principle of the supremacy of the constitution ${ }^{147}$ but it can happen that the constitutional court interprets the meaning of a constitutional provision (fundamental right) on the basis of statutory source (particularly, in case of constitutional principles regarding criminal law or criminal procedure law when the constitutional court interprets the principles nullum crimen/nulla poena sine lege, presumption of innocence, or ne bis in idem referring to the internal act on criminal proceeding or the criminal code).

The constitution (and the included norms; hence, also the fundamental rights) may also be interpreted on the basis of the case law of the constitutional court: for example, by reference to the constitutional court's decisions made previously in certain cases (as 'precedents'), to its 'practice', or to the abstract norms created thereby (e.g. organisational and operational rules). The constitution may also be interpreted based on the case law of ordinary courts. It covers the interpretation by reference to judicial practice, interpretation by reference to judicial decisions made in individual cases, ${ }^{148}$ and interpretation by reference to the abstract norms and principled acts of judicial interpretation of higher courts.

146 Practically, this formula is not applicable in the course of constitutional interpretation since there is no hierarchy between constitutional-level norms (if so, it may raise the question of whether the subordinated ones are not constitutional-level norms).

147 The most important consequence resulting from this feature of the constitution is that ' $[\mathrm{t}] \mathrm{he}$ supremacy of the constitution means the lower ranking of [the] statute' (Limbach, 2001, p. 1).

148 The 'real' and 'not real' precedent systems are distinguished by the fact that in a 'real' precedent system, only one previous judicial decision is enough to constitute reference. In a 'not real' precedent system, a series of judicial decisions, set of judgements rendered in similar cases and providing the same legal interpretation, have persuasive enough power to give reason to follow. In a 'real' precedent system, it is absolutely not 'more conclusive to have a series of decisions than a single one' because 'the law of precedent has less relation to mere numbers than to the decisive nature of the 
Either normative or individual decisions of other law enforcement bodies also belong to the legal system in a broad sense. Thus, constitutional provisions (fundamental rights) may be interpreted also based on the (typically) normative instruments of other public bodies. The constitutional courts may also use such arguments even if they cannot be expected to do so regularly. Moreover, theoretically, the interpretation of fundamental rights by the constitutional courts can be supported by the decisions of administrative bodies (e.g. tax office's resolution on questions of financial law, resolution of the election commission on disputes regarding election), by the ombudsman's recommendations, and other instances.

Furthermore, the interpretation of the state constitution based on the federal constitution (or vice versa) in federal states would also belong partly here and partly to the following method; it was not relevant in the present research since the examined states are not federations.

\subsubsection{External systemic and comparative law arguments}

Domestic (based on national law and legal practice) and external context may serve as a base for the interpretation of fundamental rights. Contrary to an ordinary court, which is more exposed to domestic law, a constitutional court, owing to the specific characteristics of fundamental rights, is freer to use substantial aspects from non-domestic positive law or judicial practice that it considers to be necessary to explore the meaning of constitutional rights, which have a more uniform international content. Since the constitutions of states mainly contain fundamental rights with international relevance (i.e. included also in international conventions), the use of international treaties for defining similar aspects can naturally play a role in the interpretation of 'internal' fundamental rights during the argumentation of the constitutional court. Furthermore, since most international treaties have some enforcement mechanism (at least in case of the ECHR and the Treaties of the EU, the most important ones at the European level), fundamental rights may be interpreted also on the basis of individual decisions or judicial practice of the international fora. In

conclusions announced' (Wells, 1878, p. 535). Regardless, we can differentiate, also in the classical precedent system, 'declaratory precedents', which are compulsory but do not qualify as 'new law' or 'new rule' (and there can be many of these in a certain type of case) and 'original precedents', which are not only compulsory but, by creating new law, also have a greater importance for the development of law. For differentiation, see Salmond, 1902, pp. 159-161. Ződi defined two subtypes of the 'unreal' or 'non-classical' precedent systems: the 'written' precedent system, in which a brief, abstract legal document is interpreted by a body expressly assigned to it; and the 'decisional systems', in which the supreme courts carrying out ordinary judicial activity rely on their own previous decisions and the following thereof is, informally, expected also from inferior courts. Ződi, 2021, available at: http://ijoten.hu/szocikk/precedens (Accessed: 11 April 2021). The constitutional court practice analysed in the present research belongs to the former group in each country, whereas the ordinary court's practice taken into account by the constitutional court typically does to the latter. Hence, we hypothesised that, in general, the 'coherent and settled' case law of a given organ (if any) will have significance. 
the course of the present research, a selection criterion of constitutional court decisions to be analysed is that they contain references to ECJ or ECtHR decisions; their decisions and judicial practice or the ECHR and (presumably) the Treaties of the EU (at least one of them) are naturally parts of all decisions examined. In this regard, therefore, it is especially necessary to examine what other international or supranational sources are referred to by national constitutional courts.

In addition to the use of the 'traditional' sources of international law, the interpretation of fundamental rights may have further sources, namely, par excellence comparative law arguments. If, for example, the constitutional court refers to a norm or a law application instrument, such as constitution, statute, or decision of (constitutional) court, of a particular foreign legal system (in case of the latter, references to the German Bundesverfassungsgericht or the Supreme Court of the United States may typically be such, in Central and Eastern Europe), then it establishes the meaning of the domestic norm (fundamental right to be interpreted) with the assistance of the positive legal norm or judicial practice of that foreign legal system. Although in this case questions regarding sovereignty may arise, according to the hypothesis of the research, such arguments cannot be considered, in general, as 'strong arguments' applied by the given constitutional court. Hence, they generate no sovereignty problem. Finally, it also can happen that the national constitutional court refers to the 'European practice', the 'principles followed by democratic countries', and similar non-specific justifying principles in a general manner; however, the reasoning weight thereof is even more doubtful.

Finally, constitutional courts may also use further external sources of interpretation as well, such as the norms of customary international law and ius cogens.

\subsubsection{Interpretation based on the intention of the legislator ('historical' interpretation) and teleological interpretation}

In teleological interpretation, the law enforcement bodies (the constitutional court, in our research) explore the meaning of the legal regulation (codified constitution or act of constitution in the examined countries) based on its objective goals and social purpose. Most often, the law enforcement body takes into account the regulation's title, preamble, or the social function implied by the text of the act (constitution) that the regulation intends to fulfil. Irrespective of the wording, it covers all arguments in case of which the constitutional court refers to the purpose of the constitution, reason for its existence, function, or goals thereof.

By means of historical interpretation, we attempt to determine the subjective will or inner intention of the legislator (constitution-maker) regarding the given legal norm. In this case, we can use ministerial (proposer's) justification, draft materials (travaux préparatoires, Materialen, legislative history), or, without citing any external sources, general references to the 'intention of the legislator (constitution-maker)', its ('obvious' or 'probably') 'will', or reasons based on the circumstances of making or 
modifying the legal provision (the text of the fundamental right in the constitution) to be interpreted.

It is disputed in legal theory whether objective and subjective teleological interpretation (i.e. interpretation based on the purpose of the norm and on the intention of the legislator, respectively) are two separate methods. ${ }^{149}$ If we think they are not, we have to decide which method 'actually' exists-whether the decision-making of the law applier takes place considering the legislator's will in the psychological sense or the objectified function expressed in the legal norm. This leads us to the basic question of what the subject of the interpretation is: what we interpret. Basically, two answers are possible.

According to subjective theory, we search for the assumable intention of the legislator in the course of the legal interpretation: what the legislator probably wanted to reach with the given legal regulation, what idea they had with making the regulation, what they intended to achieve. In this case, the detected will of the legislator would be the meaning of the text.

149 The most significant of the contemporary (or near contemporary) disputes is the American trend of originalism and the opposition within it between intentionalism and purposivism. For a demarcation of the two trends, see Colinvaux, op. cit., p. 1133; Fruehwald, 2000, pp. 976-977). According to advocates of purposivism, a judge, in the course of their interpretation of a statute, is obliged to examine its social purpose in the broad sense. This examination may be carried out with respect to 'legislative history' ('records of congressional consideration of a bill that ultimately becomes a statute, including committee reports and debates on the floor', Dworkin, 1985, p. 320), but even more by examining the particular provisions in the text of the legal norm itself, which refer to the aim thereof. This interpretation is towards the exploration of the objective social aims of the legal norm. In contrast, advocates of intentionalism start from an examination of the subjective intent of the legislator and try to determine what the legislator intended to achieve by the law. To do this, intentionalists also make extensive use of legislative history, but they look for references to personal motivations in these materials. Intentionalism has two further subgroups: archaeological and hypothetical intentionalism (cf. Fruehwald, op. cit., p. 977). The former examines the text of the statute and its legislative history to determine the probable will and intention of the legislator when they created and adopted it. The latter examines how the legislator would decide today if it had to decide about the legal regulation applicable to the changed social relations. Hypothetical intentionalism seeks the probable standpoint of the then legislator regarding today's social relationships. This approach is called 'imaginative reconstruction' (Posner, 1983, p. 817). Sunstein called the latter 'hard originalism' and rejected it, since then legislators created rules in light of then circumstances and they would obviously have created other rules in changed (today's) social situations. Purposivism and archaeological intentionalism as part of 'soft originalism' are more applicable (Sunstein, 1996, pp. 312-313). Campos defined a further type of originalism, namely, 'strong intentionalism'. The first stage is that we have to read the text to interpret it; the reading is an activity that always aims to reveal the semantic intention of the author. This intention of author is identical to the semantic meaning of the text. If we determine what the author wanted to say, then, we also determine what the author said. Therefore, the author's intention and the meaning of the text are identical. Legal actors should not only try to reveal the intention of the author, too, but recognise that there is no other way at all than that for the law enforcement entity to interpret (Campos, 1996, pp. 327-330). This assumption (as with any subtype of originalism) is based on an idealistic image. When we interpret actual legal texts, we cannot ignore the possible deficiencies and ambiguous or unclear wording of either the text itself or the author's expressed intention. 
The first problem regarding this question is that there is not a 'legislator' (a person or a body that can be identified as the particular entity creating the law), not even in the case of ministerial law-making, nor legislation by a body. In case of an act, for example, an idea, proposal, or conception may go through several phases until it finally becomes an act, and the same is true for constitutional provisions. Acts are (constitution is) normally drafted by a codification committee. Its members make proposals for certain provisions, which are amended by other members, and finally, the committee votes on it. The ministry responsible for the given area often proposes, on the initiative of any of its officers and with the approval of the minister, amendments (either on political or professional grounds) to the draft version of the text accepted in this way. The ministry of justice submits further proposals for the amendment of the same point. It will be discussed by a preparatory forum subordinated to the government and placed, in a structured form, on the agenda of the government's session, where the members of the government make their own further proposals to modify the text. Some of these proposals are accepted by the government; others are not or given different wording. The bill submitted by the government will be further modified with respect to the proposals of the members of the parliament or the parliamentary committees. Finally, the text of the norm developed in this way will be adopted by the majority of the parliament. The question arises: who is the legislator in this case? ${ }^{150}$ Probably, everyone at the same time but, thus, no one.

The second problem regarding subjective theory is that even if we could define the legislator, the question arises whether it is possible for the legislator (the 'constitution-maker') to have any will. Law is made by collegiate bodies and, a priori, a body may not have any 'will'. Even in case of law-making where one person bears the responsibility (e.g. if a minister makes a decree), we cannot talk about one-person law-making since the minister does not draft the ministerial decree; it is drafted by several people within the ministry's specialised apparatus. The minister only defines the (political/legal-political) aspects of the legislation, and in the end, by signing the decree, assumes political responsibility for its content. Only a particular person may have 'will' and not a body (or all the persons who take part in the preparation).

The third problem is in determining the 'will of the legislator' if it were to exist. We cannot draw a clear conclusion on the subjective (i.e. in its entirety conceptually undiscoverable) intention either from ministerial justification or draft materials or other sources. The will of the legislator (constitution-maker) (even if it existed) cannot be determined in its actual reality.

150 The codification committee? Its member responsible for wording the text? The members who approved the proposal? The minister responsible for the given area? The ministry's officer who initiated the proposed amendment? The minister of justice? The preparatory body of the government? The government? The member of the government voting for the bill? The Parliament as a whole? The members of the parliament voting for the proposal? All members of the parliament who voted in any way? All members of the parliament? 
According to objective theory, meanwhile, the object of legal interpretation is the text as such (independent of the author). Concerning the meaning of the text, it is irrelevant who made it; the text stands alone and its meaning can be determined by grammatical techniques. The meaning of the text would then be the consensus of the 'interpretive community'. The problem with this aspect is that no text has, in fact, (entirely) objective meaning (being the same for everyone) on which people speaking the given language could reach a consensus. Each person has different attitudes and values, not to mention their interests, which also have impacts on their relation to the meaning of the text of the norm. ${ }^{151}$ Objective meaning, which is the same for everyone, can never come into existence.

However, both sources are used in the interpretation: the proportion and frequency of these references can be measured, and they have a real impact on the way the law is applied. For this reason, it is justified to measure the occurrence of both the subjective and objective teleological interpretation and to differentiate these methods.

\subsubsection{Other arguments}

In addition to the above, there are further methods and sources which the examined constitutional courts may use in the course of the determination of the meaning of fundamental rights. These methods are not typical but their occurrence is possible; thus, it is certainly justified to enumerate them and measure the frequency of the application thereof as part of the research methodology. Even if they were not used by some law enforcement bodies, there would be no reason not to use them, since research can not only show the extent to which certain methods are used by certain bodies but also whether they are used at all.

It covers arguments based on jurisprudence-references to scholarly works in the course of interpretation of constitutional rights. In this case, the constitutional court solves the arising interpretation problem based on a particular jurosprudential work, including monographs, textbooks, articles, commentaries, already expired former constitutions, and draft constitutions that have not yet entered into force.

In the course of interpretation in light of general legal principles, principles and values determining the provisions of constitution are used, which, though not expressed in the constitution or in any part of positive law (hence, contrary to the principles of positive law as dogmatic categories, their grammatical interpretation is out of the question), determine the functioning of the legal system (ignorantia juris neminem excusat, ${ }^{152}$ 'everything which is not forbidden is allowed', nemo plus iuris ad alium transferre potest quam ipse haberet'). ${ }^{153}$

151 It is normal that the defendant and the plaintiff of a litigation interpret the same legal text completely oppositely.

152 Ignorance of the law excuses no one.

153 No one may transfer more rights than he actually has. 
Finally, by substantive interpretation, the law enforcement body (the constitutional court in our research) refers directly to generally accepted non-legal values. Such values may include certain moral principles with cardinal nature, aspects of justice, social policy considerations, the idea of equality, utility criteria (e.g. economic considerations), and enforcement of public interest. All moral, economic, environmental, statistical, social, scientific, or other similar expressly non-legal arguments belong to this method.

2.4.7. Summarising classification of methods regarding argumentation to be researched

\section{Grammatical (textual) interpretation}

1/A. Interpretation based on ordinary meaning

a) Semantic interpretation

b) Syntactic interpretation

1/B. Legal professional (dogmatic) interpretation

a) Simple conceptual dogmatic (doctrinal) interpretation (regarding either constitutional or other branches of law)

b) Interpretation on the basis of legal principles of statutes or branches of law

$1 / C$. Other professional interpretation (in accordance with a non-legal technical meaning)

\section{Logical (linguistic-logical) arguments}

2/A. Argumentum a minore ad maius: inference from smaller to bigger

$2 / B$. Argumentum a maiore ad minus: inference from bigger to smaller

2/C. Argumentum ad absurdum

2/D. Argumentum a contrario/arguments from silence

2/E. Argumentum a simili, including analogy

$2 / F$. Interpretation according to other logical maxims

\section{Domestic systemic arguments (systemic or harmonising arguments)}

$3 /$. Contextual interpretation

a) In narrow sense

b) In broad sense (including 'derogatory formulae': lex superior derogat legi inferiori, lex specialis derogat legi generali, lex posterior derogat legi priori)

$3 / B$. Interpretation of constitutional norms on the basis of domestic statutory law (acts, decrees)

$3 / C$. Interpretation of fundamental rights on the basis of jurisprudence of the constitutional court

a) References to specific previous decisions of the constitutional court (as 'precedents')

b) Reference to the 'practice' of the constitutional court

c) References to abstract norms formed by the constitutional court

$3 / D$. Interpretation of fundamental rights on the basis of jurisprudence of ordinary courts

a) Interpretation referring to the practice of ordinary courts

b) Interpretation referring to individual court decisions 
c) Interpretation referring to abstract judicial norms

3/E. Interpretation of fundamental rights on the basis of normative acts of other domestic state organs

\section{External systemic and comparative law arguments}

4/A. Interpretation of fundamental rights on the basis of international treaties

$4 / B$. Interpretation of fundamental rights on the basis of individual case decisions or jurisprudence of international fora

4/C. Comparative law arguments

a) References to concrete norms of a particular foreign legal system (constitution, statutes, decrees)

b) References to decisions of the constitutional court or ordinary court of a particular foreign legal system

c) General references to 'European practice', 'principles followed by democratic countries', and similar non-specific justificatory principles

$4 / D$. Other external sources of interpretation (e.g. customary international law, ius cogens)

5. Teleological/objective teleological interpretation (based on the objective and social purpose of the legislation)

6. Historical/subjective teleological interpretation (based on the intention of the legislator):

6/A. Interpretation based on ministerial/proposer justification

$6 / B$. Interpretation based on draft materials

$6 / C$. Interpretation referring, in general, to the 'intention, will of the constitution-maker'

$6 / D$. Other interpretation based on the circumstances of making or modifying/amending the constitution or the constitutional provision (fundamental right) in question

7. Interpretation based on jurisprudence (references to scholarly works)

8. Interpretation in light of general legal principles (not expressed in statutes)

9. Substantive interpretation referring directly to generally accepted non-legal values

\subsection{Methodological particularities of the analysis of ECJ and ECtHR decisions}

In the course of the analysis of the 30 EctHR and ECJ decisions, we pay attention to the appearance, the frequency and the actual importance of the methods described above, except that the subject of interpretation is not the constitution but the ECHR and the Protocols, as well as the EU Treaties (and, of course, the interpreter is not the domestic constitutional court but the ECtHR and the ECJ, so their perception 
of law and style of adjudication are subject to examination). Certain methods are not relevant owing to the subject of interpretation, but most arguments are identical to the ones described above (apart from the obvious differences defined by the subject of interpretation). Thus, methods $1,2,5,6,7,8$, and 9 can be used without any problems and along with all their specific arguments. From the arguments of group number 3, type 3/A can be used; and, for interpretation of ECHR, etc., the following are usable as systematical arguments: 3/B as references to the case law of the ECtHR and the ECJ: a) previous decisions ('precedents'), b) judicial practice of the forum, c) principled statements made by the forum (e.g. its own operational rules); 3/C: the interpretation of the ECHR on the basis of other materials of the Council of Europe (e.g. Venice Commission); interpretation of EU Treaties on the basis of the decisions, resolutions, etc. of other EU bodies; 3/D as references to the law of member states. Amendments to the arguments of group number 4: type 4/A can be used with references to other international agreements; $4 / \mathrm{B}$ as references to individual decisions or judicial practice of other international legal fora; arguments 4/C and 4/D can also be used without problems with the abovementioned.

\subsection{Characteristics and style of reasoning}

The statistical frequency of argument types, in itself, does not tell us everything about the practical role thereof. Hence, the present research would have not been complete if we, apart from the methodological particularities, had not taken into consideration what weight these methods have during the decision-making and what other features the argumentations of the decisions of the constitutional courts regarding constitutional rights and the ones of the European fora regarding human rights have. For this, it was necessary to determine which arguments appear typically in the practice of the given constitutional court (or of the ECtHR/ECJ): a) decisive arguments, b) defining arguments, c) strengthening arguments, or d) simple illustration with marginal significance.

a) Decisive arguments are those that themselves, even without other arguments, would have led to the given conclusion. It is possible that the decision of the constitutional court, the ECtHR, etc. contains several decisive arguments. It can happen if the same conclusion could have been grounded by any of these arguments separately, without the others. Obviously, the legitimacy of a conclusion is enhanced if it is supported by several arguments being conclusive in themselves but it has no effect on the outcome: if only one of the arguments had been available, the same decision would have been made.

b) Defining arguments are those that played a significant role in finding a certain conclusion in the course of deciding the case and making the decision, but none of them would have provided per se a basis for the decision-they were strong enough to ground the given decision only together.

c) Strengthening arguments are those without which the decision in question could have been made with the same content; such arguments merely strengthen the 
legitimacy of the decision but can be omitted because the same result would have been reached even without them.

d) Illustrative arguments are those that do not play a role in grounding the decision's reasoning. These are virtually a kind of parenthetical comments, references merely for the sake of completeness. Their main function is that the forum could prove that it is aware of this information, which does not play a role in reaching the conclusion. Typically, these are comparative arguments in which the constitutional court (ECtHR / ECJ) delineates the existing solutions to a particular problem in the world or in other countries, or where the forum refers to the statements of the parties but refutes their relevance or validity.

If a type of argument or method appears more than once in the same decision, it counts statistically as one; however, it can be assumed that the given argument is important in terms of its weight (multiple occurrences may indicate that the concerned body insists on certain methods; hence, respect of multiple occurrences may contribute to the assessment of the role perception of the concerned body).

However, the extent to which different types of arguments play a decisive role in decision-making and reasoning cannot be determined on a quantitative basis alone. In each case, this required an evaluative statement by the author of the chapter, according to their own professional convictions. Beyond the establishment of mere statistical rates, the evaluation of the practice of a national constitutional court and scientific benefit of our research depend fundamentally on whether we manage to explore which arguments are used as decisive ones in the practice of law enforcement bodies. Thus, we have to look at what is behind the text and to be familiar with the entire case law of the given organ (in addition to the examined 30 decisions) to fulfil successfully the mission of our research. To this end, the researcher of the given country, according to their own professional conviction, established, on a qualitative basis, what weight the types of arguments (arising with respect to the given organs) have in the course of decision-making and interpretation of fundamental rights.

Apart from the specific arguments and methods applied, the analysis of the judicial style of the examined organ was also the subject of our research. It is also a qualitative feature and, at the same time, an issue that requires professional evaluation and cannot be judged mechanically. In this respect, the researchers judged, on the basis of their outstanding professional experience and knowledge, in their own discretion, how the practice of the given body can be evaluated. At least the following were examined in this regard:

a) Style of reasoning: It can be enunciative in case the constitutional court (ECJ/ ECtHR) makes quasi ex cathedra statements (without careful consideration and comparison of arguments and counter-arguments); and it can be discursive arguing in case the decision is made with awareness of arguments and counter-arguments, by analysing the arguments of the petitioners and providing a legal answer to them;

b) Key concepts (fundamental rights, principles of state organisation, principles determining the functioning of the legal system, dogmatic categories, legal doctrines, etc.) that the given organ respects and accepts, i.e. which have a decisive 
influence on the body's conception of law, constitutional self-interpretation, and role perception;

c) The fundamental rights or other constitutional tests and standards applied by the given constitutional court (e.g. to resolve substantive contradictions between competing fundamental rights or to designate a hierarchy), and how close it is, for example, to the tests and standards applied by the ECtHR or the ECJ);

d) The 'addressee' of the decisions and the reasoning; to whom the constitutional court (ECtHR/ECJ) 'speaks' (e.g. lawyers in general, judges, law-makers, all citizens, educated intellectuals, international fora, constitutional judges in the minority, petitioners, etc.).

Finally, all other findings relevant to the practice of the constitutional court of a given country were welcomed in our research. However, their enumeration or previous determination was impossible since these are situational features. The assessment thereof became the task of the researcher of the given country. Although even an exemplificative list of these is unreasonable, here are a few examples: whether the Judge-Rapporteur (or the specific panel appointed to decide) is a determinant to the outcome of the case or the style of the reasoning of the decision; whether the same is affected by the designation order or the staff members who prepare the case for decision-making; whether there is a significant difference between the style and nature of the arguments related to the proceedings carried out and the decisions made in the exercise of different powers; how the given constitutional court resolves priority issues (e.g. between the constitution, ECHR, EU law); whether there are rules of interpretation in the constitution (and if so, how the constitutional court applies them); how long the justifications/reasonings are (and whether there are differences between the length, thoroughness, or structure of reasoning for each case type); and whether there are parallel arguments between majority and minority/separate opinions. Regarding the decisions of ECJ/ECtHR, the extent to which, in certain national cases, they refer to each other's decisions or underlying conventions (e.g. ECtHR to EU Treaties or Luxembourg case law; ECJ to ECtHR case law, ECHR, or other sources of the Council of Europe) was also deemed interesting.

\section{Results}

\subsection{Legal interpretation activity of the constitutional courts in Central and Eastern Europe}

To evaluate the legal interpretation activity of the constitutional courts in Central and Eastern Europe, we paid attention to the powers that provide frames for constitutional adjudication. Hence, a college basically performing norm control activity may consider different aspects from one mostly judging constitutional complaints. 
The petitioners (e.g. whether actio popularis exists in cases regarding norm control) also play a role, including their habits. The constitutional culture impacting these habits may also affect the features of law application manifested in constitutional adjudication and of the legal interpretation activity of the constitutional court. In the present research, these differential impacts were reduced by the fact that, according to the research design, only the constitutional court decisions interpreting and applying fundamental rights were examined. It did not affect the sampling base related to constitutional complaint cases but did the one of norm control cases, since we excluded the examination of cases that raised issues concerning purely the state structure, competences, or basic principles (not related to fundamental rights). The requirement that the selected cases must include references to the decisions of supranational courts also narrowed the range of cases to be examined, which could also have affected the types of the fundamental rights within the cases examined.

The concentrated constitutional courts functioning in all Central and Eastern European legal systems examined in our research had five (plus one) typical main activities: norm control (both with abstract and concrete manner), individual (direct) protection of fundamental rights (fundamental right adjudication), adjudication on competence disputes, adjudication regarding the functioning of the state (charges against public officers, banning of political parties, etc.), and adjudication on election disputes. Furthermore, courts undertake the interpretation of the constitution in connection with all these and also as separate competence. All indicated that constitutional adjudication is an activity separated (institutionally and, mostly, functionally) from ordinary adjudication and cannot be considered as a part of the justice system in the classical division of powers by Montesquieu. ${ }^{154}$

The most traditional function of the constitutional judiciary is norm control: checking the constitutionality of legislation. If, in the exercise of this power, the constitutional court finds that a statute or statutory provision is unconstitutional, it annuls the statute (statutory provision), so that it cannot produce legal effects once the annulment has taken effect. Therefore, it is a necessary condition of the concentrated constitutional adjudication that the constitutional court functioning independently could examine the constitutionality of any legal regulation or the compliance thereof with the provisions of the constitution and could annul these provisions if they were found to be unconstitutional, i.e. it could, formally, take them out from the existing legal system. There are two types of norm control: abstract and concrete. Abstract norm control means that, on the motion of the entitled person, the constitutional court examines the compliance of a norm with the constitution in a general manner (independently of a specific case or procedure). In the case of

154 It is the Polish Constitutional Tribunal that may be mentioned as the only partial exception from this. In a slightly doubtful manner, Mirosław Granat expressly wrote, '[i]t belongs to the judiciary' (cf. Granat, 2018, p. 133). This institution was regulated by Chapter VIII of the Polish Constitution of 1997 together with, but not as a part of, the 'courts and tribunals' and 'the Tribunal of State'. It cannot be stated that the Constitutional Tribunal 'would belong' to the judiciary. 
concrete norm control, there is a main case (procedure) in which the possibility of the unconstitutionality of a given statute (statutory provision) arises. Most constitutions give the right to the former to a few precisely defined public actors (parliament or a certain number of members of parliament, government, higher courts, etc.), whereas the latter can be initiated by a public body defending public interest (e.g. prosecutor's office, ombudsman, public authority also responsible for the protection of fundamental rights), the court seized of the specific case (and otherwise required to apply the rule), or (typically) the person concerned in the specific case (a party to the legal proceedings or a person with another role, or a person directly affected by the rule), whose rights have been or, if applied in the future, would be affected by the legal provision they consider unconstitutional.

The typical form of fundamental rights adjudication is the constitutional complaint and, in particular, its form developed in the German constitutional law, as 'real constitutional complaint' (Urteilsverfassungsbeschwerde). Any natural or legal person concerned in a judicial process can go to the constitutional court even if it is not the legal regulation applied by the court that the person considers to be unconstitutional but (recognising the constitutionality of the legal regulation) the court's decision itself or the legal procedure leading to that decision, i.e. the unconstitutional application of the otherwise constitutional norm (including not only procedural mistakes but, first and foremost, the unconstitutional interpretation of the given norm). The activity of the constitutional court in the field of fundamental rights interpretation examined in the framework of the research meant mainly the examination of the decisions of the constitutional court in constitutional complaint proceedings, and secondarily, the analysis of the reasoning of decisions in norm control cases. These mainly contain interpretations related to the meaning of constitutional rights.

Nevertheless, fundamental right aspects may occur, in a complementary manner, even in the exercise of other constitutional court competences. It may be the least probable in the adjudication on competence disputes, which is also the part of the original model of Kelsen and in the course of which the constitutional court settles the disputes between other constitutional bodies regarding their competence (i.e. if the constitutional bodies disagree ${ }^{155}$ on which of them may proceed and make a decision in certain cases, the constitutional court will decide it with the interpretation of the relevant provisions of the constitution ${ }^{156}$ ). It is more likely that the application and interpretation of fundamental rights occur in the course of the adjudication regarding the functioning of the state (because persons performing public functions may also have fundamental rights) and of the adjudication on election disputes (when, mainly, the interpretation of the so-called political fundamental rights, such

155 The constitutional court delivers judgement on only the conflicts between different types of public bodies. Conflicts within a given organisational system (e.g. disputes on competence of courts) will be resolved by the 'key organisation' of the given system.

156 The conflict of competence may be 'positive' if two or more bodies wish to proceed in a given case or make a certain type of decision; and may be 'negative' if no organisation wants to resolve a task resulting from the constitution. 
as the right to stand as a candidate at elections and the access to public office, may occur). Beyond these, constitutional courts may have several other concrete tasks assigned to them by the constitution-maker; however, most constitutional courts basically perform the mentioned ones (or some of them). Finally, it must be pointed out that, with erga omnes effect, only the constitutional court is entitled to interpret the constitution (within the concentrated constitutional adjudication). It necessarily performs the same when exercising any of its other concrete competences. It is also entitled to perform such adjudication, to protect the unity of constitutional order, in abstract manner, independently from concrete cases.

The institution of constitutional complaint (including - except for Poland - the possibility for challenging the judicial decision owing to the violation of constitutional rights, ie., real constitutional complaint) and the abstract and concrete norm control exist in all the six countries concerned. The other competences reveal a high degree of variation. A common feature of almost all legal systems is that apart from the constitutional review of legal regulations, even the examination of their conflicts with international conventions may be initiated (by certain petitioners), which is a particular type of norm control beyond the Kelsenian model of constitutional adjudication (but which is generally used in the countries applying concentrated constitutional adjudication).

In our research, the majority of the decisions of the six examined Central and Eastern European constitutional courts were made in constitutional complaint procedures and the smaller part thereof in norm control procedures; decisions made during exercising other competences were exceptional. The ECtHR decisions defined as a criterion for selection were made in fundamental rights cases and, hence, the constitutional court decisions that referred to those were also made in cases regarding constitutional rights-its typical form (making up the majority of the cases in practice) is the constitutional complaint. Interpretation of fundamental rights may occur in norm control cases; hence, we also expected that the selected cases would include, beyond complaints, cases initiated for judging the constitutionality of legal regulations.

As for the general methodological lessons learned from the research, the following must be pointed out. In each country, the reference to previous constitutional court decisions is the basic argumentation method. In this context, it is typical of all examined countries that they do not simply refer to previous practice but to concrete constitutional court decisions that serve as bases for the decision-making in the given later case. Since all examined constitutional courts had started functioning long before 2011 (the earliest date of decisions which could be included in the sample), all of them had already rendered several decisions regarding most issues that raise constitutional problems even if not in the same legal matters. However, because colleges of a later composition maintain the principles already elaborated regarding certain fundamental rights, the interpretative terms and findings in interpreting fundamental rights are, obviously, used in later similar decisions for judging, in other respects, the same fundamental rights. This would actually be the case even if they did not refer to those decisions explicitly; but they do. It can be assumed that they do not start with 
a clean slate when deciding a constitutional problem; rather, they weave the net of constitutionality that had been started by their predecessors (even if, exceptionally in some partial questions, they change their opinion). Accordingly, the constitutional courts become quasi-precedent courts. They are not formally bound by their earlier decisions; these ones provide a good basis to obtain a similar result in a later similar constitutional question, for a college of a different composition. ${ }^{157}$

We can find several plausible explanations for this. On the one hand, fundamental rights do not change quickly; their denominations remain the same (mainly in case of first-generation human rights functioning as real fundamental rights) and the underlying content has a minimum of several decades or, often, several hundreds of years of tradition. Most of these fundamental rights have matured scope and meaning. Even if there is dispute on partial questions among the members of the constitutional court, there are always preliminary questions or substantial starting points on which there is a consensus in the college. Thus, the college (or its current majority) can find previous decisions to be used as starting point of its later decisionmaking. Since it is also typical that constitutional courts, mentioning as many aspects arising in the given case as possible, refer to several (by as many as more than ten) previous decisions in one case, there will always be precedent decisions on the content of which no serious debate exists among constitutional court judges. Even if there is no consensus among them on what particular constitutional decision in the concrete case comes from those, certain principles mean the minimal safeguards of constitutionality, without which the protection of fundamental rights would make no sense (and these principles are typically in the basic decisions made in the first few years of the functioning of the given constitutional court).

The fact that it can increase the legitimacy of their current decisions can also encourage constitutional courts to use more previous precedent decisions. It can be realistically expected that a decision that follows directly from earlier practice already accepted and recognised by society and the legal community can expect fewer professional and social critiques compared with a decision of a novum nature made for the first time on a given issue. Finally, incorporating previous decisions into reasoning is also effective in terms of labour savings: the always busy colleges need to invest less time and energy in the constitutional reasoning since most of it has already been done by previous constitutional court decisions. Thus, it is no coincidence that in almost all 180 constitutional court decisions examined, i.e. (with one exception) in all six countries, the decisions of almost all (or actually all) examined

157 The longer a constitutional court (or other body empowered with constitutional adjudication) functions, the more often it cites decisions as precedents. This is typical not only of Central and Eastern European countries: Goldsworthy formulated the following as general experience in case of six countries (the US, Canada, Australia, Germany, India, South Africa) having different legal cultures, being located in different regions but equally having a written constitution: 'Precedents naturally play a much larger role in the interpretations of older constitutions, simply because there are more of them. When constitutions are young, courts have a greater need to seek guidance elsewhere, which diminishes as they build up their own stock of indigenous precedents' (Goldsworthy, 2006, p. 342). 
cases in each country contained reference to at least one, but in the bigger part, several, previous constitutional court decisions. The only exception is Serbia, where only 14 cases contained reference ${ }^{158}$ to previous constitutional cases; here, instead, international sources are taken into account by the constitutional court. The role of the latter is more significant here than in the other countries. The use of this manner of reasoning was decisive or at least defining in several cases. Thus, the constitutional courts of Central and Eastern European countries can be considered as quasiprecedent courts (using the concept of one of the precedent types of Zôdi, 'charter precedent courts' or, our own slightly more precise definition, case law courts).

As for the further interpretation methods, the practice of the constitutional courts in certain Central and Eastern European countries was varied. Some methods were more typical of certain colleges and less typical of other ones. Primarily, the contextual interpretation in the broad sense was employed. ${ }^{159}$ The constitution and fundamental rights included thereby must form a coherent system; hence, the tension between fundamental rights appearing to contradict at text level must be eliminated: fundamental rights must be interpreted in relation to each other and their scope must be defined in that way. Defining which fundamental right has primacy in a borderline case requires the application of measures and tests with the use of which the constitutional court performs (necessarily) contextual interpretation. In most cases, this use is necessary and inevitable to implement the principle of unity and coherence of the constitution (being obviously fictional but practically essential). At the same time, the contextual interpretation in the narrow sense, i.e. establishing the meaning of a fundamental right merely on the basis of the part of the constitution it was placed in by the constitution-maker, was not typical in any of the examined countries. They either did not occur at all in the 30 decisions examined (from which it cannot be concluded that such an interpretation does not exist at all in the legal system in question, but that it is at least not common), or only exceptionally. Similarly, further types of domestic systemic arguments appeared also only exceptionally in the examined constitutional court decisions of the given countries. Thus, while the earlier constitutional court practice, in the scope of this method, was defining (in almost every case of every country), the contextual interpretation in the broad sense (interpretation of fundamental rights referred to or reflected in each other or other constitutional provisions) was typical, the interpretation of fundamental rights on the basis of domestic statutory law was rarely used (in more or less than half of cases). ${ }^{160}$ The case law and judicial practice of domestic ordinary courts occurred in the analysed decisions at most only during the delineating of the facts of

158 It occurred also in case of the Slovakian college that, in several (a total of five) cases, no previous constitutional court practice was used as basis for interpretation or reasoning.

159 The exception is the Czech Republic, where this interpretation occurred in less than half of the cases. In Serbia and Slovakia, one could find relatively moderate occurances with two-thirds (20 cases) and slightly more than half (16 cases) of the 30 analysed items.

160 This method was used in 18 cases in Slovenia, 15 in Slovakia, and 11 in Serbia. It was detectable in six cases in Hungary, three in the Czech Republic, and none in Poland. 
constitutional complaint cases (the background of the underlying case; and, in the course thereof, in the analysis of the consistency between the judicial practice and judicial decision challenged with the complaint) and barely in the interpretation of fundamental rights, if at all. ${ }^{161}$ Finally, the interpretation on the basis of normative acts of other domestic state organs was also barely used (not exceeding one-fifth of the cases) by the constitutional courts of Central and Eastern Europe, even then only as strengthening arguments or simple illustration. ${ }^{162}$

At the beginning of our research, we hypothesised that, apart from the reference to the practice of the constitutional court, grammatical (textual) interpretation would be the most decisive method. This was proved only partly by the results: while dogmatic interpretation proved to be the frequently used method if considers with the simple conceptual dogmatic interpretation and interpretation on the basis of legal principles of statutes or branches of law (at least either of them was used in all countries and in all cases or in the majority thereof), the attempt to explore the everyday meaning of words was either absent from most of the decisions of the constitutional courts analysed, or was present in only a few cases. ${ }^{163}$ The explicitly referred consideration of dogmatic meaning may obviously be due to the fact that the normative text of the constitution is a legal text, and the legal meaning of legal terms (dogmatic categories related to constitutional law or other positive law, or the principles of branches of law) is, on the one hand, relevant and, on the other hand, often ambiguous in the course of judging the concrete constitutional problem to be decided. Hence, the explicit interpretation appearing in the reasoning is inevitably necessary. On the contrary, the exploration of the ordinary meaning may be less frequently applied because it is unambiguous or at least the constitutional court assumes that it is well known, and therefore unproblematic. Thus, its explicit interpretation is, according to the constitutional court, not necessary in most cases (interpretatio cessat in claris). Even in its limited occurrence, textual interpretation based on ordinary meaning of the text almost always (with four exceptions) meant semantic interpretation; syntactic interpretation occurred in only three Polish and one Hungarian Constitutional Court decision out of the 180 analysed constitutional court decisions. The total absence of other professional interpretations is worth noting; this kind of interpretation never appeared in the sample.

In the examined constitutional courts, external systemic arguments were applied to a significant extent but slightly less frequently than domestic systemic arguments or grammatical interpretation. Since it was a selection criterion regarding all constitutional court decisions to be analysed to have reference to ECtHR or ECJ decisions,

161 Only in Hungary has this method been used by the domestic constitutional court in more than $25 \%$ of the cases analysed.

162 The exception is Slovakia, where such an argument was used in 11 cases.

163 Thus, no interpretation based on ordinary meaning (at least not explicitly referred to) occurred in the practice of the Czech Constitutional Court we analysed. It occurred occasionally in the jurisprudence of the Polish (15 cases), Slovenian (10 cases), Serbian (8 cases), Slovak (6 cases), and Hungarian (3 cases) Constitutional Courts. 
no conclusion may be drawn from the fact that all decisions included at least one of these; such 'conclusion' would mean replacing the consequence with the cause. This is particularly true given that regarding the five-year period (between 2016 and 2020) defined in the original research design as the selection criterion for the period of making constitutional court decisions (which have references to ECtHR or ECJ decisions and have importance regarding the given legal system, legal practice, or society as a whole), the researchers of several countries noted the difficulty that, during this period, there was simply not enough relevant constitutional court decisions made that would allow them to choose 30 decisions meeting the conditions and to be analysed. For this reason, we were forced to partly modify the research design and to define a ten-year period for the examination instead. This fact alone may give rise to the assumption that reference to concrete decisions of supranational courts is not typical of the reasoning practice of constitutional courts in Central and Eastern Europe but rather exceptional; and references of this type are typical of a small part of the cases (but presumably of the cases among the most important ones).

For the same reason, the relatively high number of ECtHR or ECJ decisions outside the given ECtHR (or ECJ) decision should be treated with caution, because of the way the selection criteria were defined. Indeed, it is common experience (and we have not found otherwise in the course of the present research) that constitutional courts often treat ECtHR decisions as a 'package'; that is, if they decide to cite sources of international relevance in the case, they typically do not do so by referring to a single source but rather by using several such sources to strengthen the argument.Thus, merely from the fact that, apart from the concrete ECtHR decisions that served as bases for the selection (and later were examined also independently to define the interpretation and reasoning practice of the ECtHR), references to further ECtHR decisions were also found in the given analysed constitutional court decisions. The constitutional courts in Central and Eastern Europe may not actually refer to international sources to the extent found in the sample examined in this research. It is also true in case of further ECtHR (or ECJ) sources beyond the selected ones (the particular decisions of the ECtHR and its general 'jurisprudence') and of international conventions and supranational documents on human rights (the European Convention on Human Rights before the ECtHR and the Charter of Fundamental Rights based on the catalogue of rights ${ }^{164}$ guaranteed in ECHR before the ECJ). ${ }^{165}$ Thus, the decisions of the ECtHR rarely stand alone because these are (theoretically) interpretations and applications of the provisions on human rights of the Convention. If a constitutional court decision contains a reference to an ECtHR decision, there will be a good chance, at least in the significant part of the cases, to find a reference

164 Hoffmeister, 2015, p. 196.

165 Reference to decisions or practice in international fora are typically accompanied by reference to underlying international conventions (exceptionally so for other international conventions). This is most prevalent in Slovenia (21 cases) and Hungary (18 cases). In Slovakia (14 cases), Serbia (12 cases), and Poland (12 cases), it occurs in only a minority of decisions. In the Czech Republic, however, the use of this source is almost non-existent. 
to an underlying provision of the Convention (and to several further ECtHR decisions interpreting that provision). At the same time, the exploration of these references is not without any importance: even if we cannot conclude from it (contrary to other methods examined) how widespread the use of international sources is in the practice of the examined constitutional courts in Central and Eastern Europe, we can conclude the types of international sources these constitutional courts use, if they do. ${ }^{166}$

In this respect, the result of the research, based on the selection of the constitutional court decisions in question, is that it is much more common in the practice of the national constitutional courts of Central and Eastern Europe to refer to the practice and case law of the ECHR than to include the practice or individual decisions of the ECJ in the argumentation of fundamental rights (and this is the case not only in non-EU member Serbia but also in EU member states). The six researchers intended to assess the reasoning practice of the national constitutional courts and found more decisions referring to ECtHR decisions in their reasonings than ones referring to ECJ decisions. However, even together, their number is small. In most constitutional court decisions out of the sample, no sources with international relevance were used; the plausible reason may be that most cases before the constitutional courts do not actually have such relevance, in any country. Where it exists at all, the constitutional courts refer to the ECtHR's practice and only barely to that of the ECJ. ${ }^{167}$ However, it was also surprising that other international sources, if not often but with perceptible regularity, were used by national constitutional courts; almost all of them referred to one of these (except the Constitutional Court of Slovakia) in an extremely varied form. ${ }^{168}$

166 The hierarchy of the particular sources and the possible conflicts between sources to be followed by ordinary courts are issues that digress from our focus. They cannot be discussed in detail in a methodological volume. Since different legal documents (e.g. internal constitution and different international conventions) may contain human rights, it matters which body has the primacy to determine the content thereof and what procedure shall be followed in case of their conflicts. This question has been defined in the conception of 'multi-level constitutionalism', which 'is understood as limited national sovereignty by virtue of membership in the European Union and other international organizations rather than a shared constitutional space that no longer espouses a clear hierarchy of constitutional norms. In a multi-level constitutional world order there are various centers of law-making and interpretation that are mutually dependent and interrelated' (Pap and Śledzińska-Simon, 2019, p. 71.).

167 The ECJ is an independent organisation in its territory but its judgments may be applied and enforced only with inter partes effect and have only an orienting nature for national law-appliers (until an ECJ decision is made in that case). Regarding the certain countries examined, see Sehnálek, 2020, pp. 125-153; Stumpf, 2020, pp. 35-46. Rregarding family law, see Mostowik, 2017, pp. 7994. For a critical approach, see Śledzińska-Simon and Ziółkowski, 2019, pp. 243-267).

168 The Hungarian sample contained the vast majority of such references: the Constitutional Court of Hungary invoked, usually only as strengthening arguments or illustrations, such 'other' external sources (e.g. decisions or recommendations of international organisations) in 15 of 30 cases. In the other countries (with the exception of Slovakia, where no such reference was made), the number of cases was between 1 and 4 . 
Similar direct relation regarding the comparative law arguments does not exist. The selection of the decisions included was not affected by references to legal regulations, constitutional court decisions, or other concrete legal sources of particular foreign legal systems. Thus, their determined proportion (regarding cases with 'significance') reflects the actual situation, which can be summarised as follows: the occurrence of comparative law arguments is not common in Central and Eastern Europe but nonetheless remarkable. However, their role is only illustrative; they do not affect, either alone or together with other arguments, the merits of the decision and they do not determine it. ${ }^{169}$ As an example, they serve the judges of the constitutional courts to prove that their reasoning is not unique, not individual, and may occur in other countries. The decisions of the German Bundesverfassungsgericht are

169 After 2010, the frequency and role of the references to foreign precedents in the practice of the given national bodies were examined in a larger research covering the Central and Eastern European legal systems, including Hungary (and 15 other bodies performing constitutional adjudication from five continents). The results regarding the Constitutional Court of Hungary showed experiences similar to the ones concluded in our research in that regard. There were references to foreign sources (i.e. classical references of comparative law) in 19 of 1,016 decisions examined between 1999 and 2010 (1.8\%). Without counting the cases regarding the legislating activity of local governments and the objections of referenda being not relevant in this regard, the Constitutional Court of Hungary used such arguments in 3\% of cases in this period (cf. Szente, 2013, pp. 259-260). These arguments appeared often in cases when the complexity of the case required the foundation with foreign examples that often overlapped the references to ECtHR decisions. If references to ECtHR judgements had not been a selection criterion in our research, the number of references to foreign law would have been much lower among all examined constitutional court decisions. The determination of reasoning weight of references is more interesting. Szente set up five reasoning patterns to determine the actual reasoning role or purpose of foreign court or constitutional court decisions. Of these, the fifth ('adaptation of complete interpretative doctrines or legal construction') is considered a theoretical category but did not actually play a role in any of the decisions examined (Szente, op. cit., p. 269), while of the other four he considered the most decisive, the 'formal, illustrative citation': 'in most cases they [foreign judicial cases] are mentioned only in a very formal way, without being used for establishing a view or an argument [...]. Therefore, in general, foreign precedents are mentioned out of habit, in order to demonstrate that the [Hungarian Constitutional] Court took account of the most meaningful foreign law, and to report that a comparative analysis in any given case was implemented' (Szente, op. cit., p. 266). It is not odd that the Constitutional Court of Hungary uses the foreign court decisions 'to increase the legitimacy of its own decision' (Szente, op. cit., p. 267). The foreign pattern has no considerable influence on decision-making even in this case. The same is true for the third type (which could be considered as a subtype of the second one) when the decision is already made and only arguments supporting it are sought subsequently. Szente called it the 'selective mode' of foreign references (p. 267), which is halfway between the illustrative and the authoritative application of the foreign cases used (p. 268). The fourth argumentation purpose, albet barely observable, is finding new ideas or arguments-to borrow foreign legal patterns (p. 268). Eventuality may be observed regarding the references to foreign case law, at least in Hungary, on the basis of the examined decisions: 'there is no consensual interpretative doctrine to determine in which cases an international comparison should be given nor do general guidelines exist for choosing the method of comparison. [...] There is no rule when and in which cases foreign precedents should be cited, as these references have no clear function in legal reasoning' (Szente, op. cit, pp. 271-272). 
referred to ${ }^{170}$ but foreign sources used in this field show extreme diversity (it is surely not independent from the qualifications and knowledge of the Judge-Rapporteur of the case or of their co-counsel in preparing the decision $\left.{ }^{171}\right)$. This method is the most widespread in Slovakia, Hungary, and the Czech Republic: of the decisions examined, 21 contained such argument in Slovakia, 18 in Hungary, and 15 in the Czech Republic. This is less typical of Slovenia (8 cases) and Poland (1 case). No comparative law argument occurred in the sample in Serbia. ${ }^{172}$

The examined constitutional courts applied, to varying degrees, the logical arguments, teleological interpretation, interpretation based on jurisprudence, and that in light of general principles. Historical (subjective teleological) and substantive interpretation barely (almost never) occurred. The use of logical (quasi-logical) arguments was typically rare in the sample analysed (the Serbian organ used logical interpretation two times, the Slovenian three times, the Polish five times, and the Hungarian seven times). The Slovak and Czech Constitutional Courts, meanwhile, made greater use of this method: the Slovak Constitutional Court invoked a minore ad maius in nine cases, a maiore ad minus in five, ad absurdum in three, a contrario in one, a simili in five, and other logical maxims in six. The Czech Constitutional Court used the same arguments in $1,1,4,2,4$, and 3 cases, respectively.

The use of (objective) teleological interpretation, i.e. explicit reference to the purpose of the constitution or constitutional provisions, varied widely in the samples analysed, ranging from very limited use (in Slovakia and Poland) to almost half

170 Szente reached the same result in his cited research, cf. Szente, op. cit., p. 262. The situation is similar in case of the Austrian Verfassungsgerichthof [not examined in this research but important in the course of enumerating the region's countries (Gamper, 2013, p. 226.)]. The reasoning weight is also similar; the Austrian college also uses it for its strengthening and not decisive or defining nature: it 'has never yet really decided a case on account of foreign case law. At best, its function is that of a non-binding by-argument in order to support a legal opinion that already derives from applying domestic law' (ibid.).

171 The co-workers writing the text of the decision (e.g. advisers, law clerks, référendaires, assistants, legal officers, judicial assistants, assistant-magistrates, research consultants, rapporteurs, research judges, state advisers) have a decisive role: it varies by constitutional court to what extent they have influence on substantive decision-making but their role is important in all legal systems. For the thorough and informative enumeration of the role of the legal staff supporting the decision-making of judges substantively, and covering the constitutional courts or supreme courts of 27 countries and the ECJ (and, as a strange exception, the Venice Commission), see Zegrean and Costinescu, 2016.

172 The international comparative law research coordinated by Groppi and Ponthoreau produced interesting findings regarding this. Although there was no research in the countries examined by us, except the Constitutional Court of Hungary, it could be found in the other countries of the wider region that invoking of foreign law (or the decisions of constitutional courts or of courts) is less typical (and can be observed only in case of landmark decisions, if any). Thus, apart from the rate of $1.8 \%$ (3\% if we exclude irrelevant cases) found regarding the Constitutional Court of Hungary, a rate of $0.45 \%$ could be determined in case of the Austrian Verfassungsgerichthof (60 cases out of 13,251 , or hardly $0.1 \%$ in cases referred by the college itself, or 16 cases if we exclude complainant references). The German Bundesverfassungsgericht used foreign references to an extent similar to Hungary (32 decisions out of 1351 cases; 2.4\%); the comparative law argument is almost completely missing in the practice of the Russian (6 cases of 11,000) and Romanian constitutional court (14 cases of 13,250). Cf. Groppi and Ponthoreau, 2013, p. 412). 
of the decisions (in Serbia). ${ }^{173}$ The reference to the purpose of the constitution is relatively rare even in the country where, pursuant to the provisions of its constitution, this interpretation would be a compulsory element (in Hungary). ${ }^{174}$ The main reason for the relative 'underutilization' of this argument is not the irrelevance of the content of the purpose but that the purpose of a legal regulation is often obvious thus needs no explicit reference unless other interpretation methods do not lead to unequivocal results. In this case (but only in this case), it is necessary to expressly invoke, beyond the text of the constitution, the dogmatic aspect of fundamental rights and the constitutional court practice (which interprets the former and partly forms the latter) and the purpose of the constitutional provisions (or the entire constitution as a coherent system of rules and principles). Thus, objective teleological arguments function as the 'crutches' of the interpretation of the constitution, which, therefore, are necessary only if, in a different way, the establishing of the meaning does not seem to be possible or the legitimate interpretation of the text of the constitution does not seem to be sufficiently convincing.

The use of subjective teleological arguments was not typical. Reference to the intent of the constitution-maker or to the (social-political) circumstances of constitutive process that seem to support this intention either does not appear in the decisions examined at all (in Serbia and the Czech Republic) or only exceptionally. In Hungary, the historical argument was invoked in three cases (twice on the grounds of ministerial justification, once on the grounds of the will of the constitution-maker in general); in Slovenia, once (on the grounds of the constitution-maker's will in general); in Poland, four times (twice on the grounds of the proponent's justification, twice on the grounds of the intention of the constitution-maker in general). Only in Slovakia was there a relatively higher number of such references, namely, nine in total (twice to the proponent's justification, twice to the travaux, twice to the constitution-maker's intention in general, and three times to historical circumstances).

Perhaps the most interesting, and certainly the most controversial, of all the arguments is the use of references to jurisprudence, i.e. when the Constitutional Court refers to the works of specific scholars, by author and title, in its interpretation. In some countries, references to these scholarly works barely appear (for example, in Hungary, it appeared in four cases of the examined sample; in Serbia, it was employed only once), while in other countries it belongs to the common, frequently used methods. Slovenia, as one of the six countries examined, belongs to the latter group of legal systems, where the majority of the examined decisions ( 25 of 30) referred to concrete scholarly works, mainly to monographs, on average of four times per decision (where this argument appeared). The use of this argument is almost as

173 The national constitutional courts invoked the explicit purpose of the constitution four times in Poland, five time in Slovakia, seven times in Hungary and the Czech Republic, nine times in Slovenia, and fourteen times in Serbia.

174 The Hungarian Fundamental Law, in its Article R) (3) states: 'the provisions of the Fundamental Law shall be interpreted in accordance with their purposes, the National Avowal contained therein and the achievements of our historic constitution'. 
common in Slovakia, where the constitutional court referred to concrete results of scholarly literature in 23 cases. Finally, Poland occupies an intermediate position in this respect, with the Polish Constitutional Tribunal using jurisprudential works in eight cases, explicitly defining the decision, and the Czech Republic, where jurisprudential works were referred to in half of the cases. ${ }^{175}$ Regarding the latter, the approach is more differentiated; most of these references cover the works published in the (co-)authorship of the Judge-Rapporteur. Hence, this relatively high number of references does not mean the efforts made in favour of scientific grounding but rather the intention to propagate their own works. In these cases, it is obvious that the references to jurisprudence have only ornamental nature; the Judge-Rapporteur obviously would have proposed a draft decision based on their own view even without that reference.

The practice regarding the reference to general legal principles is similarly diffuse. It is not typical in Serbia; even if these principles are used, they do not appear in the reasoning, presumably because they represent methods of law accepted by all and trivial for the lawyer community and because they are fundamental elements of the legal system, the explication of which could be considered unnecessary or redundant. Meanwhile, the practice in the Czech Republic is on the other end; reference to general legal principles appeared in $70 \%$ of cases, though, mainly only with an illustrative nature. The other countries lie between these two extremes, with a prevalence of between 4 and 10 (but this argument is only significant in Hungary, given its weight and role in decision-making). ${ }^{176}$

Finally, substantive arguments are among the rare methods used in the Central and Eastern European countries studied: in Slovenia, three decisions (eight times in total); in the Czech Republic, also three decisions; in Serbia, two decisions; in Hungary, five decisions; and in Slovakia, ten decisions. Poland is the country with the least use of this argument, with none in the sample analysed. These references show remarkable diversity even in their scarcity; in the constitutional court decisions in Central and Eastern Europe, different non-legal decision bases appear as arguments, from the medical expert opinion in case of epidemiological restrictions (Slovenia) to professional consensus on life science (Serbia), and, in other cases, from equity (the Czech Republic), to public interest (Hungary, Slovakia) and good morals (the Czech Republic), to common sense (Slovakia). Although we could have expected that a constitutional court, which works with human rights at the border of law and morality, grabs more often the moral aspects and other non-legal arguments, our findings belie the same: substantive references are rather exceptions than general rules. This most probably is because human rights are indeed morally motivated rights with direct moral relevance but they are, since their enshrining in the constitution, also the part of positive law and, as such, their interpretation and application 
as positive law, also considering the creative methods of legal development (often disguised as legal interpretation), are, in most cases, enough for the given constitutional case to have not only lawful but also moral and fair result-'proper' social and legal outcome.

\subsection{Legal interpretation activity of the European Court of Human Rights}

\subsubsection{General characteristics of the European Court of Human Rights and its case law}

The Council of Europe (CoE), established in 1949, is the most important regional human rights organisation on the continent of which almost every country in Europe is a member. ${ }^{177}$ With the accession, the 47 member states of CoE committed themselves not to violate and to enforce ${ }^{178}$ the most important human rights. A non-exhaustive catalogue of these rights is contained in the Convention for the Protection of Human Rights and Fundamental Freedoms, signed in Rome on 4 November 1950 (hereinafter: ECHR or, simply, the Convention), which entered into force in 1953 and to which all CoE members have (had) to accede. From 1950, 16 additional protocols have been attached, the latest of which, surprisingly at first sight, is Protocol No. 15. It entered into force on 1 August 2021 and shall apply in subsequent procedures. The state parties to the Convention have (had) to confirm or ratify all these protocols. All 16 protocols have been confirmed by almost all member states of CoE. Currently, only ten Protocols, namely, Protocol Nos. 1, 4, 6, 7, 11, 12, 13, 14, 15, and 16, are in force. Protocol Nos. 2, 3, 5, 8, 9, and 10 have been replaced and repealed by Protocol No. $11 .{ }^{179}$ The rights included by the Convention and its additional protocols are enforced by the ECtHR, i.e. named after its registered office, the Strasbourg Court. Until the entry into force of Protocol No. 11 adopted in 1998, it was possible to accede to the convention and the protocols without accepting the jurisdiction of the ECtHR. Since then, accession to these also means submission to the jurisdiction of the Strasbourg Court, including a commitment that the contracting states pay awarded compensation if the ECtHR convicts them in breach of convention.

177 Belarus, Kazakhstan (also having some European territory), the Vatican, and Kosovo (not yet recognised by several states) are not members of this organisation.

178 The contracting states accepting the jurisdiction of the ECtHR do not simply commit themselves not to violate the fundamental rights covered by the ECHR but also to support their enforcement with state measures even in relations between non-state entities (Cf. Flander and Tičar, 2019, p. 424).

179 Protocol No. 15 clarifies the aspects of the principle of subsidiarity and margin of appreciation of the member states; it could enter into force only after the ratification by all member states of CoE. Protocol No. 16, which allows the courts of the member states to request, with the suspension of the procedure before the court of the member state, a non-binding advisory opinion regarding the interpretation of fundamental rights and freedoms covered by the Convention or the Protocols thereto, entered into force on 1 August 2018 because the ratification of ten states was enough thereto. However, it applies only to states that have ratified it. At the time of writing (in August 2021), 16 member states (including Slovakia and Slovenia) have ratified it, but the majority of the states have not. The Czech Republic, Hungary, Poland, and Serbia have not ratified nor even signed it. 
The ECtHR is basically entitled to act in two types of legal disputes: those between states and those between natural persons/legal entities and states. The former ones are not relevant for the present research since violation of individual human rights may not occur in such cases. Moreover, such legal disputes take place extremely rarely (once in a period of several years); hence, they are of negligible interest in other respects as well.

Until 1998, a procedure in Strasbourg had two levels: the European Commission of Human Rights assessed the complaints at first (but often also at last) instance; and the ECtHR decided, at second instance, major cases assessed by the Commission. This system has changed from 1 November 1998 with the entry into force of Protocol No. 11: the Commission was abolished (but its decisions made before 1998 can still be referred and applied if they still have relevance) and the Court was reformed. ${ }^{180}$ At present, the procedure of the Court, theoretically, has two phases: the assessment of admissibility and, in case of admissibility, the decision on the merits. However, owing to the increasing caseload and to speed up the procedure, the decision on the merits (if positive) is made together with the assessment of admissibility (if the application is admissible) in most cases. The Court could hold a hearing to decide the merits of the case (and occasionally to declare its admissibility), but it mostly makes decisions on the basis of the documents and written applications and observations of the parties to the procedure (the applicant and the state accused of breach of the convention).

Single-judge formations or committees of three judges may declare an application inadmissible. In 2010, the latter ones were empowered to decide cases in which wellgrounded case law is available on the merits (e.g. in cases regarding unreasonable delay of judicial procedures). In other cases, decisions on the merits are made by five chambers of seven judges each and, in cases with particular importance or in matters of principle (if the chamber decided on the merits, but not in the case of the chamber's decision declaring the application inadmissible), the decision of the Grand Chamber consisting of 17 judges may be requested (but it is not possible to bring a case before the Grand Chamber if a committee made a decision on the merits, which could be made only unanimously). If a single judge, a committee, or a chamber declares an application inadmissible, there is no remedy against the decision. The Grand Chamber accepts the requests against the chambers' decisions on merits only in the rarest cases, especially when it wants to decide fundamental interpretation questions or set a precedent with taking a position regarding an unresolved issue or deviate from previous case law. ${ }^{181}$

For the chambers (committees, in certain cases) to examine the application on the merits and make a decision on the content regarding the violation of a fundamental

180 The court consists of a number of judges equal to that of the parties; all parties are entitled to delegate one member (who are elected by the Parliamentary Assembly of the CoE).

181 A panel of five judges of the Grand Chamber decides whether to accept the request; there is no remedy against this decision. 
right by a governmental organisation, the application must not be inadmissible. There are nine main reasons for inadmissibility: 1) material reasons (ratione materiae), i.e. the applicant stated the violation of a right that was not subject to the Convention (e.g. right to work, right to citizenship); 2) personal reasons (ratione personae), i.e. the application was not submitted by a person entitled to it (e.g. not the victim of the presumed violation) ${ }^{182}$ and the entitled person submits the application not against the appropriate government body (court, prosecution, police, public administration body); 3) temporal reasons (ratione temporis), i.e. the rights under the Convention and the protocols thereto may be judged by the ECtHR only if the violation occurred after the respondent state had ratified the Convention and the given protocol ensuring the given right; 4) the applicant's failure to exhaust the socalled effective legal remedies, which provide a chance for substantial modification of the decision, available in the legal system of the respondent state. In general, the ordinary means of remedy (e.g. appeal against administrative or judicial decisions, and judicial review of administrative decisions) qualify as effective, whereas the revision qualifies as non-effective means of legal remedy. Regarding the review of final decisions by the supreme judicial forum and regarding the constitutional complaint, the practice of Strasbourg is divergent. In the case of the latter, the opinion seems to be crystallising that these are effective; hence, their exhaustion is required from the applicant. 5) If, in case of applications before 1 August 2021, more than six months or, in case of applications after that date, more than four months have passed from the delivery of the decision made as a result of the last effective remedy to the party until posting the application to the ECtHR. 6) If the application is manifestly ill-founded. 7) If the violation occurred outside the jurisdiction of the respondent state or the territory effectively controlled by it. 8) If the case is substantially the same as one already examined by the Court (res iudicata). ${ }^{183}$ 9) If the applicant has not suffered a significant disadvantage (de minimis non curat praetor). For the case law of Strasbourg (and for its development or conventional assessment of the laws of the contracting states), the most important of these is the manifest illfoundedness because the ECtHR conducts substantive assessment and defines the content of the rights under Convention.

182 It can a case related to the freedom of conscience and religion, e.g. if the concrete victim is a natural person but the application is submitted to the ECtHR not by them but by the church of which the victim is a member. Similarly, if spouses submit an application in each other's cases, that, as a general rule, will be inadmissible owing to personal reasons. An exception to the latter, in a special case, is possible: in the Dalban case (Dalban $v$. Romania [GC], no. 28114/95, 28 September 1999), the process initiated in 1995 could be continued on the request of the widow in 1999, i.e. after the death of the late applicant. The ECtHR considered that, according to the interpretation in favour of the applicant, the late applicant qualified as a 'victim' as long as the national courts or authorities had not remedied the injustice suffered. Since it did not happen in that case, the ECtHR accepted the widow's request to consider her, as the procedural successor of her late husband, the 'victim'.

183 For the procedural dogmatic role of res iudicata and its relations with fair trial and legal certainty (independent from general, concrete legal systems), see Köblös, 2017, p. 80. 
The ECtHR (in contrast, for example, to the constitutional court of the Central and Eastern European countries) does not perform norm control-it cannot annul any legal regulation of the contracting states and, except for interim measures, it cannot oblige either the bodies, authorities of the states, or the states themselves (their governments) to take any measures (to repeal or amend judgments or decisions, to oblige the body that made the complained decision to conduct a new procedure, to legislate). It cannot even sanction the failure to implement judgments; for this, the CoE may only use diplomatic pressure of the Committee of Ministers monitoring the implementation. The Court may do two things: establish that the contracting state violated the Convention (or any protocols thereto already ratified by the given state), or, in case of violation of the Convention, award the applicant compensation and oblige the state to pay the applicant's costs. ${ }^{184}$

Finally, to understand the practice of Strasbourg, we have to be aware that the ECtHR is basically a court of case law (a precedent court) that uses the text of the Convention only regarding the subject matter to be judged (i.e. when it determines in which types of cases it has competence and in which, not). It forms and develops the aspects regarding the merits of the case before it, case by case, using individual cases. It uses two procedural techniques also formed in common law, namely, the distinguishing and the overruling, to deviate from previous decisions. Distinguishing means that if two cases are different from each other regarding a relevant fact, it is possible to deviate from the decision made in the former case (i.e. the former case does not qualify as precedent regarding the later case). Overruling means that if it is justified by changed circumstances (social, economic, legal, political), the former case law may be revised and, in later cases, only the judicial decisions made after the revision, in accordance with the new practice, serve as precedents to be followed. Since particular facts of the concrete case are extremely important for the ECtHR, and these facts, owing to the specificities of the given case, will never be completely the same, it is relatively simple to amend its practice with the technique of distinguishing, if necessary, or to define exceptions from the general rule in the concrete cases. It is rarely necessary for the Court to express explicitly that it, consciously and admittedly, ends its previous practice and lays new foundation for its judging activity.

184 In addition, the Court is entitled to apply, in case of strict conditions, an interim measure before the judgment and to oblige the member state (or its acting bodies) to act or refrain from acting. It is used mostly in cases regarding extradition and expulsion to prohibit a contracting state of the ECHR from extraditing or expelling a person who would be threatened with death or torture in that country. Hungary, for example, has been obliged several times with interim measures by the ECtHR in recent times to give the asylum seekers staying in the previously established transit zones food even in the period after the final administrative decision until the judging of the judicial review against the authority's decision. 


\subsubsection{Legal interpretation activity of the European Court of Human Rights: general findings}

By far the most important, most frequently used and most influential method of interpretation of the ECtHR in terms of the weight of its reasoning is its own past practice. All analysed ECtHR decisions contained reference to previous jurisprudence and not only the Court's own practice is referred in general but also the given legal question is decided with reference to concrete judgments. ${ }^{185}$ Theoretically, the ECtHR is a precedent court. On the basis of interpretation methods used and sources of arguments, the same can be clearly demonstrated empirically. Thus, the legal practice of the Court always manifests in concrete sources (in precedent cases cited exactly), which also means that, for deciding the same cases, its judges can use and refer to previous cases. This hypothesis was also confirmed by our empirical survey of the data: the later a decision is made, the more concrete precedent cases are referred to, not only in different but also in the same legal questions.

In most cases, there is a basic decision (an ancient source shaping the practice and deciding the essential questions related to human rights to be interpreted, included by the Convention). As leading case, it affects all later ECtHR decisions interpreting the given fundamental right and on which the later decisions judging the particular problems of the given fundamental right may build. These special decisions in these special cases also function as precedents and are (along with the original basic decision) referred to in all similar cases by chambers judging later cases. Thereby, a kind of pyramid system is built with a leading case at the top, which can affect all later decisions interpreting and using the given human right; below that are decisions defining overall considerations regarding certain subareas; and, at the bottom, the more specialised decisions concentrating on a particular legal relation or legal problem. Hence, a multi-level precedent system has to be taken into consideration in the course of making an ECtHR decision, whose system is built further by the judges' decisions that may be or, in certain cases (if the given decision did not only use but also developed the legal guidance of the previous precedent), must be referred in a later case together with the ones already available. This internal urge stems from the self-understanding of the ECtHR that, for uniformity, legal equality, legal certainty, and foreseeability, expects its judges (or apparatus preparing judicial decisions) to resolve cases of the same nature in the same manner.

In addition to previous practice, contextual interpretation in the broad sense is a method used in a significant part of the cases, appearing in the vast majority (almost all) of the analysed decisions. Contextual interpretation in the narrow sense was

185 Since there were very few ECJ decisions in the examined sample, we cannot make well-grounded statements regarding that. However, there was a comprehensive examination (based on the statistical analysis of 5,578 ECJ decisions made between 1992 and 2011) which found that the reference by ECJ to its own decisions as precedents is case-dependent: it is typical in (successful) infringement proceedings but in case of preliminary rulings, it mainly occurs in cases that relate to internal free market, i.e. competition law or fundamental freedoms (Derlén, 2015, p. 1073-1098). 
completely missing from the ECtHR's practice, applied in none of 180 decisions examined. The credo of the ECtHR is that certain provisions of the Convention cannot be interpreted in themselves but with respect to and in harmony with each other (harmonious interpretation).

Grammatical interpretation, within which the dogmatic interpretation dominates (within this, interpretation on the basis of legal principles is more important than the simple conceptual dogmatic interpretation), and teleological interpretation are also frequently used methods. Within grammatical interpretation, the ordinary meaning of the words and the expressions rarely appears because the problematic words and concepts requiring interpretation of the Convention are basically legal concepts or, if not, they, in the context of declaring the violation of the Convention, become that. Legal meaning always covers the legal sense reflecting the ECtHR's own convictions. The Court does not use the legal concepts of the contracting states but the conceptual meaning on the basis of the dogmatics created by it (autonomous interpretation). It is also interesting in comparison that ordinary semantic interpretation barely appears in decisions (in only one-tenth of cases) and only in two of these were the interpretations of the text (of the Convention) by ECtHR based expressly on the dictionary meaning. Interpretation according to other professions appeared also only in two cases; syntactic interpretation did not even occur in the sample of 180 elements analysed.

Finally, the last of the regularly used methods is teleological interpretation. Such reference occurs roughly in a half or a third of the cases; the exact proportion cannot be determined because the interpretation according to the purpose typically appears only with another method, integrated in a further argument, as an additional finding. Ultimately, the judges, in the course of all interpretations, consider the purpose and function of the Convention and the human rights included thereby. Often, it affects the decision only as background knowledge; the subject, purpose, function, or the meaning of the given fundamental right are explicitly referred to only in a part of the cases.

The reason these methods, not inluding the references to precedents, dominate in the course of the interpretation of the Convention by the ECtHR may be that these have been the methods declared to be taken into consideration by ECtHR from 1975. The ECtHR declared in Golder ${ }^{186}$ in 1975 that provisions of the Vienna Convention of 1969 on the Law of Treaties concerning interpretation of treaties must also be applied in the course of interpretation of the Convention. Although the Vienna Convention did not even enter into force at the time (only in 1980), the ECtHR could, without infringing the principle of non-retroactivity, declare the application of relevant provisions on legal interpretation rules thereof because, according to its reasoning, these legal interpretation norms are the generally accepted principles of international law. That is, according to the ECtHR, these rules of interpretation are binding not because the Vienna Convention is binding but because they are general 
principles of international law that would bind the court even if they were not laid down in writing anywhere. ${ }^{187}$

The text, being relevant in the course of interpretation of the Convention and to be interpreted with appropriate derogations, of Articles 31 to 33 of the Vienna Convention invoked by the ECtHR in 1975 and, being basis for the interpretation of the ECHR owing to the settled practice of the ECtHR, is given as follows. ${ }^{188}$ Under 'General rules of interpretation', Article 31 declares that 'A treaty shall be interpreted in good faith in accordance with the ordinary meaning to be given to the terms of the treaty in their context and in the light of its object and purpose'. ${ }^{189}$ Under the title 'Supplementary means of interpretation', Article 32 defines, not exhaustively, other methods and sources: 'Recourse may be had to supplementary means of interpretation, including the preparatory work of the treaty and the circumstances of its conclusion, in order to confirm the meaning resulting from the application of

187 'The Court is prepared to consider [...] that it should be guided by Articles 31 to 33 of the Vienna Convention of 23 May 1969 on the Law of Treaties. That Convention has not yet entered into force and it specifies, at Article 4, that it will not be retroactive, but its Articles 31 to 33 enunciate in essence generally accepted principles of international law to which the Court has already referred on occasion. In this respect, for the interpretation of the European Convention, account is to be taken of those Articles subject, where appropriate, to "any relevant rules of the organization"-the Council of Europe-within which it has been adopted [...]'. Golder v. the United Kingdom, para 29.

188 The full text is as follows:

Article 31 (General rule of interpretation) ' 1 . A treaty shall be interpreted in good faith in accordance with the ordinary meaning to be given to the terms of the treaty in their context and in the light of its object and purpose. 2. The context for the purpose of the interpretation of a treaty shall comprise, in addition to the text, including its preamble and annexes: (a) Any agreement relating to the treaty which was made between all the parties in connexion with the conclusion of the treaty; (b) Any instrument which was made by one or more parties in connexion with the conclusion of the treaty and accepted by the other parties as an instrument related to the treaty. 3 . There shall be taken into account, together with the context: (a) Any subsequent agreement between the parties regarding the interpretation of the treaty or the application of its provisions; (b) Any subsequent practice in the application of the treaty which establishes the agreement of the parties regarding its interpretation; (c) Any relevant rules of international law applicable in the relations between the parties. 4. A special meaning shall be given to a term if it is established that the parties so intended'. Article 32 (Supplementary means of interpretation) 'Recourse may be had to supplementary means of interpretation, including the preparatory work of the treaty and the circumstances of its conclusion, in order to confirm the meaning resulting from the application of Article 31, or to determine the meaning when the interpretation according to Article 31: (a) Leaves the meaning ambiguous or obscure; or (b) Leads to a result which is manifestly absurd or unreasonable.'

Article 33 (Interpretation of treaties authenticated in two or more languages) ' 1 . When a treaty has been authenticated in two or more languages, the text is equally authoritative in each language, unless the treaty provides or the parties agree that, in case of divergence, a particular text shall prevail. 2. A version of the treaty in a language other than one of those in which the text was authenticated shall be considered an authentic text only if the treaty so provides or the parties so agree. 3 . The terms of the treaty are presumed to have the same meaning in each authentic text. 4 . Except where a particular text prevails in accordance with paragraph 1, when a comparison of the authentic texts discloses a difference of meaning which the application of articles 31 and 32 does not remove, the meaning which best reconciles the texts, having regard to the object and purpose of the treaty, shall be adopted'.

189 Paragraph 1, Article 31. 
article 31, or to determine the meaning when the interpretation according to article 31: (a) Leaves the meaning ambiguous or obscure; or (b) Leads to a result which is manifestly absurd or unreasonable'. Finally, according to Article 33 (Interpretation of treaties authenticated in two or more languages): ' 1 . When a treaty has been authenticated in two or more languages, the text is equally authoritative in each language, unless the treaty provides or the parties agree that, in case of divergence, a particular text shall prevail.' The other rules of interpretation are not relevant regarding an international convention (including ECHR).

It is questionable how well a system of rules prepared for the interpretation of texts of treaties may be applied to interpret the provisions of an international convention, especially that of a multilateral international human rights document. However, certain interpretation methods may be common because both include legal texts, the detection of which is possible in identical or very similar ways. Important interpretation sources, at least, indicate a significant overlap. The choice of the ECtHR in 1975, according to which Articles 31 to 33 of the Vienna Convention of 1969 on the Law of Treaties must be applied to interpret the Convention, seems to be proper.

These methods are not of equal importance, which is strengthened both by the titles of relevant Articles of theVienna Convention and by the ECtHR decisions made in concrete cases and the interpretations included thereby. Both the Vienna Convention and the ECtHR, as we have seen, consider the methods of interpretation listed in Article 31 of the Vienna Convention, i.e. textual interpretation (establishing the ordinary meaning, especially the legal semantic meaning compared with everyday meaning), contextual interpretation, and (objective) teleological interpretation (detection of meaning according to object and purpose), to be primary methods. Meanwhile, the maxim of argumentum ad absurdum [Article 32 (b)] may be applied as supplementary meaning. Other means may also be used for the avoidance thereof (i.e. the 'manifestly absurd or unreasonable' result), for confirming the meaning established with the main methods and for exploring the proper meaning of ambiguous provisions. These means are not exhaustively enumerated in Article 32 of the Vienna Convention. In addition to the maxim of argumentum ad absurdum, only one further method, the technique of subjective teleological interpretation (preparatory work of the treaty) is mentioned. It includes all possible sub-methods of historical interpretation. Moreover, there is a reference to all of them in the practice of the ECtHR, even if only rarely.

The findings of our research partly confirmed the declared practice of the ECtHR: that the ECtHR interprets the different rights included by the Convention in the manner determined in Articles 31 to 33 of the Vienna Convention and applies them in concrete cases with the meaning established in that manner. The ECtHR's most frequently used method is the interpretation based on its own precedent and not the grammatical, contextual, or objective teleological interpretation may presumably be because it had to use directly the main methods under the Vienna Convention mostly in the early years and decades of its judicial activity when it developed its 
increasingly consolidating jurisprudence regarding the given fundamental rights and the main field of application thereof. Subsequently, it was enough to refer to its decisions performing these interpretations as precedents, but it was not necessary to perform the same type of interpretation repeatedly. The newer the case, or the older the practice of a given legal problem, the less the ECtHR refers to direct, primary legal interpretation methods (because the less necessary it is) and the more sufficient it was to refer to previous precedent decisions that have performed these interpretations.

As for the further 'supplementary' means, they occur in the ECtHR's decisions at a considerably lower rate. In addition to the references to its own case law (occurring in all cases), the contextual meaning (appearing in the vast majority of the cases), the (mainly legal) semantic grammatical interpretation (occurring approximately in the half of the cases and including references to legal principles), and objective teleological interpretation (occurring in a half or a third of the cases but regularly related to other methods and, therefore, the rate of which can be determined only with approximate accuracy), and arguments with the nature of international law are interpretation sources used relatively often (roughly in a third of the examined decisions). It should also include further international treaties (other than the Convention), whose argument type itself occurs in nearly one-third of the cases and not only as ornamental or illustration but as strengthening or even defining arguments. The reason for the international treaties' importance in the practice of the ECtHR may be that the ECtHR itself is also an 'international' (supranational) court and the legal source applied is an international convention. Hence, it respects international sources and, to develop and avoid derogating the meaning of the provisions of the ECHR, uses and refers to them. In this regard, the ECtHR expressly recognises not being bound to applying only other international treaties to which the member states of the CoE or the concerned state itself acceded since it says that minimum common expectations (the sources of which may be any other international convention with similar subject) form the content of human rights. Thus, the ECtHR refers to the provisions of other regional conventions on human rights (e.g. American Convention on Human Rights, African Charter on Human and Peoples' Rights) or to other international conventions (e.g. Universal Declaration of Human Rights) several times, most often, not surprisingly, to the Vienna Convention of 1969 on the Law of Treaties. It also refers to judicial practice or individual decisions of different international or supranational fora (e.g. Inter-American Court of Human Rights, African Court on Human and Peoples' Rights) intended to enforce these conventions (the catalogue of human rights) if it considers them to be relevant in the certain case. International conventions and decisions of international judicial for a, together with other possible sources of international law, form a coherent reference base of 'international law' in almost a third of the examined cases. Regarding the latter, the ECtHR most often (approximately in 10\% to $20 \%$ of the cases) refers to different documents of the institutions of the CoE (Venice Commission, 
Parliamentary Assembly). ${ }^{190}$ The ius cogens, the general principles of international law or customary international law also occur (in a few cases) among substantial decision sources.

Logical interpretation appears relatively rarely. There is no outstanding method among the individual arguments. In their rare appearance, almost all (quasi-)logical arguments are used by the ECtHR, but their role in the reasoning could not be determined owing to the ECtHR's decision-making style. They are present as subsidiary arguments in the text of ECtHR decisions, alongside references to precedent decisions, but it is not known to what extent they played a role in the ECtHR's upholding of, rather than deviation from, the precedents cited. The ECtHR refers to national law as a source of reasoning with roughly similar frequency, perhaps even less frequently. The alleged domestic legislation on which the applicant's alleged violation of the Convention is based is always involved in the ECtHR's fact finding, but in this case, domestic law is invoked as part of the facts on which the finding of a violation of the Convention is based (as a statement of the nature of the domestic legislation) rather than as a source or argument for interpreting the Convention. The latter arises only in a small part of the cases when the ECtHR invokes, as strengthening argument or as illustration to the detecting of the content of the rights under the Convention, the 'consistent' practice of the contracting states of ECHR. The ECtHR delineates the national regulations of some member states as an example. The classical comparative law argument is even rarer and commonly appears as reference to the European practice or a kind of democratic consensus regarding rule of law and, mostly, it has only a strengthening or ornamental nature. The ECtHR does not refer to sources of domestic organisations (e.g. decisions of national constitutional courts).

The reference to general legal principles only exceptionally occurs. Most of the referred legal principles are dogmatic legal concepts or legal values that can be found in the text of the Convention (or of its preamble). In addition, the ECtHR refers to key concepts formed by its judicial activity and that mean the generalisation of the purposes of the ECtHR than the wording of 'sublimated' legal principles existing outside of positive law. The same is true for substantive arguments: the ECtHR barely refers to those; instead, it focuses on the meaning and function of the ECHR as a whole and on the purpose generalised from the individual provisions and human rights. Thus, determination of the Convention's purpose and the 'united meaning' of the context of the given rights under that 'from within the Convention' (and the related determination

190 Regarding this, Varga (former member of the Venice Commission) pointed out that the difference between soft law and binding law begins to relativise, especially in cases when either the ECtHR expects (and sanctions the non-compliance) or the EU institutions requests (and has legal and political consequences in case of deviation from the 'opinions' of the Venice Commission) the content of these documents (especially, of the opinion of the Venice Commission). See Varga Zs., 2016, p. 196. It complicates the situation that not only the EU Member States are members of the Council of Europe (the advisory body of which is the Venice Commission) but also the European Union itself. Cf. Sehnálek, 2017, pp. 337-338. 
of the key concepts partly found in the ECHR and partly deduced therefrom) practically replaces the substantive arguments (or make their use unnecessary).

The procedure pursuant to Article 33 of the Vienna Convention is a special interpretation method according to which it is possible to compare the different authentic versions of the Convention's provisions: to interpret the authentic texts in English and French with respect to each other, if it is helpful. Although this technique is extremely special, the Court applied it (as a defining argument) in some cases.

Subjective teleological interpretation also appears rarely in the practice of the ECtHR. It explicitly referred, a few times, to the travaux, i.e. the documents related to the creation of the ECHR or the protocols thereto, occasionally to the (social or legal) circumstances of formation thereof and sometimes to the proposer's justification.

However, the ECtHR makes no reference to academic works: in the sample examined, not once did the judges cite any specific work of jurisprudence attributable to a particular author, even as illustrations. This is certainly because the ECtHR reserves to itself alone the right to determine the meaning of the provisions of the Convention in the context of the 'autonomous' meaning of concepts. This autonomy, this independence, would be seen to be surrendered if recourse were to be had directly to an external source, external to the ECtHR, which has no specific (international) legal legitimacy.

The ECtHR considers only its own practice to be relevant (this is the main basis for all decisions), which has a significant importance regarding consistency (legal certainty, predictability). In addition to its own jurisprudence, contextual interpretation (in broad sense) is the other significant method serving an indispensable aspect in the practice of the ECtHR. The main methods of the Vienna Convention on the Law of Treaties (except the just-mentioned contextual interpretation), which have comprised the wide range of interpretation methods recognised officially from 1975, were used only in half of the cases (in case of legal dogmatic interpretation towards the establishment of the autonomous or legal meaning, declared by the ECtHR, of ordinary meaning) or even less (in case of objective teleological interpretation). In about a third of the cases, the ECtHR used arguments of an international law nature (but often these were used simultaneously, reinforcing each other), and it referred to the domestic legal norms of the Member States in less than a third of the cases (usually purely as a 'legal outlook') and (quasi-)logical formulas. Often, the ECtHR does not even refer explicitly to the latter ones (and to the meaning seeking the 'object and purpose' of provisions). Hence, the use of these arguments can often be determined only through in-depth analysis of the text (or it cannot be decoded and its use can only be guessed).

The same may also occur for other arguments. In parallel with the formation of its judicial practice activity, the ECtHR refers increasingly less to content aspects determining the decision and replaces these by invoking its own previous decisions. In this way, it hides the grounds of its decisions, which are not recognisable with a reading of only the given decision but with that of the referred precedent decisions (or with knowing the even earlier decisions that had been referred by the referred decision, and so on, until the leading case, the first decisive decision made in the given case). Legal certainty is, however, declared to be an important aspect in the 
judicial practice of the ECtHR intended to be served by references to previous decisions. With this technique, the actual grounds of the given decision often remain hidden or can only be inferred through studying the referred precedent decisions. Although the wording style of ECtHR decisions is open, and the text of the decisions contains pros and cons examined by the ECtHR before making its decision (and their validity or unfoundedness as a result), for this, the ECtHR delineates its own precedent decisions as 'display windows', although its consideration could hardly be more than searching for and referring to relevant decisions from its own practice. This may be the reason the ECtHR used subjective teleological arguments (mainly referring to travaux), substantive arguments, and arguments from the law of the member states only in some cases.

Finally, the ECtHR used, as a rare exception, the establishment of the ordinary meaning of words (e.g. dictionary definition), interpretation arising from the bilingualism of the Convention, and other professional interpretations as semantic methods. It rarely used general legal principles and did not use either syntactic or contextual interpretation in the narrow sense or classical comparative law arguments and did not refer to legal scholarly works at all.

The text of the judgements is extremely rich in various legal aspects developed by the ECtHR, which it uses either instead of recalling the substantive arguments outside the text of the Convention and certain provisions (human rights) therein or the purpose of the Convention as a whole, or perhaps to support its previous practice. The legal aspects serve to demonstrate that the ECtHR considers the Convention to be a complex source, the text of which is only a starting point, but whose meaning lies in the subject matter protected-the human rights it guarantees. For this reason, the ECtHR interprets the Convention as provisions that are intended to guarantee not rights that are theoretical or illusory but rights that are practical and effective. ${ }^{191}$ For this effectivity to prevail actually, the ECtHR should consider that 'the Convention is a living instrument which [...] must be interpreted in the light of present-day conditions'. ${ }^{192}$ The ECtHR connected the doctrine of 'living instrument' with the European consensus: ${ }^{193}$ 'the Court cannot but be influenced by the developments and commonly accepted standards [...] of the member States of the Council of Europe'. ${ }^{194}$ This

191 Airey v. Ireland, application no. 6289/73, 9 October 1979, para 24.

192 Tyrer $v$. The United Kingdom, application no. 5856/72, 25 April 1978, para 31.

193 For a moral critique of consensus-based adjudication (and for apologetics of moral or evolutive decisions) and inevitable moral choice of judges in general, see Letsas, 2004, pp. 279-305.

194 Ibid. 'The Court must, however, have regard to the changing conditions in Contracting States and respond, for example, to any emerging consensus as to the standards to be achieved' (Chapman $v$. The United Kingdom, application no. 27238/95, 18 January 2001, § 70.) For the same but with 'evolving convergence' instead of 'emerging consensus', see Christine Goodwin v. The United Kingdom, application no. 28957/95, 11 July 2002, § 74.) Although the European consensus does not automatically mean the unconventionality of a member state legislation that deviates from the European majority position, it merely makes a presumption that the given member state legislation is outdated but the concerned member state may prove that its specific social and historical conditions justify the challenged legislation (and make it consistent with the Convention). Cf. Dzehtsiarou, 2011, p. 1733. 
became the base of the so-called evolutive or dynamic interpretation, which allows the Convention to have (with changes in social conditions, development in legal regulations of the member states, alteration in political and economic circumstances) an up-to-date meaning that can solve effectively the human rights problems of the given age (and which is roughly uniform across Europe). ${ }^{195}$ Finally, all these move towards the formation of European constitutional law is acknowledged by the ECtHR itself when it considers the Convention as 'a "constitutional instrument of European public order" in the field of human rights'. ${ }^{196}$

For the evolutive interpretation not to be arbitrary and for the regulation of the member states not to be replaced by a legal regulation created by judges, the ECtHR accepts the particular (often very different) solutions of the member states to certain social problems that are marked by the doctrine of margin of appreciation of member states. ${ }^{197}$ According to this doctrine, a member state of the CoE is free to decide what legal regulation it introduces as long as it remains within the frames of the field specified by the ECHR and its 'dynamic interpretation'. However, the ECtHR reserves the right of deciding how wide this latitude can be. Overall, it has complete control over the functioning of human rights under the Convention and, by evolutive interpretation, it can always develop and redefine it, at any time, in light of changed social conditions or other relations. Thus, this doctrine is nothing but the enforcement of the principle of subsidiarity (used also in federal states and in the EU) with the condition that the marking of the limits and, therefore, the convention-compliant assessment of the legal regulations of the member states (more precisely, administrative or judicial decision-making based thereon) depend solely on the judgment of the ECtHR, which raises similar sovereignty concerns, such as the relation between national constitutional courts (and ordinary courts) in the member states of EU and the ECJ.

195 In the mentioned Tyrer case, the ECtHR found that corporal punishment is contrary to the prohibition of degrading punishment pursuant to Article 3 of the Convention. In the concrete case, a 15year old child was sentenced, for the assault of a schoolmate, to three strokes of birch and it was enforced.

196 Bosphorus Hava Yolları Turizm ve Ticaret Anonim Şirketi v. Ireland [GC], application no. 45036/98, $\S 156$. All these encourage many commentators to talk about the Convention as a 'complementary constitution' or 'ancillary constitution' (Grabenwarter, 2015, p. 259).

197 This expression, transferred from the French administrative law to the practice of the ECtHR, was formulated in a concrete case (Handyside $v$. The United Kingdom, application no. 5493/72, 7 December 1976) related to the freedom of expression (ECHR Article 10 para 2) (according to which, this article 'leaves to the Contracting States a margin of appreciation. This margin is given both to the domestic legislator ('prescribed by law') and to the bodies, judicial amongst others, that are called upon to interpret and apply the laws in force') but, in a different form, the Court referred to the states' margin of manoeuvre even earlier (already at the end of the 1960s) in a special case ('Relating to certain aspects of the laws on the use of languages in education in Belgium' $v$. Belgium, application no. 1474/62; 1677/62; 1691/62; 1769/63; 1994/63; 2126/64, 23 July 1968, better known as: 'Belgian Linguistic Case (No. 2)'). Later, the doctrine became general principle accepted in the use of all articles of the Convention. 


\subsection{National constitutional courts and the ECtHR: similarities and differences}

The most important similarity in the practice of the Central and Eastern European constitutional courts and the ECtHR in interpreting fundamental rights is the very similar standard of limitation of fundamental rights. Although criteria regarding certain fundamental rights (e.g. procedural rights in general and the right to a fair trial in particular) are used by all adjudicating fora (moreover, certain partial rights thereof are often considered as absolute rights), it is also a common feature that, in case of collision of constitutional rights, all of them use the proportionality test for the restriction of fundamental rights. ${ }^{198}$ These tests, apart from having small differences between certain types, have at least four common assessment criteria. These steps are general specifications that are valid before all fora. ${ }^{199}$ In addition to the formal criteria (e.g. the requirement that the restriction of a fundamental right must be made by acts), ${ }^{200}$ the following substantive conditions are necessary for a restriction of a fundamental right (if it is not an absolute right, because they are not subject to restriction): ${ }^{201} 1$ 1) There must be a constitutional objective (typically another fundamental right or constitutional value), the protection of or need to enforce which justifies the restriction of the right in question (legitimacy). 2) The restriction of the fundamental right in question must be capable of achieving this legitimate objective-it must be possible to ensure or promote the enforcement of the other fundamental right (or constitutional value) by restricting the fundamental right in question (suitability). 3) It must not be possible to protect this other fundamental right (or constitutional value) in any other way than by restricting a fundamental right or by restricting precisely this fundamental right (and not a less-important fundamental right) - the conflict of fundamental rights or constitutional objectives (restriction of a given fundamental right to achieve a legitimate aim) must be unavoidable (necessity). 4) Even if the preceding conditions are met, a restriction of a fundamental right may only be imposed if the restriction of the fundamental right in

198 This is also true for other countries; its advantage is its flexibility, which allows for changing constitutional law in changing circumstances, and its 'popularity' is due to this. Szente and Gárdos-Orosz, 2018, p. 304.

199 For the functioning of proportionality test before the national constitutional courts, see Sonnevend and Jakab, 2015, pp. 80-82.

200 The requirement of the level of acts is not a purely formal criterion. Since acts are more transparent (their text and content are more easily accessible to the people), and since the requirement of democratic legitimacy requires that decisions must be traceable to the will of the citizens (and the more interference in people's fundamental rights is involved, the more necessary it is to trace decisions to the will of the people), the requirement of the level of acts also serves substantive purposes.

201 In itself, in order for those conditions to be examined, it is necessary to fulfil some preconditions (e.g. to prove whether the referred right of the applicant or petitioner was affected by the challenged regulation or action of state). As 'step zero', the ECtHR examines whether the state action affected the article referred by the applicant, i.e. whether the interference by public authority impaired the applicant's right ensured by the given article. After this, it determines whether the restrictive action of the state (e.g. a court decision) was prescribed by law. The proportionality test regarding the restriction will be conducted only if the answer is yes in both cases. 
question would cause less harm to the fundamental right than the benefit which the other fundamental right (or constitutional value) could provide-the benefit of the restriction of a fundamental right must outweigh the harm caused or to be caused by the restriction (proportionality). ${ }^{202}$

The fora examined also have in common the most important key concepts they employ. Both for the national constitutional courts and the ECtHR, the idea of the rule of law and the principle of democracy, which can be found both in the documents of domestic public law and international law to be applied by these fora (in the national constitutions and the Convention), are of great importance. All human rights mean the realisation of the material rule of law, the main depository of which is a judicial body (in case of national constitutions, these are the constitutional courts of the Central and Eastern European countries, or maybe other bodies empowered with similar powers, such as supreme courts, in other legal systems, ${ }^{203}$ and the ECtHR in case of the Convention). Where substantive fundamental right adjudication exists, there the rule of law may be realised as a background concept and as a final requirement to which the efficiency of enforcement of fundamental rights can be attached and which can be formulated for constitutional courts (and the ECtHR) as an ultimate objective to be attained. ${ }^{204}$ Democracy is a principle safeguarding the rule of law (and, thereby, the enforcement of human rights) that must be protected for itself and its 'service' provided for guaranteeing the rule of law

202 The requirement to respect the essential content of a fundamental right often appears among the requirements of proportionality as an additional standard, but this is part of proportionality. Restricting the essential content of a fundamental right is disproportionate in any comparison, since in this case the given fundamental right (also restricted in its essential content) would become practically empty, functionless.

203 States having constitutional adjudication may have 'diffuse' or 'centralise' review. All states examined by us belong to the latter group while the Supreme Court of the United Kingdom, of Canada, and of the United States to the former one. Saunders, 2019, pp. 414-440.

204 Historically, the rule of law (Rechtsstaat) meant two basic things. At the beginning, this covered the formal rule of law at the end of the 18th century and in the 19th century. This meant that state bodies could not proceed either against the laws (contra legem) or without the laws, i.e. without a statutory basis (praeter legem). Thus, the key point was predictability, i.e. clear and unambiguous laws should be enforced in a manner that can be pre-planned. This purely formal system of criteria contained expectations, such as the chance to learn the legal regulations, i.e. their public announcement to avoid too quick changes, clear and easy-to-understand legal regulations, and their actual enforcement. This was not trivial even in the 18th century; for instance, France ran the legal institute of the lettre de cachet, which covered the French absolute monarchy's subsequent legislative right, e.g. the possibility for the monarch 'to terminate a prosecution or, without relying on the judges, convict or imprison an individual without a trial and without even an offence having been committed' (Elliott, 2011, p. 5). However, this formal rule of law was given a lot of criticism, especially between the two world wars, and later, after World War II, it became evident that it could not be maintained in itself because, for instance, even Nazi Germany could be treated as a state governed by the 'rule of law', at least in its formal sense. For this reason, there was clear consensus after World War II that the term 'rule of law' had to be filled with proper contents. The most famous statement was Radbruch's well-known formula. Radbruch, 1946, pp. 105-108. 
(and which must be reconciled with the rulew of law; ${ }^{205}$ these two have a complex relation system). ${ }^{206}$

All special principles or doctrines other than the key concepts employed by the examined bodies are only intended to concretise the latter; they are aspects arising from the jurisprudence of the ECtHR and of the constitutional courts to be taken into account. Such comprise the test of impartiality ${ }^{207}$ used in the case of the right to a fair trial, principles of predictability and foreseeability serving as justification of decisions based on previous practice, equality before the law, and the legal certainty covering all these ${ }^{208}$ Furthermore, the fiction of uniformity and consistency of legal documents to be interpreted that serves as necessary basis for interpretation in case of all must be recognised. Hence, particular fundamental rights are consistent and not in conflict with one another other-they form a uniform and consistent system and, if it is not true at the level of the text, it is necessary to give an interpretation of the particular fundamental rights that allows this harmony to be achieved.

Finally, a common feature of the practice of each forum is that they pay special attention to their own previous practice. As regards the ECtHR and several constitutional courts we analysed, this is the case without exception. Even in the case of

205 It is no coincidence that these principles are often defined in one provision by the constitutions.

206 For this relation system, see Toth, 2021, pp. 77-97. If we consider constitutionalism as the institution serving the implementation of the rule of law, the situation is even more complicated because 'material constitutionalism' may serve substantial principles and also formal aspects of popular sovereignty, which, in certain cases, may collide with each other. Schütze called the former (with some simplification) 'liberal constitutionalism' and the latter 'democratic constitutionalism' (cf. Schütze, 2019, pp. 54-60.), which attributes too much role to the drafting of a constitution, to its pedigree in a broad sense, thereby making the differences appear greater than those that, in principle, follow from the division (with the operation of adequate rule of law guarantees, or more precisely, the recognition of the rule of law guarantees of democracy).

207 Impartiality has two measures: the subjective and the objective test of impartiality. According to the Court, '[t]he existence of impartiality for the purposes of Article 6 para. 1 [...] must be determined according to a subjective test, that is on the basis of the personal conviction of a particular judge in a given case, and also according to an objective test, that is ascertaining whether the judge offered guarantees sufficient to exclude any legitimate doubt in this respect' (Hauschildt $v$. Denmark, application no. 10486/83, 24 May 1989, para 46.) 'Under the objective test, it must be determined whether, quite apart from the judge's personal conduct, there are ascertainable facts which may raise doubts as to his impartiality' (Hauschildt $v$. Denmark, para 48).

208 'It is true that [...] the Court is not bound by its previous judgments; indeed, this is borne out by Rule 51 para. 1 of the Rules of Court. However, it usually follows and applies its own precedents, such a course being in the interests of legal certainty and the orderly development of the Convention case-law. Nevertheless, this would not prevent the Court from departing from an earlier decision if it was persuaded that there were cogent reasons for doing so. Such a departure might, for example, be warranted in order to ensure that the interpretation of the Convention reflects societal changes and remains in line with present-day conditions' (Cossey v. The United Kingdom, application no. 10843/84, 27 September 1990, § 35.). 'The Court considers that, while it is not formally bound to follow any of its previous judgments, it is in the interests of legal certainty, foreseeability and equality before the law that it should not depart, without good reason, from precedents laid down in previous cases' (Chapman $v$. The United Kingdom, application no. 27238/95, 18 January 2001, § 70). 
the other constitutional courts, almost all decisions of these bodies referred to their own previous decisions. This means that decisions of their own previous practice served as precedent for practically all fora. Although the ECtHR never considers the decisions of the particular constitutional courts, it is not true conversely: the decisions of the ECtHR, a supranational forum intended to enforce an international convention, namely, the ECHR, enjoy particular attention in the course of the adjudication of national constitutional courts. The phenomenon can be observed everywhere, to varying extents. The one extreme is Hungary, where, in the past years, an expressly ECtHR-sceptic attitude could be observed-decision-makers tried to pay less attention to the practice of the ECtHR and to refer as few decisions thereof as possible. The other extreme is the practice in Serbia where, according to the Constitution, the decisions of the ECtHR must be taken into account. The Serbian constitutional court considers these decisions to be binding and uses them as precedent, attributing an even more important role to them than to its own previous constitutional court decisions. Although with varying intensity, the constitutional courts (not only in these countries) ${ }^{209}$ make their decisions based on the knowledge that the same case may be brought before the ECtHR, which cannot oblige the domestic constitutional court to change its decision. This constitutional court would still lose prestige if the latter were to be obliged to change a Strasbourg decision interpreting fundamental rights differently and protecting them more strongly than the constitutional court. ${ }^{210}$ Even if they do not confess, constitutional courts always avoid this situation (maybe the slightest effort in this direction is available at the Constitutional Court of Hungary) and to follow the judicial practice of the ECtHR

209 Based on the statistical analysis of caseload data of the courts by Hofmann, the ECtHR held, regarding the examined Central and Eastern European countries, that there was a violation of Convention rights mostly concerning Poland (at least until 2012) if we see the absolute numbers, and concerning Hungary, if we see the rate of violations regarding judgements (cf. Hofmann, 2015, pp. 277-278). As for the entire region (Central and Eastern Europe, including the countries of the Balkan and Baltics), it cannot be stated that the number or the rate of violations of the Convention would be higher; and it is also true for the EU-member Central and Eastern European countries (i.e. the subcategory including also the states examined by us) and also for Serbia: these states 'do not show apparent differences concerning either the type of violation judgements or the general subject matter of Court decisions as compared to other contracting parties' (Hofmann, op.cit., p. 278).

210 Krisch used three aspects to analyse the basis of the domestic courts (also including the constitutional courts in this motivation system) to be ready to follow the expectations and decision-making aspects of the ECtHR (or of the ECJ). The first category contains the attitudes of judges, e.g. a judge on the 'activist' side of the 'activism-restraint' line will treat the decisions of Strasbourg with greater respect than a judge being an advocate of voluntary restraint of judges. This difference may finally be placed on the ius aequum-ius strictum line on comprehensive legal theoretical basis. The second aspect consists of the 'normative commitments', which stem from the notion of the autonomy of law as an institutional system vis-à-vis politics: the more autonomous a judge thinks the law is, the more they will refrain from overruling specific (domestic) law. The third aspect consists of 'strategic considerations', which are influenced by extra-legal and extra-jurisprudential factors (e.g. whether the judge wishes to be re-elected or to preserve his or her position and autonomy) (cf Krisch, 2010, pp. 146-148). 
in advance, ${ }^{211}$ with which, even unintentionally, they contribute to the convergence of the national and supranational interpretation of human rights, ${ }^{212}$ to the predictability of the law and, finally, through to legal certainty.

The disadvantage of this approach is that national particularities and specific problems in individual countries may require a different approach, and the doctrine of margin of appreciation may be helpful for this different approach. Given that the ECtHR itself decides on its limits, there is a real risk of uniformity and of national particularities being ignored. A solution that also considers aspects of member states and the idea of human rights and their common content regarding rule of law, the doctrine of margin of appreciation may be an adequate basis. This doctrine, as an aspect focusing on the core of fundamental rights, may, in addition to recognition of the room for manoeuvre in member states, serve the protection and enforcement of fundamental rights. Substantive convergence (with its advantages and disadvantages) has been an already known existing phenomenon. The present research empirically proved that methodological convergence also exists.

211 It is true as a general European trend. Only the Conseil constitutionnel in France hesitates to refer to the provisions of the ECHR and the decisions of the ECtHR and to consider their content in the six Western and Southern European legal systems examined by Davide Paris. In the other countries (Austria, Belgium, Germany, Italy, and Spain), although the ECHR is not recognised as a source of constitutional law, 'constitutional courts resort to various techniques to incorporate [the ECHR] in their constitutional yardsticks, thus enabling themselves to review the compliance of domestic acts with the ECHR' (Paris, 2017, p. 624)

212 In fact, the relationship is more complex. Masterman drew attention to the fact that the relationship is two-way. On the one hand, international legal sources undoubtedly influence the internal constitutional system of individual states, but, on the other hand (and this is also observed in the case of the ECtHR), the internal constitutional provisions and constitutional development of the state parties also influence the ECtHR's judgements (if there is a consensus in the constitutional principles and values of these states). Thus, the two levels (in our case, the national constitutions and the constitutional courts applying them, on the one hand, and the ECHR and the ECtHR intended to enforce it, on the other hand) are characterised by symbiosis and circularity. Cf. Masterman, 2019, p. 491-492. 


\section{Bibliography}

AleXY, R. (2003) 'On Balancing and Subsumption. A Structural Comparison', Ratio Juris, 16(4), pp. 433-449.

Allison, J. (2007) The English Historical Constitution: Continuity, Change and European Effects. Cambridge: Cambridge University Press.

AtiYAh, P., Summers, R. (1987) Form and Substance in Anglo-American Law. A Comparative Study of Legal Reasoning, Legal Theory, and Legal Institutions. Oxford: Clarendon Press.

BARZUn, C. (2013) 'Impeaching Precedent', University of Chicago Law Review, 80(4), pp. 1625-1682.

Bellamy, R. (2009) Political Constitutionalism. Cambridge: Cambridge University Press.

BengoetxeA, J. (1993) The Legal Reasoning of the European Court of Justice. Oxford: Clarendon Press.

BRENNINKMEIJER, A. (1994) 'The Influence of Court of Justice Case Law on the Procedural Law of the Member States' in Vervaele, J. Administrative Law Application and Enforcement of Community Law in the Netherlands. Deventer-Boston, Kluwer.

BYDLINSKI, F. (1982) Juristische Methodenlehre und Rechtsbegriff. New York: Springer-Verlag.

CAmpos, P. (1996) 'A Text is Just a Text', Harvard Journal of Law and Public Policy, 19(2), pp. 327-333.

Colinvaux, R. (1997) 'What Is Law? A Search for Legal Meaning and Good Judging Under a Textualist Lens', Indiana law Journal, 72(4), pp. 1133-1163.

CooK, W. (1993) 'Scientific Method and the Law' in Fisher, W., Horwitz, M., Reed, T. American Legal Realism. New York: Oxford University Press.

DAVID, R. (1985) Major Legal Systems in the World Today. Third Edition. London: Stevens \& Sons Ltd.

DENNINGER, E. (1985) 'Judicial Review Revisited: The German Experience', Tulane Law Review, 59, pp. 1013-1031.

DerléN, M., Lindholm, J. (2015) 'Characteristics of Precedent: The Case Law of the European Court of Justice in Three Dimensions', German Law Journal, 16(5), p. 1073-1098.

DEVENISH, G. (1991) 'The Nature of Legal Reasoning Involved in the Interpretation of Statutes', Stellenbosch Law Review, 2(2), pp. 224-241.

DuXbury, N. (2008) The Nature and Authority of Precedent. Cambridge: Cambridge University Press.

DWORKIN, R. (1985) A Matter of Principle. Oxford: Oxford University Press.

DWORKIn, R. (1996) 'Objectivity and Truth: You'd Better Believe It', Philosophy \& Public Affairs, 25(2), pp. 87-139.

DzeHtSiARou, K. (2011) 'European Consensus and the Evolutive Interpretation of the European Convention on Human Rights', German Law Journal, 12(10), pp. 1730-1745.

Dyevre, A., JAKAB, A. (2013) 'Introduction: Understanding Constitutional Reasoning', German Law Journal, 14(8), pp. 983-1015.

EECKHOUT, P. (2012) EU External Relations Law. Oxford: Oxford University Press.

ELLIOTT, C. (2011) French Criminal Law. New York: Routledge .

ELliotT, S. (1956) 'Techniques of Interpretation' in Schwartz, B. (ed.) Code Napoleon and the Common-Law World. New York: New York University Press.

ENGISCH, K. (1943) 'Logische Studien zur Gesetzesanwendung'. C. Winter, Heidelberg.

FIKENTSCHER, W. (1975) Methoden des Rechts. Band III. J. C. B. Mohr, Tübingen 
FLANDER, B., TIČAR, B. (2019) 'The Right to Security - An Outline of the Legal Regulation at the State and Local Levels in Slovenia', Revija za kriminalistiko in kriminologij, 70(5), pp. 422-438.

FRANK, J. (1973) Courts on Trial: Myth and Reality in American Jurisprudence. Princeton, New Jersey: Princeton University Press.

FRUEHWALD, S. (year) 'Pragmatic Textualism and the Limits of Statutory Interpretation: Dale v. Boy Scouts of America', Wake Forest Law Review, 35, pp. 973-1027.

GADKOWSKI, A. (2016) 'The doctrine of implied powers of international organizations in the case law of international tribunals', Adam Mickiewicz University Law Review, 6, pp. 45-59.

GAMPER, A. (2013) 'Austria: Non-cosmopolitan, but Europe-friendly - The Constitutional Court's Comparative Approach' in Groppi, T., Ponthoreau, M. (eds.) The Use of Foreign Precedents by Constitutional Judges. Oxford: Hart Publishing.

GEE, G., WEBBER, G. (year) 'What is a political constitution?', Oxford Journal of Legal Studies, 30(2), pp. 273-299.

Gebauer, M. (2000) 'Uniform Law, General Principles and Autonomous Interpretation', Uniform Law Review, 5(4), pp. 683-706.

GLOS, G. (1994) 'The Constitution of the Czech Republic of 1992', Hastings Constitutional Law Quarterly, 21(4), pp. 1049-1069.

GoldsworTHY, J. (2013) 'Clarifying, Creating, and Changing Meaning in Constitutional Interpretation', German Law Journal, 14(8), pp. 1279-1295.

GOLDSWORTHY, J. (ed.) (2006) Interpreting Constitutions. Oxford: Oxford University Press.

GoodharT, A. (1945) 'Determining the Ratio Decidendi of a Case' in Vanderbilt, A. (ed.) Studying Law: Selections from the Writings of Albert J. Beveridge - John Maxcy Zane Munroe Smith - Roscoe Pound - Arthur L. Goodhart - Eugene Wambaugh - John H. Wigmore - Charles B. Stephens. New York City: Washington Square Publishing Corporation.

GOODRICH, P. (1986) Reading the Law. Oxford: Basil Blackwell.

Groppi, T., Ponthoreau, M. (2013) 'The Use of Foreign Precedents by Constitutional Judges: A Limited Practice, An Uncertain Future' in Groppi, T., Ponthoreau, M. (eds.) The Use of Foreign Precedents by Constitutional Judges. Oxford: Hart Publishing.

GoudIE, J. (2004) 'An International Court of Human Rights', Inter Alia: University of Durham Student Law Journal, pp. 5-8.

GrabenWARTER, C. (2015) 'The European Convention on Human Rights: Inherent Constitutional Tendencies and the role of the European Court of Human Rights' in Bogdandy, A., Sonnevend, P. (eds.) Constitutional Crisis in the European Constitutional Area. Oxford: Hart Publishing.

GranAT, M. (2018) 'Constitutional judiciary in crisis: The case of Poland' in Szente, Z., Gárdos-Orosz, F. (eds.) New Challenges to Constitutional Adjudication in Europe. New York: Routledge.

GreENAWALT, K. (year) 'Constitutional and Statutory Interpretation' in Coleman, J., Himma, K., Shapiro, S. (eds.) The Oxford Handbook of Jurisprudence and Philosophy of Law. Online: Oxford Handbooks Online.

Grey, T. (1999) 'The New Formalism' in Stanford Law School Working Paper, No. 4.

HART, H.L.A. (1997) The Concept of Law. Second Edition. Oxford: Clarendon Press.

HARTMANN, B. (2008) 'Verfassungsbeschwerden, Rechtsweg, Landesverfassung' in Pieroth,

B., Silberkuhl, P. (eds.) Die Verfassungsbeschwerde. Location: Wolters Kluwer.

HECK, P. (1914) Gesetzauslegung und Interessenjurisprudenz. Verlag von Mohr, Tübingen. 
HiRschl, R. (2019) 'Comparative Methodologies' in Masterman, R., Schütze, R. (eds.) The Cambridge Companion to Comparative Constitutional Law. Cambridge: Cambridge University Press.

HIRSCHL, R. (2006) 'The New Constitutionalism and the Judicialization of Pure Politics Worldwide', Fordham Law Review, 75(2), pp. 721-754.

HoECKE, M., OST, F. (1998) 'Legal Doctrine in Crisis: Towards a European Legal Science', Legal Studies, 18(2), pp. 197-215.

HOFFMEISTER, F. (2015) 'Enforcing the EU Charter of Fundamental Righrs in Member States' in Bogdandy, A., Sonnevend, P. (eds.) Constitutional Crisis in the European Constitutional Area. Oxford: Hart Publishing.

Hofmann, M. (2015) 'Central and European Member Staztes of the EU and European Convention on Human Rights' in Bogdandy, A., Sonnevend, P. (eds.) Constitutional Crisis in the European Constitutional Area. Oxford: Hart Publishing.

HoldsworTH, W. (1938) A History of English Law. Volume XII. London: Methuen \& Co. Ltd.

Holmes, O. (1897) 'The Path of the Law', Harvard Law Review, 10(8), pp. 457-478.

Holland, T. (1916) The Elements of Jurisprudence. Oxford: Clarendon Press.

HORKAY-HÖrcher, F. (2012) 'The National Avowal' in Csink, L., Schanda, B., Varga Zs., A. (eds.) The Basic Law of Hungary: A First Commentary. Dublin: Clarus Press.

JAKAB, A. (2013) 'Judicial Reasoning in Constitutional Courts: A European Perspective', German Law Journal, 14(8), pp. 1215-1275.

JAKAB, A., FrÖHLICH, J. (2017) 'The Constitutional Court of Hungary' in Jakab, A., Dyevre, A., Itzcovich, G. (eds.) Comparative Constitutional Reasoning. Cambridge: Cambridge University Press.

JAKAB, A., Dyevre, A., ITzCovich, G. (2015) 'CONREASON - The Comparative Constitutional Reasoning Project. Methodological Dilemmas and Project Design', MTA Law Working Papers (Hungarian Academy of Sciences), pp. 1-24.

JAKAB, A., Dyevre, A., Itzcovich, G. (2017) 'Conclusion' in Jakab, A., Dyevre, A., Itzcovich, G. (eds.) Comparative Constitutional Reasoning. Cambridge: Cambridge University Press.

JAKAB, A., Dyevre, A., ItzcoviCH, G. (2017) 'Introduction: Comparing Constitutional Reasoning with Quantitative and Qualitative Methods' in Jakab, A., Dyevre, A., Itzcovich, G. (eds.) Comparative Constitutional Reasoning. Cambridge: Cambridge University Press.

JHERING, R. (1877) Der Zweck im Recht. Erster Band. Leipzig: Druck und Verlag von Breitkopf \& Härtel.

Jones, B. (1904) 'Stare Decisis' in Garland, D. et al. (eds.) American and English Encyclopaedia of Law. Northport: Edward Thompson Co.

KALINOWSKI, G. (1959) 'Y a-t-il une logique juridique?', Logique et Analyse, 2(5), pp. 48-53.

KelEMEN, K. (2018) Judicial Dissent in European Constitutional Courts: A Comparative and Legal Perspective. New York: Routledge.

KÖвLÖS, А. (2017) 'Lis pendens and res judicata in the Hungarian Law of Civil Procedure', Hungarian Journal of Legal Studies, 58(1), pp. 79-92.

KREY, V. (1978) 'Zur Problematik richterlicher Rechtsfortbildung contra legem', JuristenZeitung, 33(11/12), pp. 361-368.

KRISCH, N. (2010) Beyond Constitutionalism: The Pluralist Structure of Postnational Law. Oxford: Oxford University Press.

Kronman, A. (1990) 'Precedent and Tradition', Yale Law Journal, 99(5), pp. 1029-1068.

LARENZ, K., CANARIS, C. (1995) Methodenlehre der Rechtswissenschaft. Dritte, neu bearbeitete Auflage. Berlin - Heidelberg: Springer Verlag. 
Lebovitz, A. (2017) 'Franklin Redivivus: The Radical Constitution, 1791-1799', American Journal of Legal History, 57, pp. 1-50.

LEMMENS, K. (2018) 'The Margin of Appreciation in the ECtHR's Case Law', European Journal of Law Reform, 20(2-3), pp. 78-96.

LetsAS, G. (2004) 'The Truth in Autonomous Concepts: How to Interpret the ECHR?', European Journal of International Law, 15(2), pp. 279-305.

LIMBACH, J. (2001) 'The Concept of the Supremacy of the Constitution', The Modern Law Review, 64(1), pp. 1-10.

LupU, Y., VoETEN, E. (2012) 'Precedent in International Courts: A Network Analysis of Case Citations by the European Court of Human Rights', British Journal of Political Science, 42(2), pp. 413-439.

MACCORMICK, N. (1995) 'Argumentation and Interpretation in Law', Ratio Juris, 6(1), pp. 16-29. / Argumentation, 9(3), pp. 467-480.

MACCORMick, N., Summers, R. (eds.) (1991) Interpreting statutes: a comparative study. Aldershot: Dartmouth Publishing Company.

MAIne, H. (1861) Ancient Law: Its Connection with the Early History of Society, and its Relation to Modern Ideas. London: John Murray.

MARMOR, A. (1990) 'No Easy Cases?', Canadian Journal of Law \& Jurisprudence, 3(2), pp. 61-79.

MASTERMAN, R. (2019) 'Multi-Layered Constitutions' in Masterman, R., Schütze, R. (eds.) The Cambridge Companion to Comparative Constitutional Law. Cambridge: Cambridge University Press.

MitCHELL, C. (1988) The French Legislative Assembly of 1791. Leiden - New York - København - Köln: E. J. Brill.

Mostowik, P. (2017) 'Legislative Activities of European Union Versus Fundamental Principles of Paternity and Maternity in Member States', International Journal of the Jurisprudence of the Family, 79(8) , pp. 79-94.

Murkens, J. (2013) From Empire to Union: Conceptions of German Constitutional Law since 1871. Oxford: Oxford University Press.

Nelson, W. (2018) Marbury v. Madison: The Origins and Legacy of Judicial Review. Second Edition, Revised and Expanded. Location: University Press of Kansas.

ORGAD, L. (2010) 'The preamble in constitutional interpretation', International Journal of Constitutional Law (I-CON), 8(4), pp. 714-738.

PAP, A., ŚLEDZIŃSKA-SIMON, A. (2019) 'The Rise of Illiberal Democracy and the Remedies of Multi-Level Constitutionalism', Hungarian Journal of Legal Studies, 60(1), pp. 65-85.

PARIS, D. (2017) 'Constitutional Courts and the European Court of Human Rights: A Comparative Perspective', Zeitschrift für ausländisches öffentliches Recht und Völkerrecht, 77, pp. 623-649.

PELC, K. (2014) 'The Politics of Precedent in International Law: A Social Network Application', American Political Science Review, 108(3), pp. 547-564.

PERelman, C. (1966) 'Judicial Reasoning', Israel Law Review, 1(3), pp. 373-379.

Perelman, C. (1965) 'Justice and Justification', Natural Law Forum, 10(1), pp. 1-20.

Perelman, C. (1963) The Idea of Justice and the Problem of Argument. London: Routledge \& Kegan Paul.

PERElmAn, C. (1982) The Realm of Rhetoric. Notre Dame, Indiana: University of Notre Dame Press.

PERELMAN, C. (1968) ‘What Is Legal Logic?’, Israel Law Review, 3(1), pp. 1-6. 
POKOL, B. (2019) 'Az alkotmányi jog kérdéseiből', Journal of Legal Theory, Law Working Papers Series, 2.

POKOL, B. (2019) 'Der juristokratische Staat: die Analyse seiner Aspekte' in Pokol, B., Téglási, A. (eds.) Die stufenweise Entstehung des juristokratischen Staates. Budapest: Dialóg Campus.

POKOL, B. (2007) 'Interprétation et jurisprudence en Hongrie' in Hondius, E. (ed.) Precedent and the Law: Reports to the XVIIth Congress / International Academy of Comparative Law, Utrecht, 16-22 July 2006. Brussels: Bruylant.

POKOL, B. (2005) Jogelmélet. Budapest: Századvég.

POKOL, B. (2000) 'Statutory Interpretation and Precedent in Hungary', East European Quarterly, 34(4), pp. 465-488.

POSNER, R. (1983) 'Statutory Interpretation - in the Classroom and in the Courtroom', University of Chicago Law Review, 50(2), pp. 800-822.

Pound, R. (1906) 'Causes of Popular Dissatisfaction with the Administration of Justice', paper read by Roscoe Pound of Lincoln, Nebraska, at the twenty-ninth annual meeting of the American Bar Association. American Bar Association, Chicago.

Pound, R. (1914) Readings in Roman Law and the Civil Law and Modern Codes as Developments thereof. Cambridge: Harvard University Press.

RADBRUCH, G. (1946) 'Gesetzliches Unrecht und übergesetzliches Recht', Süddeutsche Juristen-Zeitung, 1(5), pp. 105-108.

RADIN, M. (1993) 'The Theory of Judicial Decision: On How Judges Think' in Fisher, W., Horwitz, M., Reed, T. (eds.) American Legal Realism. New York - Oxford: Oxford University Press.

REDISH, M. (1996) 'Interpretivism and the Judicial Role in a Constitutional Democracy: Seeking an Alternative to Originalism', Harvard Journal of Law and Public Policy, 19(2), pp. 525-532.

Regelsberger, F. (1893) Pandekten. Erster Band. Leipzig: Verlag von Duncker \& Humblot.

RESCHER, N. (1998) 'The Role of Rhetoric in Rational Argumentation', Argumentation, 12, pp. 315-323.

SALMOND, J. (1902) Jurisprudence or the Theory of the Law. London: Stevens and Haynes.

SAMuEls, A. (1984) 'The Eiusdem Generis Rule in Statutory Interpretation', Statute Law Review, 5(1), pp. 180-183.

SAUNDERS, C. (2019) 'Courts with Constitutional Jurisdiction' in Masterman, R., Schütze, R. (eds.) The Cambridge Companion to Comparative Constitutional Law. Cambridge: Cambridge University Press.

SAVIGNY, F. C. VON (1840) System des heutigen Römischen Rechts. Erster Band. Berlin: Publisher.

SCAliA, A., GARnER, B. (2012) Reading Law: The Interpretation of Legal Texts. St. Paul, Minnesota: Thomson/West.

SCAllen, E. (1995) 'Classical Rhetoric, Practical Reasoning, and the Law of Evidence', American University Law Review, 44(5), pp. 1717-1816.

SCHAUER, F. (1987) 'Precedent', Stanford Law Review, 39(3), pp. 571-606.

SCHLINK, B. (2001) 'Der Grundsatz der Verhältnismäßigkeit' in Badura, P., Dreier, H. (eds.) Festschrift, 50 Jahre Bundesverfassungsgericht. Band 2, Tübingen.

SchmitT, C. (2008) Constitutional Theory. Location: Duke University Press.

SCHÜTZE, R. (2019) 'Constitutionalism(s)' in Masterman, R., Schütze, R. (eds.) The Cambridge Companion to Comparative Constitutional Law. Cambridge: Cambridge University Press. 
SEHNÁLEK, D. (2017) 'Interpretation of International Agreements Concluded by the European Union and its Member States' in Bělohlávek, A., Rozehnalová, N. (eds.) Czech Yearbook of International Law, Volume VIII, Application and Interpretation of International Treaties. New York: Juris, The Hague: LexLata, pp. 327-346.

SEHNÁlEK, D. (2020) 'The European Perspective on the Notion of Precedent - are EU and Czech Court Decisions Source of Law?', European Studies, 7, pp. 125-153.

SKUBISZEWSKI, K. (1989) 'Implied Powers of International Organizations' in Dinstein, Y., Tabory, M. (eds.) International Law at a Time of Perplexity. Essays in Honour of Shabtai Rosenne. Dordrecht, The Netherlands: Martinus Nijhoff Publishers.

ŚLEDZIŃSKA-SIMON, A., ZIóŁKOWSKI, M. (2019) 'Constitutional Identity in Poland: Is the Emperor Putting On the Old Clothes of Sovereignty?' in Calliess, C., Schyff, G. (eds.) Constitutional Identity in a Europe of Multilevel Constitutionalism. Cambridge: Cambridge University Press.

SONNEVEnD, P., JAKAB, A., CsINK, L. (2015) 'The Constitution as an Instrument of Everyday Party Politics: The Basic Law of Hungary' in Bogdandy, A., Sonnevend, P. (eds.) Constitutional Crisis in the European Constitutional Area. Oxford and Portland (Oregon): Hart Publishing.

STUMPF, I. (2020) 'Sovereignty, Constitutional Identity and European Law', Hungarian Review, 11(3), pp. 35-46.

Summers, R. (1992) Essays on the Nature of Law and Legal Reasoning. Berlin: Duncker \& Humblot.

Sunstein, C. (1996) 'Five Theses on Originalism', Harvard Journal of Law and Public Policy, 19(2), pp. 311-315.

SwEET, A. (2009) 'On the Constitutionalisation of the Convention: The European Court of Human Rights as a Constitutional Court', Revue Trimestrielle des Droits de l'Homme, 80, pp. 923-944.

SzABÓ, M. (1999) A jogdogmatika előkérdéseiről. Miskolc: Bíbor Kiadó.

SzABó, M. (2001) Trivium. Miskolc: Bíbor Kiadó.

SzENTE, Z. (2013) 'Unsystematic and Incoherent Borrowing of Law. The Use of Foreign Judicial Precedents in the Jurisprudence of the Constitutional Court, 1999-2010' in Groppi, T., Ponthoreau, M. (eds.) The Use of Foreign Precedents by Constitutional Judges. Oxford Portland (Oregon): Hart Publishing.

Szente, Z., GÁrdos-Orosz, F. (2018) 'Constitutional courts under pressure' in Szente, Z., Gárdos-Orosz, F. (eds.) New Challenges to Constitutional Adjudication in Europe. New York: Routledge.

SZILÁGYI, P. (2003) Jogi alaptan. Budapest: Osiris.

TEubneR, G. (2004) 'Societal Constitutionalism: Alternatives to State-Centered Constitutional Theory?' in Joerges, C., Sand, I., Teubner, G. (eds.) Constitutionalism And Transnational Governance. Oxford-Portland (Oregon): Hart Publishing.

Teubner, G. (2015) 'Transnational Economic Constitutionalism in the Varieties of Capitalism', The Italian Law Journal, 1(2), pp. 219-248.

То́тн J., Z. (2018) 'Changes which Occurred in the Role of the Hungarian Constitutional Court in Protecting the Constitutional System', Acta Universitatis Sapientiae, Legal Studies, 7(1), pp. 95-107.

Tótн J., Z. (2016) 'Legislation, Judicature and Constitutional Judicial Review: The Enforcement of Substantive Justice in the Practice of the Constitutional Court of Hungary' in Author/Editor Ethical Economic Thinking and Competitiveness. Budapest: Károli Gáspár University of the Reformed Church in Hungary. 
Tóтн J., Z. (2016) 'The Methods of Statutory Interpretation in the Practice of the High Courts of Hungary', Annales Universitatis Mariae Curie-Skłodowska, Sectio M Balcaniensis et Carpathiensis, Lublin - Polonia, 1, pp. 173-201.

Tóth J., Z. (2021) 'Rule of Law vs. Democracy' in Belov, M. (ed.) Populist Constitutionalism And Illiberal Democracies: Between Constitutional Imagination, Normative Entrenchment and Political Reality. Cambridge - Antwerp - Chicago: Intersentia.

TRócsánYI, L. (2012) 'The Creation of the Basic Law of Hungary' in Csink, L., Schanda, B., Varga Zs., A. (eds.) The Basic Law of Hungary: A First Commentary. Dublin: Clarus Press.

VARGA Zs., A. (2016) 'Constitutional identity and judgements of the ECtHR' in Barabás, A., Belovics, E. (eds.) Sapiens in sapientia. Budapest: OKRI - Pázmány Press.

VAŠÁK, K. (1977) 'Human Rights: A Thirty-Year Struggle. The Sustained Efforts to give Force of law to the Universal Declaration of Human Rights', UNESCO Courier, 30(11), pp. 29-32.

WADE, E., BRADLEY, A. (1993) Constitutional and administrative law. Eleventh edition. London - New York: Longman.

Walton, D., Macagno, F., SARToR, G. (2021) Statutory Interpretation: Pragmatics and Argumentation. Cambridge: Cambridge University Press.

Wells, J. (1878) Treatise on the Doctrines of Res Adjudicata and Stare Decisis. Des Moines, IA: Mills \& Co.

WindsCHEID, B. (1873) Lehrbuch des Pandektenrechts. Erster Band. Düsseldorf: Verlagshandlung von Julius Buddeus.

WRIGHT, G. H. VON (1991) 'Is there logic of norms?', Ratio Juris, 4(3), pp. 265-283.

WRÓBLEWSKI, J. (1969) 'Legal reasonings in legal interpretation', Logique et Analyse, 45, pp. 3-31.

WRÓBLEWSKI, J. (1974) 'Legal Syllogism and Rationality of Judicial Decision', Rechtstheorie, 1 , pp. 33-46.

ZEgreAn, A., Costinescu, M. (eds.) (2016) The Role of Assistant-Magistrates in the jurisdiction of Constitutional Courts. Bucureşti: Universul Juridic.

ZŐDI, Zs. (2021) 'Precedens' in Jakab, A., Könczöl, M., Menyhárd, A., Sulyok, G. (eds.) IJOTEN. Budapest, available at http://ijoten.hu/szocikk/precedens.

ZWEIGERT, K., KÖTZ, H. (1998) An Introduction to Comparative Law. Third Edition. Oxford: Oxford University Press. 